\title{
Variation in Phosphorus
}

Acquisition Efficiency

among Maize Varieties as

\section{Related to Mycorrhizal}

\section{Functioning}

\section{Xinxin Wang}




\section{Thesis committee}

\section{Promotors}

Prof. Dr Th.W. Kuyper

Personal chair at the Department of Soil Quality

Wageningen University

Prof. Dr E. Hoffland

Personal chair at the Department of Soil Quality

Wageningen University

\section{Co-promotor}

Prof. Dr G. Feng

Professor at the Department of Plant Nutrition

China Agricultural University, Beijing, China

\section{Other members}

Prof. Dr L. Mommer, Wageningen University

Prof. Dr M. Bucher, University of Cologne, Germany

Dr W. van der Werf, Wageningen University

Prof. Dr E.T. Lammerts van Bueren, Wageningen University

This research was conducted under the auspices of the C.T. de Wit Graduate School for Production Ecology and Resource Conservation 


\title{
Variation in Phosphorus
}

\section{Acquisition Efficiency}

among Maize Varieties as

Related to Mycorrhizal

\section{Functioning}

\section{Xinxin Wang}

\author{
Thesis \\ submitted in fulfilment of the requirements \\ for the degree of doctor \\ at Wageningen University \\ by the authority of the Rector Magnificus \\ Prof. Dr A.P.J. Mol, \\ in the presence of the \\ Thesis Committee appointed by the Academic Board \\ to be defended in public \\ on Tuesday 7 June 2016 \\ at 11 a.m. in the Aula.
}


X.X. Wang

Variation in phosphorus acquisition efficiency among maize varieties as related to mycorrhizal functioning, 168 pages.

PhD thesis, Wageningen University, Wageningen, NL (2016) With references, with summary in English

ISBN: 978-94-6257-798-5 


\section{Table of Contents}

\begin{tabular}{|c|c|}
\hline Chapter 1 & General introduction \\
\hline \multirow[t]{2}{*}{ Chapter 2} & Mycorrhizal field responsiveness and phosphorus \\
\hline & acquisition efficiency of maize (Zea mays L.) varieties \\
\hline \multirow[t]{2}{*}{ Chapter 3} & Phosphate uptake from phytate by arbuscular \\
\hline & mycorrhizal maize \\
\hline \multirow[t]{3}{*}{ Chapter 4} & The arbuscular mycorrhizal symbiosis enhances \\
\hline & P uptake and increases productivity by mixtures \\
\hline & compared to monocultures \\
\hline \multirow[t]{2}{*}{ Chapter 5} & Influence of maize varieties and arbuscular \\
\hline & mycorrhizal fungi on intraspecific plant - soil feedback \\
\hline \multirow[t]{9}{*}{ Chapter 6} & General discussion \\
\hline & References \\
\hline & Summary \\
\hline & Acknowledgements \\
\hline & Publication list \\
\hline & PE\&RC Training and Educational Statement \\
\hline & Curriculum vitae \\
\hline & Affiliations of co-authors \\
\hline & Funding \\
\hline
\end{tabular}





\section{CHAPTER 1}

General introduction 


\section{Chapter 1}

\section{Phosphorus $(\mathrm{P})$ as an essential nutrient for plants}

Phosphorus $(\mathrm{P})$ is an essential plant nutrient that limits agricultural production on many soils (Vance 2001). Although the total amount of P in soils is usually much higher than plant demand, most $\mathrm{P}$ occurs in forms that are unavailable for plant uptake (Shenoy and Kalagudi 2005). P can be unavailable for plant uptake because the chemical sinks (adsorption and fixation on metal (hydr)oxide surfaces, precipitation as insoluble P-salts) are stronger than the biological sinks (roots plus associated beneficial rhizosphere organisms). Also a large part of soil P (30-80\%) is available as organic P (Dalal and Quilt 1977). Plants can only take up orthophosphate $\left(\mathrm{HPO}_{4}^{2-}, \mathrm{H}_{2} \mathrm{PO}_{4} ;\right.$; depending on soil $\left.\mathrm{pH}\right)$ from the soil solution. Plants and rhizosphere organisms need enzymes (phytase, phosphate monoesterase (known as acid and alkaline phosphatases), and phosphate diesterase) to hydrolyse organic $\mathrm{P}$, after which it can be taken up as orthophosphate. The largest part of organic $\mathrm{P}$ is inaccessible to plants (Turner and McKelvie 2002). The strength of the chemical sink determines how much organic $\mathrm{P}$ can be hydrolysed by enzymes, whereas the amount of phosphatase in the environment is less likely a limiting factor (Tinker and Nye 2000). Inositol phosphates (phytate) form the largest component of the soil organic P pool, whereas more simple organic $\mathrm{P}$ forms, such as nucleic acids, sugar phosphates, and phospholipids represent smaller fractions (Stewart and Tiessen 1987). Therefore, phytate is a potentially important source of $\mathrm{P}$ for plants, however, it could also be argued that the large contribution of phytate to the organic $\mathrm{P}$ pool reflects the slower turnover compared to other $\mathrm{P}$ sources due to the strong interaction with the mineral soil matrix.

Because of low $\mathrm{P}$ availability high agricultural productivity is usually achieved by the application of mineral $\mathrm{P}$ fertilizer that is produced industrially. However, with an increasing demand for agricultural produce, the current rate of mining of high-grade fossil $\mathrm{P}$ rocks, a non-renewable resource, cannot be sustained. Opinions differ when we will reach so-called peak phosphorus, the time point when global $\mathrm{P}$ production rates will decline. Peak phosphorus may occur in decades (Cordell et al. 2009) or a few centuries (Sattari et al. 2012). Phosphate rock, the source for mineral $\mathrm{P}$ fertilizer, is also non-substitutable. Therefore agriculture needs to increase the efficiency with which $\mathrm{P}$ is acquired and used. Furthermore, excessive $\mathrm{P}$ fertilizer application in the industrial countries has 
caused substantial environmental damage in the past decades, resulting in $\mathrm{P}$ leaching and eutrophication of ground and surface waters.

Improving $\mathrm{P}$ acquisition and $\mathrm{P}$ use efficiency is a major challenge for sustainable agriculture. There are two major ways to enhance $\mathrm{P}$ acquisition efficiency, viz., (i) plant breeding for traits that allow improved acquisition of $\mathrm{P}$ (through changes in root morphology, such as longer and thinner roots, higher specific root length) or longer and more dense root hairs, and through changes in root physiology, such as production of organic anions or phosphatases); and (ii) harnessing the mutualistic relation between crops and arbuscular mycorrhizal fungi (AMF). Both strategies are not mutually exclusive, as plant breeding can involve selection for traits that impact on the mycorrhizal symbiosis (Galván et al. 2011; Hetrick et al. 1992; Kaeppler et al. 2000; Vance et al. 2003). However, it is not well known to what extent different mechanisms of $\mathrm{P}$ acquisition can be stacked in one genotype or whether trade-offs among those mechanisms occur, as mechanisms for $\mathrm{P}$ acquisition could be costly in terms of carbon (C) invested. Such a trade-off has been reported for rice, where increased $\mathrm{Zn}$ uptake through organic anions and through the mycorrhizal symbiosis could not be stacked (Gao et al. 2012). Downregulation of organic anion production in the genus Kennedia in the mycorrhizal condition also suggests a trade-off (Ryan et al. 2012). However, Lynch (2007) suggested that root hairs and the symbiosis with AMF could be combined and do not show a trade-off. Rhizosphere acidification and enhanced production of phosphatases are also additive processes in the case of chickpea and maize (Li et al. 2004). A general framework for evaluating possible trade-offs has not yet been proposed. If traits cannot be combined in one variety, an alternative option to enhance $\mathrm{P}$ acquisition efficiency could be to combine different varieties (see below).

\section{Phosphorus use in China}

In 2006, China consumed 5.3 million metric tonnes P fertilizer (The Yearbook of China Statistics 2007), while the United States of America only consumed 1.8 metric tons P fertilizer (FAO Resource STAT 2006). The bioavailability of soil P was a limiting factor for crop yield in China and crops on more than $70 \%$ of arable land in China suffered from P deficiency until 1980. Till that time Olsen-P was on average less than $10 \mathrm{mg} \mathrm{kg}^{-1}$ soil (Li et al. 2011). 


\section{Chapter 1}

Nowadays, excessive use of $\mathrm{P}$ fertilizer by farmers occurs in China, especially in the North China Plain, which is one of the major areas for intensive crop production. In the North China Plain, the annual net $\mathrm{P}$ accumulation was 53 $\mathrm{kg} \mathrm{P} \mathrm{ha}{ }^{-1}$ year-1. Input was $92 \mathrm{~kg} \mathrm{P} \mathrm{ha}^{-1}$ year $^{-1}$ and agronomic output was $39 \mathrm{~kg} \mathrm{P}$ ha $^{-1}$ year $^{-1}$ (Vitousek et al. 2009). Li et al. (2011) calculated that in total $242 \mathrm{~kg} \mathrm{P}$ $\mathrm{ha}^{-1}$ had accumulated, based on the balance of $\mathrm{P}$ inputs and outputs from 1980 to 2007 in China. At the same time, excessive P fertilizer inputs have caused environmental problems, including eutrophication of surface waters (Aulakh et al. 2007; Sharpley et al. 2000).

In China the remaining accessible high-quality phosphate rock reserves would only suffice till 2050 (Zhang et al. 2008). Once high-quality phosphate rock runs out, China will have to resort to low-quality phosphate rock or to importing $\mathrm{P}$ fertilizer, resulting in increasing prices of $\mathrm{P}$ fertilizer. At that time, Chinese agriculture will have to face potential food insecurity.

In the last decades, several soil P management strategies, including soilbased and plant/rhizosphere-based $\mathrm{P}$ management strategies, have been developed by Chinese farmers and agricultural scientists, and these strategies have been successful (Chen et al. 2014; Li et al. 2011; Li et al. 2015). However, to achieve sustainable $\mathrm{P}$ use in Chinese agriculture is still challenging, for example how to optimize soil P management for crop yield and how to decrease P losses simultaneously by improving soil P status in P deficient soils (Li et al. 2011).

Besides breeding new cereal varieties with higher $\mathrm{P}$ uptake efficiency, and more effective P management, Chinese agriculture still needs more methods that can improve $\mathrm{P}$ utilization efficiency, including the use of soil beneficial microorganisms and new planting patterns (Li et al. 2011).

\section{Arbuscular mycorrhizal fungi}

Arbuscular Mycorrhizal Fungi (AMF) usually form mutualistic symbiotic associations with roots of two thirds of terrestrial plant species, including almost all major crops (Cardoso and Kuyper 2006; Smith and Read 2008). AMF can improve plant nutrition, particularly of immobile nutrients like $\mathrm{P}$ and $\mathrm{Zn}$ and $\mathrm{Cu}$. They also have a range of further beneficial impacts on plant performance, related to enhanced ability of plants to withstand abiotic and biotic stress (Smith and Read 2008). Plant species differ in the degree to which they depend on and benefit from the mycorrhizal symbiosis (Janos 2007). There is also variation in 
mycorrhizal responsiveness within plant species, both for wild plants and crops, suggesting that agricultural practices may have inadvertently selected for traits that impact on mycorrhizal functioning. Crops that show intraspecific variation for mycorrhizal responsiveness include cereals (wheat, barley, rice and maize), legumes, tomato and onions (Galván et al. 2011; Kaeppler et al. 2000). Variation in mycorrhizal responsiveness has been studied with a focus on orthophosphate; variation in mycorrhizal responsiveness when a large fraction of soil $\mathrm{P}$ is in the organic form has been little explored (Dodd et al. 1987). Variation in responsiveness in the presence of organic $\mathrm{P}$ could be due to phytase and phosphatase activity by both the plant and the mycorrhizal fungus. Their separate roles cannot be investigated in the field, but experiments with hyphal compartments, which because of the use of very fine mesh $(<25 \mu \mathrm{m})$ are accessible to fungal hyphae but not to plant roots, have shown a role for mycorrhizal fungal enzymes (or for enzymes produced by bacteria that are closely associated with mycorrhizal fungal hyphae). The literature on the role of the fungus in production of various $\mathrm{P}$ hydrolysing enzymes is currently contradictory, with some experiments showing that AMF can hydrolyse organic $\mathrm{P}$ and with other experiments showing that (most) organic $\mathrm{P}$ is inaccessible for mycorrhizal plants (Cardoso and Kuyper 2006; Koide and Kabir 2000).

Currently around 250 species of AMF have been described, but modern molecular methods (and especially the use of next-generation sequencing of root and environmental samples) suggest that the actual number of species may be an order of magnitude higher (Krüger et al. 2012). The relevant question is to what extent these different species are functionally equivalent or show functional complementarity (Koide 2000). For that reason it is important to experiment with more than one fungal species, or include experiments with species mixtures.

AMF have been shown to provide the dominant route for plant $\mathrm{P}$ uptake, through suppression of the plant transporters in the root epidermis and root hairs, and specific upregulation of mycorrhiza-induced plant $\mathrm{P}$ transporters (Smith et al. 2003). Therefore the contribution of AMF to P supply of plants can be larger than $90 \%$ (Li et al. 2006). Under certain field conditions, it has been estimated that a reduction of $80 \%$ of the recommended $\mathrm{P}$ fertilizer could be achieved by inoculation with AMF (Jakobsen 1983). Despite these impressive numbers, largescale exploitation of AMF in agriculture has so far not happened. Various causes explain the limited use of AMF management in agriculture. First of all, mineral 


\section{Chapter 1}

fertilizers are still reasonably cheap leading to high or even excessive use. High P fertilizer input can suppress mycorrhizal colonization of and subsequent mycorrhizal functioning in plants. Furthermore, current plant breeding practices have taken place under nutrient-rich conditions and it has been suggested that such conditions may inadvertently have selected against the ability of modern crop varieties to benefit from the mycorrhizal symbiosis.

Although application of fertilizers often inhibits AMF, soil may still contain a diverse community of AMF even with intensive crop management (Gai et al. 2015; Oehl et al. 2004). Even when soil P availability is high, AMF can improve plant growth (Vestberg et al. 2011). Such studies imply that indigenous AMF communities can be species-rich and harbour sufficient inoculum potential in intensive farming systems. For these reasons it is still promising to take advantage of the indigenous AMF, for instance by breeding crop varieties with higher mycorrhizal responsiveness, in order to reduce the dependence of crop production on mineral $\mathrm{P}$ fertilizers.

\section{Mycorrhizal responsiveness in the field}

Mycorrhizal responsiveness is defined as the increased growth or P uptake of a plant resulting from AMF colonization (Janos 2007). Mycorrhizal responsiveness is either expressed as a relative value (the biomass or P content of mycorrhizal plants relative to that of non-mycorrhizal plants) or as an absolute value (the increase in biomass or $\mathrm{P}$ content due to the presence of mycorrhiza). Advantages and disadvantages of using relative or absolute values for responsiveness have been discussed by Janos (2007) and Galván et al. (2011). Plant species differ in their mycorrhizal responsiveness. Both root diameter and root hair abundance and length have been shown to be major explanatory variables for mycorrhizal responsiveness. Mycorrhizal responsiveness is also a function of soil fertility at very low soil fertility and at very high soil fertility mycorrhizal responsiveness declines or can even become negative. There is not only variation among plant species in mycorrhizal responsiveness, but intraspecific variation in responsiveness has also been observed for almost every plant investigated for that property. Intraspecific variation in mycorrhizal responsiveness, when tested in the same soil, can be substantial, with relative responsiveness of different varieties or varieties ranging from negative values (where non-mycorrhizal plants produce more 
biomass than mycorrhizal plants) to highly positive values (mycorrhizal plants being larger than non-mycorrhizal plants) (Khalil et al. 1994).

Most studies on genetic variation in mycorrhizal responsiveness of crops focused on the relationship between the plant and one AMF species under controlled conditions (Chu et al. 2013; Kaeppler et al. 2000). Such controlled experiments have two potential drawbacks. First, the use of a non-mycorrhizal control may be considered questionable as most plants form mycorrhiza under field conditions. Second, in the field plants are confronted with a (species-rich or species-poor) community of AMF. As plants could to some extent select the fungi with which they associate (Helgason et al. 2002; Kiers et al. 2011), the predefined (by the researcher) choice for one AMF species may not easily allow extrapolating the results of such studies to field conditions. But testing for mycorrhizal responsiveness in the field may be practically impossible, as it is near-impossible to set up a non-mycorrhizal control in the field.

Determining field responsiveness, that is the responsiveness of plants under field conditions with different amounts of mycorrhizal inoculum, may therefore provide more insight in the functioning of mycorrhiza under agronomically relevant conditions. With such experiments the amount of mycorrhizal inoculum can be artificially reduced to obtain a mycorrhiza-poor control (rather than a non-mycorrhizal control) by fumigation or fungicide use, the use of non-mycorrhizal plants as pre-crop or by treatments that reduce the mycorrhizal fungal biomass through rotating cores. However, some of these treatments have unwanted effects (fumigation or the use of fungicides may kill many other organisms as well, including root-pathogenic fungi; non-mycorrhizal pre-crops like members of the Brassicaceae also change the composition of the soil biotic community). For that reason treatments that specifically reduce the extent of the external mycorrhizal mycelium (the extraradical hyphae) are preferred. The extraradical mycelium not only functions in the uptake of nutrients (Li et al. 1991), but also acts as natural source of inoculum that colonizes new plants (Brundrett and Abbott 1994). Therefore, mycorrhizal researchers use rotated cores, whereby the core is surrounded by a nylon mesh device based on hyphal diameter, that allow hyphae but not roots to enter the core, to set up controls with low amounts of mycorrhiza (Johnson et al. 2002; Johnson et al. 2001; Zhang et al. 2012). Johnson et al. (2001) demonstrated that rotated cores significantly reduce the amount of mycelium in the core as well as the root colonization of the growing 


\section{Chapter 1}

plants. Furthermore, rotation of hyphal in-growth cores has no confounding effects on soil abiotic properties (Leifheit et al. 2014). Thus, rotated cores are a good device to test for field responsiveness of crop varieties in the presence of a native AMF community.

\section{The relationship between maize varieties and AMF}

Maize (Zea mays L.), one of the main cereals in agriculture, has been bred into thousands of varieties. There are genetic differences among maize varieties in $\mathrm{P}$ uptake under non-mycorrhizal and under mycorrhizal conditions (Da Silva et al. 1992; Kaeppler et al. 2000). In terms of maize germplasm, there are three categories: hybrid, inbred line and landrace. The inbred line refers to genotypes developed by selfing at each generation; hybrid refers to genotypes produced by crossing different inbred lines for commercial cropping; landrace refers to genotypes maintained by natural crossing after maize cultivation began since the $16^{\text {th }}$ century. An et al. (2010) documented differences in mycorrhizal root colonization of hundreds of varieties (141 inbred lines, 38 hybrids, and 76 landraces). They observed that modern hybrids exhibited greater fractional colonization than inbred lines and older landraces and concluded that modern plant breeding programs do not inevitably result in lower or even suppression of mycorrhizal colonization. Oliveira et al. (2009) reported that two maize inbred lines, which differed in $\mathrm{P}$ use efficiency, influenced the community composition of the indigenous AMF in their rhizosphere. They also stated that variety identity was more important than soil $\mathrm{P}$ status in differentiating AMF community composition. It is therefore relevant to investigate how Chinese maize varieties respond to native AMF and affect their AMF community in the field. Evaluating different maize germplasms could clarify how AM colonization of different maize varieties varies, and how this translates into differences in mycorrhizal responsiveness. These results may provide information that enables the use of the genetic variation of the crop toward the development of sustainable agro-ecosystems where mycorrhizal functioning is taken into account. Moreover, identifying mycorrhizal responsiveness of maize varieties in the field can provide more realistic information on AMF functioning in the field compared to that in the greenhouse. Finally, through comparing mycorrhizal fungal communities of different maize varieties, we can assess the influence of modern breeding programs on plant selectivity for specific mycorrhizal fungi. 


\section{Overyielding through combining maize varieties (within-species intercropping)}

In both natural and agro-ecosystems a positive relation between plant species richness and productivity has been observed. This yield increase is known as the phenomenon of overyielding (HilleRisLambers et al. 2004; Tilman et al. 2006), when a combination of species produces more biomass than expected from the average production of the component species grown in monoculture. Overyielding has been repeatedly observed in grassland experiments (Hooper and Vitousek 1997; Tilman et al. 2006). Overyielding also occurs in intercropping systems in agriculture. Li et al. (2014) reviewed overyielding in agriculture, and noted that both complementarity and facilitation are involved. Complementarity refers to niche differentiation in space (through differences in rooting depth) and time (through phenological differences) (Loreau and Hector 2001), while facilitation refers to a plant species that can improve its environment by enhancing nutrient availability or resource capture that makes the environment more suitable and beneficial for other species as well (Pugnaire et al. 1996). Turner (2008) hypothesized complementarity when different plants differentially mobilize and acquire P from various organic sources. No support for his hypothesis has however been published. As P can only be taken up as orthophosphate, the potential for niche differentiation through preferential acquisition of $\mathrm{P}$ from various forms is much smaller than in the case of $\mathrm{N}$, where plants could specialize in the uptake of ammonium, nitrate or simple organic $\mathrm{N}$ or fix atmospheric $\mathrm{N}_{2}$ (McKane et al. 2002). Facilitation refers to a beneficial effect of one species on the other through $\mathrm{P}$ mobilization that benefits both the target species and also its neighbours. Facilitation could occur in cases of rhizosphere acidification, production of organic anions or phytase or phosphatase enzymes (Li et al. 1997). Teasing apart facilitation and complementarity empirically is difficult (Hinsinger et al. 2011; Li et al. 2014), and both mechanisms are often taken together and described as complementarity in the biodiversity literature (Loreau and Hector 2001).

The reviews by Li et al. (2014) and Brooker et al. (2015) make clear that the role of the mycorrhizal symbiosis in overyielding has been largely neglected. If different plant species are linked in a common mycorrhizal network (CMN), facilitation or complementarity can also occur as described by Walder et al. (2012) 


\section{Chapter 1}

in the case of sorghum (Sorghum bicolor) and flax (Linum usitassisimum). These authors showed that sorghum invested most carbon in the symbiosis $(70 \%)$, but received only a small share of the benefits $(20 \%$ of $\mathrm{N}$ and only $6 \%$ of $\mathrm{P})$, whereas flax invested much less (30\% of C), while obtaining most benefits $(80 \%$ of $\mathrm{N}$, $94 \%$ of $\mathrm{P})$.

Most studies have addressed the issue of biodiversity and overyielding through a study of different species. However, variation in phenological, physiological and architectural traits between varieties within species can be substantial, providing a basis for intraspecific complementarity or facilitation. Only few studies on variety mixtures within a cereal species have been published. In a laboratory experiment, Wang et al. (2007) observed that mixing a P-efficient and a P-inefficient wheat variety in a soil amended with iron phosphate resulted in significantly increased P-uptake by the P-efficient (and more competitive) variety, whereas the P-inefficient acquired less P. This study did not look explicitly at mycorrhizal functioning. In mixtures of rice varieties that were susceptible and resistant to blast disease, disease incidence in the susceptible variety was reduced compared to the situation where that variety grew in monoculture, resulting in overyielding (Zhu et al. 2000). Mixing different spring barley varieties also improved yield, reduced fungicide application and improved agronomic characteristics (Newton et al. 2002). While it may be impossible to stack different plants traits that maximize nutrient uptake (and hence increase productivity) due to inherent trade-offs during evolution, combining contrasting varieties to achieve overyielding may be a more promising route towards enhanced agricultural productivity due to improved nutrient uptake and use efficiency (Denison 2012). However, whether combining different maize varieties can enhance P uptake efficiency and biomass, and whether there is a mycorrhizal role in this enhanced $\mathrm{P}$ uptake, are both unknown.

The role of AMF in overyielding in mixtures of different species has been reported (Scheublin et al. 2007; Van der Heijden et al. 1998). When sorghum and flax were grown together, the poorer competitor (flax) benefitted from AMF, whereas sorghum hardly experienced a yield reduction in the presence of flax (Walder et al. 2012). Another study, however, reported the opposite result, as AMF species enhanced competitive inequality (Fellbaum et al. 2014). Their result showed that AMF discriminated among host plants that shared a CMN, and AMF preferentially allocated nutrients to the high-quality host (i.e., a host that provides 
more $\mathrm{C}$ to the fungus) rather than to the low-quality host. A study by Weremijewicz and Janos (2013) also reported that AMF increased size inequalities in monocultures of Andropogon gerardii. Competition studies have shown a range of outcomes when plants were grown in the non-mycorrhizal and mycorrhizal condition (Lin et al. 2015; Moora and Zobel 1996; Zobel and Moora 1995). The presence of mycorrhiza both amplified competitive inequalities but also allowed the weaker competitor in the non-mycorrhizal condition to become a stronger competitor in the mycorrhizal condition. I am not aware of studies that investigated the impact of AMF on the relation between variety diversity and productivity.

\section{Plant - soil feedback effects within maize varieties}

Growing plants affect their soil, resulting in changes in soil biological, chemical and physical properties (Bezemer et al. 2006; Ehrenfeld et al. 2005; Klironomos 2002). These changes can subsequently feedback on the growth of the same or different plant species that are grown subsequently. Positive feedback means that a plant species alters its soil environment in a way that increases its own growth relative to that of other species; negative feedback means that a plant species alters its soil environment in a way that decreases its own growth relative to that of other plant species (Bever 2003; Bever et al. 1997). Negative feedback is usually explained by the build-up of plant species-specific pathogens, whereas positive feedback could be due to the build-up of plant-species specific mycorrhizal inoculum. However, a mycorrhizal role has also been demonstrated in cases of negative feedbacks, when plants were associated with mycorrhizal fungi from which they did not derive the largest benefit (Bever 2002a; b).

Plant - soil feedbacks are important for monocropping and crop rotations (crop mixtures in time), as an alternative to intercropping (crop mixtures in space). Most studies on plant - soil feedbacks have involved different plant species. It is likely that the same mechanisms pertain to different varieties of the same plant species. However, the role of the arbuscular mycorrhizal symbiosis in plant - soil feedbacks with different crop varieties (cereals) has not been studied.

\section{Outline of the thesis}

My thesis aims at understanding the role of the arbuscular mycorrhizal symbiosis in phosphorus acquisition efficiency of different maize varieties. By studying the 


\section{Chapter 1}

mycorrhizal role in that intraspecific variation, I hope to (mechanistically) understand which plant traits (including plant traits related to mycorrhizal functioning) can be combined to increase $\mathrm{P}$ acquisition efficiency, and whether combining maize varieties, in space or time, can be an alternative route towards more efficient $\mathrm{P}$ use. My thesis intends to provide answers to the following four research questions:

1. How do maize varieties differ in mycorrhizal responsiveness under field conditions with native communities of AMF?

2. Can (mycorrhizal) maize utilize P from phytate, the major source of organic $P$, and what is the quantitative importance of phytate- $\mathrm{P}$ use for $\mathrm{P}$ nutrition of two different maize varieties in the presence of different species of AMF?

3. Can combining different maize varieties in both non-mycorrhizal and mycorrhizal conditions improve $\mathrm{P}$ acquisition resulting in overyielding, and which mechanisms (selection effect, complementarity effect) contribute to overyielding? 4. Are there significant plant - soil feedbacks when different maize varieties are grown in their own soil and in soil where another maize variety was previously grown, and is there a mycorrhizal role in determining the direction and / or magnitude of that feedback?

Experiments were conducted under both greenhouse and field conditions.

Following this introductory chapter, Chapter 2 analyses a field experiment, where the mycorrhizal field responsiveness of a number of maize varieties was investigated. I also investigated whether different maize varieties associate with different species of AMF.

Chapter 3 describes a rhizobox experiment where phytate was added to the hyphal compartment in order to understand the effect of different maize varieties and different $A M F$ species on phytate utilization.

Chapter 4 investigates whether combining different maize varieties results in overyielding in both pot and field experiments during two years. A pot experiment was conducted with monocultures and mixtures with different $\mathrm{P}$ sources with a defined species of AMF. At the same time, a field experiment was conducted with monocultures or mixtures in the presence of a community of AMF (where crop mixtures could also affect species composition compared to the monocultures). The aim of this chapter was to assess the possibility of combing maize varieties, and to assess the function of AMF in this mixture. 
Chapter 5 focuses on the feedback or legacy effects of AMF on subsequent maize varieties. My aim was to explore plant - soil feedback effects on maize growth. An experiment in two phases was carried out, a conditioning phase and a feedback phase, to determine the plant - soil feedback dynamics of maize varieties in the mycorrhizal and non-mycorrhizal condition. In the initial conditioning phase sterilized soil was used to grow maize varieties; these varieties were inoculated with different AMF species. In the subsequent feedback phase, each soil community (of two varieties and three AMF species, plus the mixed AMF community) was used as conditioned soil to grow the maize varieties on their home and away soil.

This thesis concludes with a General Discussion (Chapter 6), in which interactions among maize varieties, $\mathrm{P}$ resources and AMF will be discussed as related to the general aim of my thesis. Moreover, I will give some implications of my study and make suggestions for future research based on the results of my studies. 

CHAPTER 2

Mycorrhizal field responsiveness and phosphorus acquisition efficiency of maize (Zea mays L.) varieties

Xinxin Wang, Ning Shi, Fei Wang, Ellis Hoffland, Gu Feng, Thomas W.

Kuyper 


\section{Chapter 2}

\section{Abstract}

The effect of one single arbuscular mycorrhizal fungal (AMF) species on yield and phosphorus $(\mathrm{P})$ uptake (mycorrhizal responsiveness) of different maize varieties is well studied, but how responsiveness operates in the field, when plants can be colonized by different species of AMF and different maize varieties may exhibit selectivity towards certain AF species, remains poorly understood. This study investigated how maize varieties vary in mycorrhizal field responsiveness by using in-growth cores that could be rotated (to achieve a low-mycorrhiza treatment) or not rotated (to achieve normal colonization levels). Twenty maize varieties were included, four inbred lines, twelve hybrids, and four landraces. Shoot biomass, P uptake, mycorrhizal colonization and mycorrhizal responsiveness in cores with and without rotation were assessed in three fields with different histories of $\mathrm{P}$ fertilizer. P acquisition efficiency was also determined. In each field, both shoot biomass and colonization were significantly influenced by variety and rotation. However, there were no categorical differences among landraces, inbred lines and hybrids for biomass, $\mathrm{P}$ uptake, mycorrhizal colonization or mycorrhizal responsiveness. $\mathrm{P}$ acquisition efficiency was higher for landraces and lower for hybrids. The fields were poor in AMF species (only four AMF species were identified with molecular methods), with small differences between fields with high and low P fertilizer application, and small differences among four different maize varieties. Mycorrhizal responsiveness was negatively correlated with growth in the low-mycorrhizal condition and with $\mathrm{P}$ acquisition efficiency, indicating that plant breeding may have impacted on the mycorrhizal symbiosis, but may not have reduced mycorrhizal responsiveness.

Keywords: native AM mycorrhizal colonization; maize; phosphorus uptake; mycorrhizal responsiveness; genotypic variation; mycorrhizal community; ingrowth cores 


\section{Mycorrhizal field responsiveness and phosphorus acquisition efficiency of maize (Zea mays L.) varieties}

\section{Introduction}

Phosphorus $(\mathrm{P})$ is one of the least available macronutrients to plants in soils, and $\mathrm{P}$ limitation is therefore a major constraint to crop productivity. $\mathrm{P}$ limitation is not due to a shortage of total $\mathrm{P}$ in soil, but a consequence of the strong chemical sinks ( $\mathrm{P}$ adsorption and fixation on metal (hydr)oxides, precipitation as metal phosphates) that result in low $\mathrm{P}$ concentrations in the soil solution (Turner et al. 2005). To increase crop productivity, either $P$ availability (through addition of mineral P fertilizer, a non-renewable and non-substitutable resource) and/or the efficiency by which plant roots (including the beneficial rhizosphere microbiota) acquire and subsequently use $\mathrm{P}$ should increase.

Arbuscular mycorrhizal fungi (AMF) play an important role in nutrient acquisition, especially P (Smith and Read 2008). The majority of plant species including crop species depend on and are responsive to the mycorrhizal symbiosis. The degree to which plants respond to the mycorrhizal symbiosis is a function of plant species (especially root traits), soil conditions (inherent fertility, $\mathrm{pH}$ and soil management) and AMF species. Responsiveness, the relative or absolute increase in biomass or yield or nutrient content of a mycorrhizal plant compared to a nonmycorrhizal plant (Janos 2007), is therefore not a unique plant trait, but is determined by the tripartite interaction plant $\times$ AMF $\times$ environment (including management). Different plant species show, when grown in the same soil with the same inoculum source, large variation in responsiveness. This variation has been linked to root traits: plants with thin roots with abundant and long root hairs are generally little responsive to AMF, whereas plants with thick, unbranched roots with sparse and short root hairs show large responsiveness (Baylis 1975). Next to interspecific variation in responsiveness, intraspecific variation in responsiveness has also been demonstrated for wild plants and (especially) for major crops, such as the main cereals (wheat, barley, maize, rice), legumes, tomato, onion and cassava (Baon et al. 1993; Galván et al. 2011; Gao et al. 2007; Hajiboland et al. 2010; Hetrick et al. 1996; Kaeppler et al. 2000; Sieverding and Toro 1988; Wilson and Hartnett 1998).

Experiments to test for mycorrhizal responsiveness of crop species or varieties are commonly executed under controlled conditions. Plants grown in pots without mycorrhiza (usually after soil fumigation, pasteurization or sterilization) and with mycorrhiza (added by the investigator, together with the 


\section{Chapter 2}

AMF-associated soil microbiota through a microbial wash) are compared (Klironomos 2003). The source of mycorrhizal inoculum is often a specific fungal species, with which the plant may or may not occur in the field (Klironomos 2003). Such experiments pose a number of potential problems. First, the comparison with a non-mycorrhizal plant may be problematic, considering that plants are very seldom, if ever, found in the field without any mycorrhiza. Second, the species selection of AMF may not reflect the specificity or selectivity that the plant would display, when it is confronted in the field with a higher diversity of AMF. Third, the species used are predominantly those that can readily be cultured and maintained in the lab, and such 'lab rats' often possess more ruderal properties than many other species that occur in the field. Fourth, greenhouse conditions often pose additional problems with light availability and pot size. Therefore, assessing responsiveness in the field could provide more insight in mycorrhizal functioning.

Plenchette et al. (1983) assessed field mycorrhizal responsiveness by fumigating field soils and comparing non-inoculated (and hence non-mycorrhizal) and inoculated plants. Alternatively, one could assess mycorrhizal field responsiveness through comparing plants with lower levels of mycorrhizal colonization with plants that have higher colonization levels. Creating different colonization levels in the field can be achieved by inoculum addition to the mycorrhizal treatment, a practice that gives very variable results (Lekberg and Koide 2005), or by reducing mycorrhizal fungal abundance in the 'control' treatment. Reducing mycorrhizal abundance in the field can be achieved by various means, such as fumigation, solarization, the use of fungicides, bare fallows or the use of non-mycorrhizal plants (especially members of the Brassicaceae), but these treatments have impacts on other soil properties as well. Currently researchers prefer to grow plants in cores with sterilized soil inside, surrounded by a nylon mesh (mesh size around $30 \mu \mathrm{m}$ ) that allows hyphae but not roots to enter the core (Johnson et al. 2002; Johnson et al. 2001; Zhang et al. 2012). Rotating these cores damages and reduces the external mycelium and hence mycorrhizal functioning (Johnson et al. 2001) without impacting on roots or other soil properties (Leifheit et al. 2014).

Maize (Zea mays L.) is a major agricultural crop. Thousands of varieties have been bred, which can be grouped in three categories: landraces, inbred lines and hybrids. Inbred line refers to varieties developed by selfing at each generation; 


\section{Mycorrhizal field responsiveness and phosphorus acquisition efficiency of maize (Zea mays L.) varieties}

hybrid refers to varieties produced by crossing different inbred lines for commercial cropping; landrace refers to varieties maintained by natural crossing after maize cultivation began since the $16^{\text {th }}$ century. Kaeppler et al. (2000) compared 28 inbred lines of maize for mycorrhizal responsiveness in a low-P and a high-P soil and concluded that there is considerable genetic variation for mycorrhizal responsiveness on low-P soils and that this variation could be harnessed to develop varieties for soils where $\mathrm{P}$ is the major limiting factor. Wright et al. (2005) compared an African landrace with a European hybrid line and noted that the hybrid line had not lost its ability to respond to mycorrhiza and therefore may have retained traits that could be useful under low-input agriculture. Chu et al. (2013) compared mycorrhizal responsiveness of four Chinese maize varieties, one old landrace and three modern hybrids, and also showed that maize breeding may not have selected against the ability to benefit from mycorrhiza under low-P conditions. Next to variation in mycorrhizal responsiveness, different varieties could also differ in the degree to which their roots are colonized by AMF and this trait may be correlated with differences in responsiveness. An et al. (2010) documented differences in mycorrhizal colonization of hundreds of varieties (141 inbred lines, 38 hybrids, and 76 landraces) of maize. They found that plant breeding did not result in the suppression of colonization of the modern maize hybrids. Field studies on variation in maize varieties with respect to their interaction with mycorrhizal fungi are scarce. Oliveira et al. (2009) reported that differences in P efficiency of tropical maize varieties influenced mycorrhizal fungal community composition, with more efficient varieties harbouring a larger number of AMF species.

Currently some 250 species of AMF have been described, but the application of molecular methods (especially high-throughput sequencing of soil and root samples) suggests a substantially higher number of species globally, possibly an order of magnitude larger than the number of described species (Krüger et al. 2012). Individual ecosystems can harbour a high number of species, especially under more natural conditions. Agricultural intensification, including the application of substantial amounts of mineral $\mathrm{P}$ fertilizer, soil disturbance through ploughing, bare fallowing and monocropping, generally reduced species richness (Muriithi-Muchane 2013; Oehl et al. 2004; Verbruggen and Kiers 2010). Cases have been described with less than five species of AMF species (Helgason et al. 1998; Oehl et al. 2003). 


\section{Chapter 2}

The objectives of our field experiment were to determine by using ingrowth cores:

1. Mycorrhizal colonization of different maize categories (landraces, inbred lines, hybrids) in fields with a long-term P-fertilizer experiment;

2. Mycorrhizal field responsiveness, in terms of biomass and P content, of these different categories;

3. Phosphorus acquisition efficiency of these different categories;

4. Relationships among mycorrhizal colonization, mycorrhizal field responsiveness and phosphorus acquisition efficiency;

5. Mycorrhizal fungal community composition of four different varieties.

We preferred to look at these three categories, rather than at individual varieties, in order to assess whether and how breeding practices have impacted on the association between crops and their associated AMF.

\section{Materials and methods}

\section{Soil}

A field experiment was set up from May 11 $1^{\text {st }}, 2009$ to June 26 $6^{\text {th }}, 2009$ at the Changping long-term Fertilizer Station of China Agricultural University, Beijing. A P-fertilizer trial had been executed for the last 16 years under continuous maize in three different adjacent fields with three different $\mathrm{P}$ application rates $(0,67.5$ and $135 \mathrm{~kg} \mathrm{P}_{2} \mathrm{O}_{5} \mathrm{ha}^{-1} \mathrm{yr}^{-1}$; equivalent to 0,30 and $\left.60 \mathrm{~kg} \mathrm{P} \mathrm{ha}^{-1} \mathrm{yr}^{-1}\right)$. Except for differences in $\mathrm{P}$ availability (Olsen-P), there were no significant differences in soil properties among the fields ( $\mathrm{P}$ treatments) (Table 2.1). For that reason we use three P levels and three fields interchangeably. All fields received $\mathrm{N}$ as urea at a rate of $135 \mathrm{~kg} \mathrm{~N} \mathrm{ha}^{-1} \mathrm{yr}^{-1}$ and $\mathrm{K}$ at a rate of $225 \mathrm{~kg} \mathrm{ha}^{-1} \mathrm{yr}^{-1}$ (as $\mathrm{K}_{2} \mathrm{O}$ ). Fertilizers were applied before the in-growth cores were installed when the fields were under fallow. Soil was collected from the field, passed through a 2 -mm sieve and sterilized by radiation with ${ }^{60} \mathrm{Co} \gamma$-ray at $10 \mathrm{kGy}$. 


\section{Mycorrhizal field responsiveness and phosphorus acquisition efficiency of}

maize (Zea mays L.) varieties

Table 2.1. Soil chemical properties of experimental fields.

\begin{tabular}{|c|c|c|c|c|c|c|c|}
\hline $\begin{array}{l}\text { Soil } \\
\text { treatment }\end{array}$ & $\begin{array}{l}\text { P } \\
(\mathrm{kg} \mathrm{ha}- \\
1)\end{array}$ & $\begin{array}{l}\mathrm{N} \text { (as urea) } \\
\left(\mathrm{kg} \mathrm{ha}^{-1}\right)\end{array}$ & $\begin{array}{l}\mathrm{K}_{2} \mathrm{O} \\
(\mathrm{kg} \mathrm{ha} \\
\left.{ }^{-}\right)\end{array}$ & $\mathrm{pH}$ & $\begin{array}{l}\text { Total } \\
\mathrm{N} \\
\left(\mathrm{g} \mathrm{kg}^{-1}\right)\end{array}$ & $\begin{array}{l}\text { Available } \\
\text { P } \\
\left(\mathrm{mg} \mathrm{kg}^{-1}\right)\end{array}$ & $\begin{array}{l}\text { Organic } \\
\text { matter } \\
\left(\mathrm{g} \mathrm{kg}^{-1}\right)\end{array}$ \\
\hline P0 & 0 & 135 & 225 & 7.81 & 0.9 & 2.9 & 17.8 \\
\hline P1 & 30 & 135 & 225 & 7.97 & 0.7 & 6.4 & 15.4 \\
\hline P2 & 60 & 135 & 225 & 7.79 & 0.7 & 15.0 & 17.2 \\
\hline
\end{tabular}

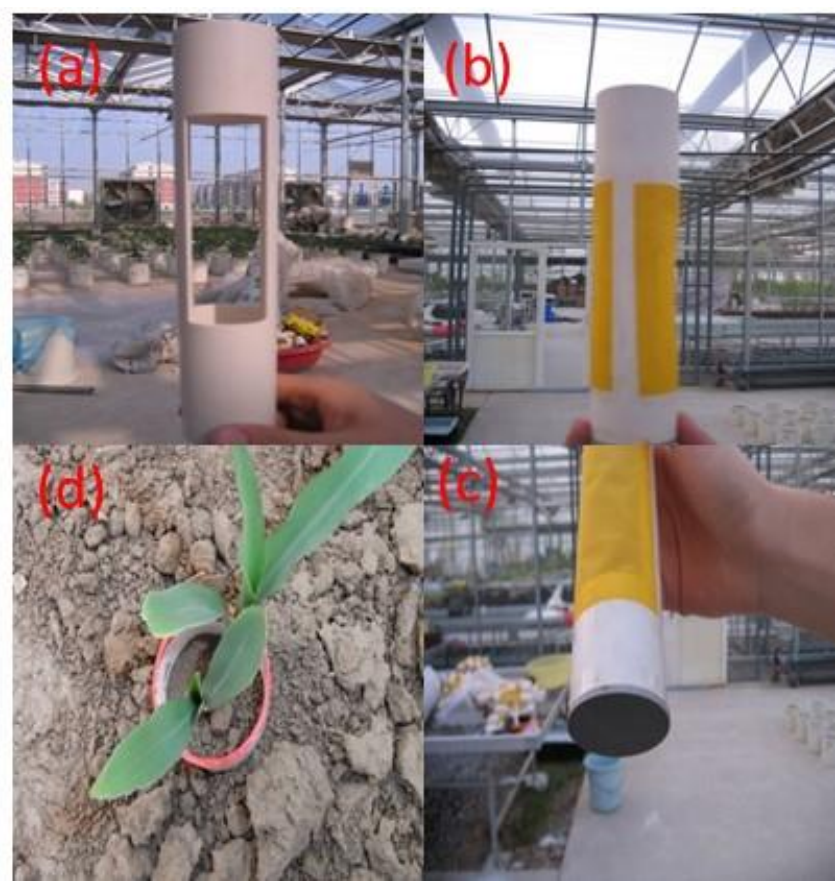

Fig. 2.1. In-growth core with (clockwise) "open windows" (a), with nylon mesh (b), with the bottom (c), and with growing maize plants in the field (d).

\section{In-growth cores}

In-growth cores were made of polyvinylchloride (PVC) water pipes, with length $25 \mathrm{~cm}, 5 \mathrm{~cm}$ inner diameter and $5.4 \mathrm{~cm}$ outer diameter (Fig. 2.1). Every core contained two 'windows' of $12 \mathrm{~cm}$ length $\times 4 \mathrm{~cm}$ width, placed symmetrically at 


\section{Chapter 2}

two sides of a core. The distance between the bottom of the core and the edge of the window was $5 \mathrm{~cm}$. Every window was sealed with $30 \mu$ m nylon mesh through which hyphae but not roots could pass. The base of each core was sealed by a circular PVC board with $5.4 \mathrm{~cm}$ diameter. The cores were inserted till a depth of $22 \mathrm{~cm}$, and the upper $3 \mathrm{~cm}$ were above the soil. Cores were filled (up to the soil atmosphere layer, hence over a length of $22 \mathrm{~cm}$ ) with $240 \mathrm{~g}$ sterilized soil. Cores of the rotation treatment were rotated $360^{\circ}$ twice weekly until harvest.

\section{Test plant}

Twenty maize varieties were used: Jinhuanghou (JHH), Baimaya (BMY), Huangmaya (HMY) and Yinglizi (YLZ) are landraces bred in the 1950s; Zhongdan2 (ZD2), Huang417 (H417), Yedan13 (YD13), Nongda108 (ND108), Zhongdan958 (ZD958), Junddan20 (JD20), Xiuqing13 (XQ13), Liyu13 (LY13), Liyu16 (LY16), Jinhai5 (JH5), Xianyu335 (XY335) and 32D22 are modern hybrids; 181, 197, Wu312 (W312) and 478 are inbred lines.

In each core, two maize seeds (surface-sterilized for 10 min in $10 \% \mathrm{H}_{2} \mathrm{O}_{2}$ followed by $3 \mathrm{~min}$ in $70 \%$ ethanol) were sown; they were thinned to one plant after germination. During the experiment, tap water was added every day, but not during rainy days. In May, the daytime temperature ranged from $14-26{ }^{\circ} \mathrm{C}$ and in June from $20-30{ }^{\circ} \mathrm{C}$. Rainfall was $30 \mathrm{~mm}$ in May and $50 \mathrm{~mm}$ in June.

\section{Harvest and sample analysis}

Plants were harvested 45 days after sowing. At harvest, plant shoots were cut in the field. Subsequently the cores with roots were removed from the soil and transported to the lab, where the roots were carefully removed from the soil. The shoots were oven-dried at $105{ }^{\circ} \mathrm{C}$ for $30 \mathrm{~min}$ to cease metabolic activity and then at $72{ }^{\circ} \mathrm{C}$ for $48 \mathrm{~h}$ and finally ground to a fine powder. Roots were washed with deionized water and then preserved at $-20^{\circ} \mathrm{C}$.

Frozen roots were cut into $1-\mathrm{cm}$ segments and thoroughly mixed. A $0.5-\mathrm{g}$ subsample was cleared with $10 \%(\mathrm{w} / \mathrm{v}) \mathrm{KOH}$ at $90{ }^{\circ} \mathrm{C}$ for $2 \mathrm{~h}$ and stained with trypan blue for quantification of mycorrhizal colonization according to the method by Trouvelot et al. (1986). Shoot P concentration was determined by the standard vanado-molybdate method (Murphy and Riley 1962), after digestion in a $\mathrm{H}_{2} \mathrm{SO}_{4}-\mathrm{H}_{2} \mathrm{O}_{2}$ mixture at $360{ }^{\circ} \mathrm{C}$ for $2 \mathrm{~h}$. 


\section{Mycorrhizal field responsiveness and phosphorus acquisition efficiency of maize (Zea mays L.) varieties}

\section{Polymerase chain reaction (PCR), T-RFLP and Cloning}

Root samples were collected from four varieties: HMY, JHH, ZD2 and XY335 from two P treatments (P1 and P2; samples from P0 were taken but problems during storage resulted in too poor DNA quality). One-cm long root segments were randomly selected from each root system. Root samples were ground into homogeneous powder using a ball-bearing grinder. DNA extraction was executed from $50 \mathrm{mg}$ of that powder following the directions for use of the Plant Genomic DNA Kit (TIANGEN). Fungal identifications were based on the Large Subunit (LSU) of the ribosomal cluster after a nested PCR. The first PCR reaction was performed with the eukaryotic primers LR1 and NDLL22 (Van Tuinen et al. 1998), whereas the second reaction was performed from the product of the first reaction with the AMF general primers FLR3 and FLR4 (Gollotte et al. 2004). PCRs were performed in the final volume of $20 \mu \mathrm{l}$ and the cycling conditions were as follows: initial denaturation at $93^{\circ} \mathrm{C}$ for $3 \mathrm{~min}$, then 30 cycles with denaturation at $93{ }^{\circ} \mathrm{C}$ for $40 \mathrm{~s}$, annealing at $54{ }^{\circ} \mathrm{C}$ for $40 \mathrm{~s}$, followed by elongation at $72{ }^{\circ} \mathrm{C}$ for $50 \mathrm{~s}$. The cycle was finalized by elongation at $72{ }^{\circ} \mathrm{C}$ for $10 \mathrm{~min}$. The expected length of the PCR products was confirmed by electrophoresis in 1\%(w/v) denaturing agarose gels in TAE buffer.

The purified PCR products were digested with restriction enzyme Taq1 for $4 \mathrm{~h}$ at $65^{\circ} \mathrm{C}$. The digestion volume was $20 \mu \mathrm{l}$ including 10-15 $\mu \mathrm{l}$ product. Finally, the data were collected using electrophoresis in a capillary by NUOSAI company (Beijing, China). The results of the peaks were exported by software Peak scanner and aligned in the online software T-REX. PCRs amplification products were ligated into the vector pMD19-T (TA Cloning Kit for Sequencing, TAKARA). Ligation mixtures were transformed into competent E. coli JM109 cells (TAKARA). From each sample 80 white colonies were selected for sequencing at BGI (Beijing Genome Institute). Sequences were obtained from the $28 \mathrm{~S}$ LSU rDNA region (each terminal fragment around $380 \mathrm{bp}$ in length). These sequences were submitted to the BLAST query tool (Altschul et al. 1997) and database (www.ncbi.nih.gov/blast/) for analysis and sequences that showed more than $97 \%$ similarity were considered to belong to one phylotype (molecular 'species').

One sequence was randomly taken from each phylotype and aligned with MUSCLE in the software MEGA 6 (Tamura et al. 2013), and a phylogenetic 


\section{Chapter 2}

analysis was carried out by distance analysis using the neighbour-joining method with the p-distance model, and a gamma shape parameter of 0.05 .

\section{Experimental design and data analysis}

The experiment was done on three separate fields for three $\mathrm{P}$ levels. The experiment was carried out with five replicates, giving $600(3 \times 2 \times 20 \times 5)$ cores in total. In each field two factors were tested: (1) Rotation (without or with rotation); (2) Variety (twenty maize varieties). Subsequently we tested for each field and separately for the rotated and non-rotated cores whether there were categorical differences among landraces, inbred lines and hybrids. For calculations of mycorrhizal responsiveness and $\mathrm{P}$ acquisition efficiency we used the average of the five cores, as the design did not have a block structure.

Mycorrhizal responsiveness (MR) was calculated for biomass $\left(\mathrm{MR}_{\text {biom }}\right)$ and $\mathrm{P}$ uptake $\left(\mathrm{MR}_{\mathrm{P}}\right)$ separately. Because in the more fertile field non-mycorrhizal plants outperformed mycorrhizal plants, we decided to use a formula for MR that is symmetrical around zero:

$\mathrm{MR}=\ln$ (non-rotated core / rotated)

Plant $P$ acquisition efficiency was calculated as:

$\mathrm{PAE}=$ biomass of variety at $\mathrm{P}_{0} /$ biomass of variety at $\mathrm{P}_{2}$

Statistical analyses were performed with SPSS software, version 22.0 (SPSS Inc. Chicago, IL, USA). Three two-way analyses of variance (one per field / $\mathrm{P}$ treatment) were performed to test for significant sources of variation in dependent variables (colonization, biomass and $\mathrm{P}$ uptake). One-way analysis of variance was performed for categorical differences in colonization, biomass, $\mathrm{P}$ uptake, $\mathrm{MR}_{\text {biom, }} \mathrm{MR}_{\mathrm{P}}$, and $\mathrm{PAE}$. Correlations between variables (averages for every variety) were tested using Pearson's correlation coefficient $(P<0.05)$. Data on mycorrhizal species composition were subjected to non-metric multidimensional scaling (NMDS). 


\section{Mycorrhizal field responsiveness and phosphorus acquisition efficiency of maize (Zea mays L.) varieties}

\section{Results}

\section{Mycorrhizal colonization}

Analysis of variance indicated that at all three P levels rotation, variety and the variety $\times$ rotation interaction were significant sources of variation (Table 2.2). Rotation reduced average colonization levels to $5-10 \%$ at each P level (Table 2.3). The non-rotated cores at P2 showed significantly lower colonization levels (33\%) than P0 and P1 (45-46\%; P< 0.001). Levels of colonization of non-rotated cores in the three different $\mathrm{P}$ treatments were not significantly correlated with each other. There were no differences among the three categories of maize varieties (landrace, inbred lines and hybrid) in fractional colonization in non-rotated cores for each $P$ level $(P=0.73,0.53$ and 0.23 respectively; Fig. 2.2).

Table 2.2. Significance of $\mathrm{F}$ values derived from analysis of variance for shoot biomass, shoot $\mathrm{P}$ content (mg plant $\left.{ }^{-1}\right)$ and mycorrhizal root colonization (\% of root colonized) measured on twenty corn varieties at three different $\mathrm{P}$ levels.

\begin{tabular}{llllllll}
\hline Independent & & \multicolumn{2}{l}{ Shoot biomass } & \multicolumn{2}{l}{ P content } & \multicolumn{2}{l}{ Colonization } \\
\cline { 3 - 8 } Variables & df & F & $P$ value & F & $P$ value & F & $P$ value \\
\hline P supply (P) & 2 & 2,422 & $<0.001$ & 1,210 & $<0.001$ & 75 & $<0.001$ \\
Rotation (R) & 1 & 513 & $<0.001$ & 397 & $<0.001$ & 4,469 & $<0.001$ \\
Varieties (V) & 19 & 15 & $<0.001$ & 11 & $<0.001$ & 6 & $<0.001$ \\
$\mathrm{P} \times \mathrm{R}$ & 2 & 18 & $<0.001$ & 56 & $<0.001$ & 56 & $<0.001$ \\
$\mathrm{P} \times \mathrm{V}$ & 38 & 7 & $<0.001$ & 7 & $<0.001$ & 6 & $<0.001$ \\
$\mathrm{R} \times \mathrm{V}$ & 19 & 7 & $<0.001$ & 7 & $<0.001$ & 7 & $<0.001$ \\
$\mathrm{P} \times \mathrm{R} \times \mathrm{V}$ & 38 & 6 & $<0.001$ & 5 & $<0.001$ & 6 & $<0.001$ \\
\hline
\end{tabular}

\section{Plant biomass, $P$ uptake and $P$ acquisition efficiency}

Rotation treatment, variety and their interaction were significant sources of variation for both biomass and shoot $\mathrm{P}$ content, for all $\mathrm{P}$ levels (Table 2.2). Rotation significantly decreased shoot biomass and P content in most cases (Fig. 2.3). With increasing $\mathrm{P}$ application, shoot biomass and $\mathrm{P}$ content increased (Fig. 2.3). There were no categorical differences in biomass in both rotated and nonrotated cores, but the biomass differences in the field without $\mathrm{P}$ fertilizer for the 


\section{Chapter 2}

non-rotated cores were almost significant $(\mathrm{P}=0.054)$, with landraces being larger than inbred lines and hybrids ( $0.61 \mathrm{~g}$ versus 0.45 and $0.47 \mathrm{~g})$.

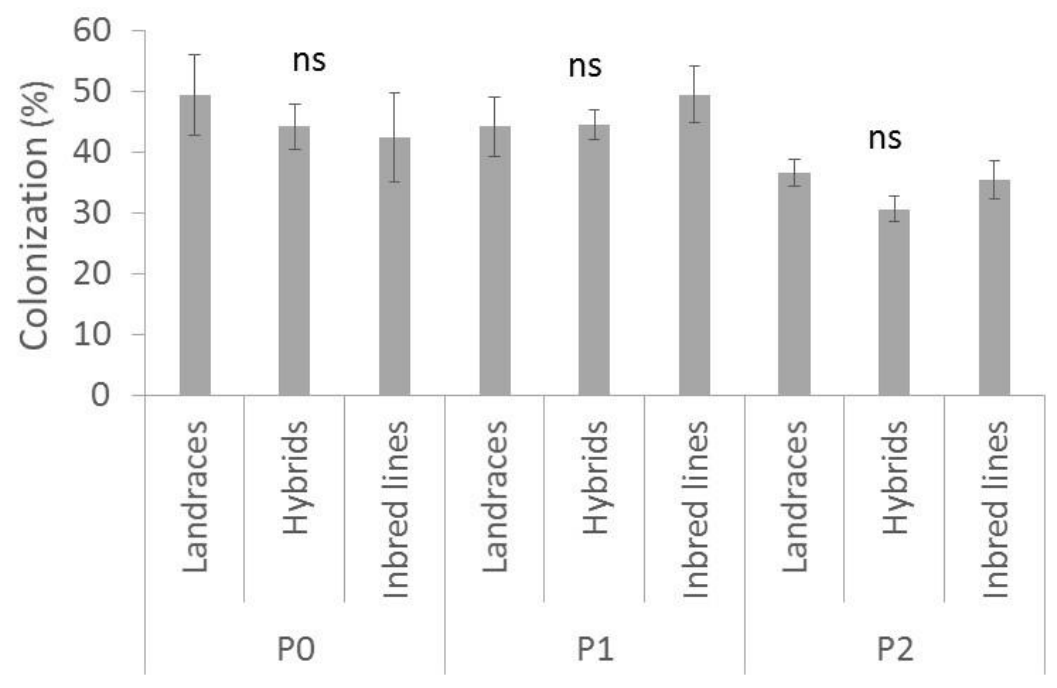

Fig. 2.2. Fractional mycorrhizal root colonization by native AMF community among three groups of maize in non-rotated cores at three different $\mathrm{P}$ levels. "ns" indicates no significant difference among three categories at each $\mathrm{P}$ level.

Mycorrhizal responsiveness was highest at $\mathrm{P}_{0}$. Plants in non-rotated cores were on average $52 \%$ larger than plants in rotated cores. Mycorrhizal responsiveness declined in fields with $\mathrm{P}$ fertilizer (plants in non-rotated cores in $\mathrm{P}_{1}$ and $\mathrm{P}_{2}$ were on average $37 \%$ and $21 \%$ larger than plants in rotated cores, respectively). Mycorrhizal $\mathrm{P}$ responsiveness was also highest at $\mathrm{P}_{0}$, with plants in non-rotated cores containing $76 \%$ more $\mathrm{P}$ than plants in rotated cores). Mycorrhizal $\mathrm{P}$ responsiveness also declined in the fields with higher $\mathrm{P}$ availability (plants in nonrotated cores contained $69 \%$ and $55 \%$ more $\mathrm{P}$ than plants in rotated cores in $\mathrm{P}_{1}$ and $\mathrm{P}_{2}$ respectively). Higher $\mathrm{MR}_{\mathrm{P}}$ than $\mathrm{MR}_{\text {biom }}$ indicated luxury $\mathrm{P}$ uptake. The significant interaction term with variety indicated that both mycorrhizal responses were variety-specific. There were no significant differences in mycorrhizal responsiveness or mycorrhizal $\mathrm{P}$ responsiveness among landraces, inbred lines and hybrids, regardless of $\mathrm{P}$ level ( $\mathrm{P}>0.05$ in all six cases; Fig. 2.4). 


\section{Mycorrhizal field responsiveness and phosphorus acquisition efficiency of maize (Zea mays L.) varieties}

Phosphorus acquisition efficiency was significantly different among the three categories $\left(\mathrm{F}_{2,17}=4.67 ; \mathrm{P}=0.02\right)$. PAE was 0.38 for landraces, 0.29 for inbred lines and 0.25 for hybrids.

Table 2.3. Fractional root colonization (\%) of twenty varieties of maize with rotation and non-rotation at three different $\mathrm{P}$ levels.

\begin{tabular}{llllllll}
\hline & & no P & \multicolumn{3}{l}{$30 \mathrm{~kg} \mathrm{P} \mathrm{ha}^{-1}$} & $60 \mathrm{~kg} \mathrm{P} \mathrm{ha}^{-1}$ \\
\cline { 2 - 7 } Category & Variety & $\mathrm{R}$ & $\mathrm{NR}$ & $\mathrm{R}$ & $\mathrm{NR}$ & $\mathrm{R}$ & $\mathrm{NR}$ \\
\hline Landrace & JHH & $7 \pm 1$ & $42 \pm 2$ & $9 \pm 2$ & $43 \pm 2$ & $11 \pm 3$ & $37 \pm 3$ \\
Landrace & BMY & $9 \pm 2$ & $41 \pm 1$ & $5 \pm 1$ & $36 \pm 2$ & $5 \pm 1$ & $42 \pm 6$ \\
Landrace & HMY & $6 \pm 0.5$ & $69 \pm 1$ & $8 \pm 2$ & $40 \pm 2$ & $5 \pm 2$ & $31 \pm 5$ \\
Landrace & YLZ & $6 \pm 1$ & $46 \pm 3$ & $6 \pm 1$ & $58 \pm 2$ & $5 \pm 1$ & $37 \pm 5$ \\
Hybrid & ZD2 & $9 \pm 1$ & $25 \pm 2$ & $8 \pm 1$ & $44 \pm 4$ & $7 \pm 1$ & $28 \pm 2$ \\
Hybrid & H417 & $7 \pm 1$ & $34 \pm 3$ & $9 \pm 1$ & $55 \pm 5$ & $7 \pm 1$ & $19 \pm 3$ \\
Hybrid & YD13 & $5 \pm 1$ & $50 \pm 3$ & $7 \pm 2$ & $55 \pm 4$ & $6 \pm 2$ & $27 \pm 2$ \\
Hybrid & ND108 & $6 \pm 1$ & $56 \pm 3$ & $7 \pm 1$ & $35 \pm 3$ & $5 \pm 1$ & $27 \pm 3$ \\
Hybrid & ZD958 & $6 \pm 1$ & $30 \pm 2$ & $6 \pm 1$ & $44 \pm 3$ & $4 \pm 1$ & $19 \pm 1$ \\
Hybrid & XY335 & $8 \pm 1$ & $35 \pm 3$ & $7 \pm 1$ & $44 \pm 5$ & $7 \pm 2$ & $38 \pm 4$ \\
Hybrid & JD20 & $9 \pm 4$ & $47 \pm 2$ & $5 \pm 1$ & $36 \pm 1$ & $5 \pm 2$ & $28 \pm 3$ \\
Hybrid & XQ73 & $6 \pm 1$ & $42 \pm 3$ & $7 \pm 1$ & $57 \pm 7$ & $5 \pm 1$ & $30 \pm 3$ \\
Hybrid & LY13 & $6 \pm 0.5$ & $47 \pm 4$ & $10 \pm 0.5$ & $30 \pm 2$ & $6 \pm 2$ & $40 \pm 4$ \\
Hybrid & LY16 & $8 \pm 1$ & $41 \pm 2$ & $7 \pm 1$ & $44 \pm 2$ & $7 \pm 1$ & $42 \pm 8$ \\
Hybrid & JH5 & $6 \pm 1$ & $72 \pm 3$ & $6 \pm 1$ & $45 \pm 3$ & $7 \pm 1$ & $36 \pm 6$ \\
Hybrid & 32 D22 & $9 \pm 1$ & $53 \pm 3$ & $4 \pm 1$ & $46 \pm 6$ & $9 \pm 4$ & $33 \pm 4$ \\
Inbred line & 181 & $9 \pm 1$ & $34 \pm 3$ & $8 \pm 2$ & $59 \pm 4$ & $8 \pm 2$ & $33 \pm 3$ \\
Inbred line & 197 & $7 \pm 1$ & $39 \pm 4$ & $14 \pm 3$ & $42 \pm 5$ & $8 \pm 3$ & $44 \pm 6$ \\
Inbred line & W312 & $8 \pm 1$ & $33 \pm 2$ & $6 \pm 1$ & $41 \pm 5$ & $5 \pm 0.5$ & $29 \pm 2$ \\
Inbred line & 478 & $6 \pm 1$ & $64 \pm 3$ & $5 \pm 1$ & $56 \pm 5$ & $5 \pm 1$ & $36 \pm 2$ \\
\hline
\end{tabular}




\section{Chapter 2}
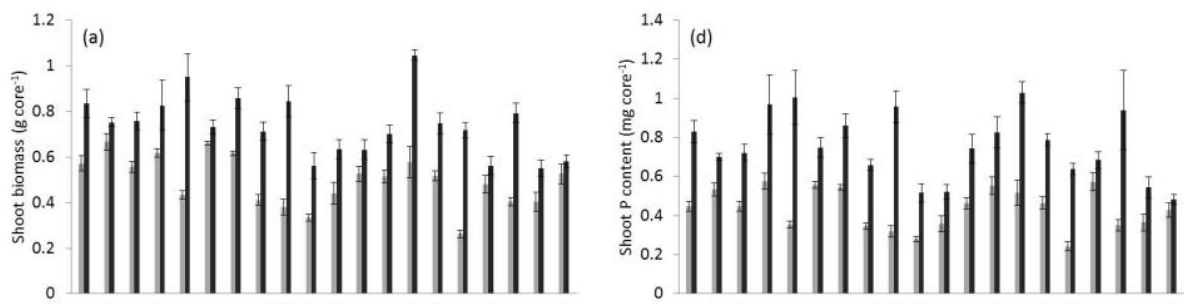

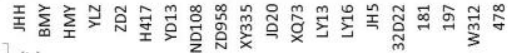

(b)
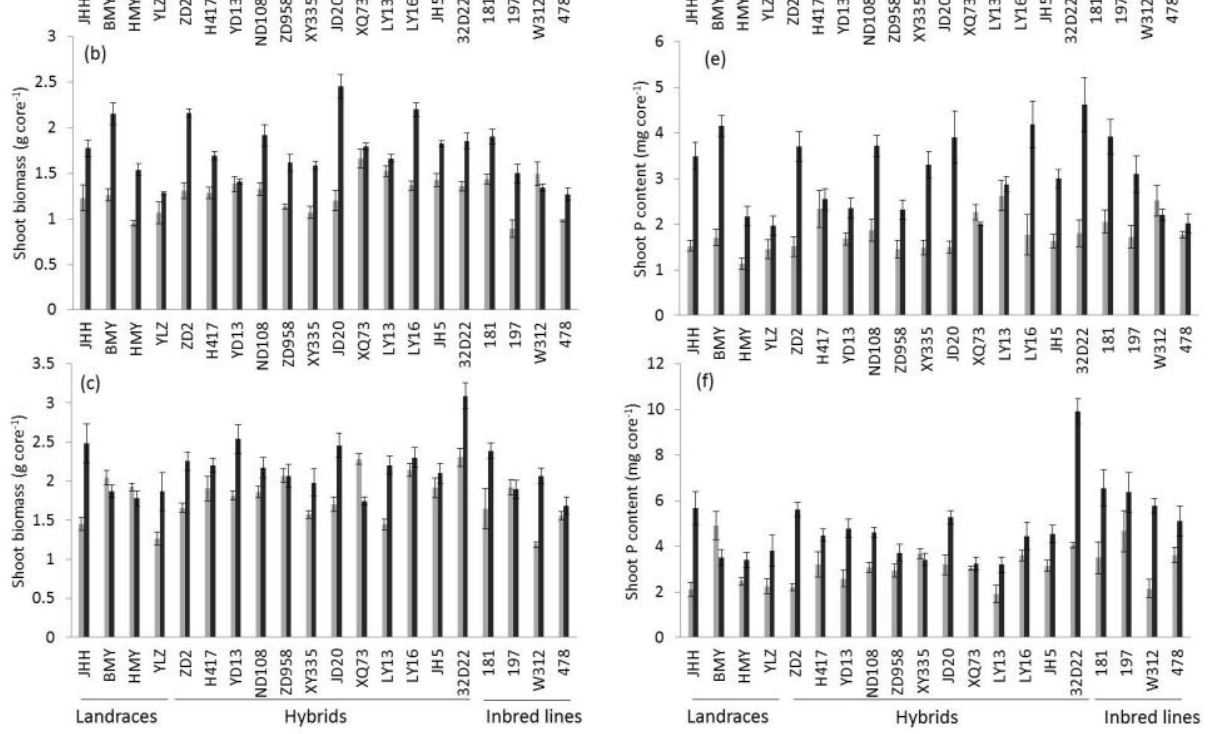

Fig. 2.3. Shoot biomass (a, b, c) and $\mathrm{P}$ content (d, e, f) of different maize varieties at $\mathrm{P}_{0}(\mathrm{a}, \mathrm{d}), \mathrm{P}_{1}$ (b, e) and $\mathrm{P}_{2}$ (c, f). Grey bars refer to rotated cores (reduced colonization), black bars to non-rotated cores (normal colonization). Note differences in Y-axes for the three P fertilizer treatments.

\section{Correlations between parameters}

For all three $\mathrm{P}$ applications a negative correlation was observed between biomass in the low-mycorrhizal condition (rotated cores) and mycorrhizal responsiveness $\left(r=-0.71,-0.54\right.$ and -0.71 for $\mathrm{MR}_{\text {biom }} ;-0.60,-0.70$ and -0.61 for $\mathrm{MR}_{\mathrm{P}} ; P<0.01$ in all cases), indicating that high mycorrhizal responsiveness is related to poor performance in the low-mycorrhizal condition, irrespective of $\mathrm{P}$ availability. $\mathrm{MR}_{\text {biom }}$ and $\mathrm{MR}_{\mathrm{P}}$ were significantly negatively correlated with $\mathrm{P}$ acquisition efficiency $(r=-0.66$ and -0.56 respectively; $P<0.01$; Fig. 2.5$)$, indicating that 
varieties that benefitted more from mycorrhiza were less efficient in acquiring $\mathrm{P}$ in the non-mycorrhizal condition.

Shoot biomass in rotated cores and non-rotated cores did not correlate significantly $(P>0.05)$, regardless of the $\mathrm{P}$ application rate. The same applied to shoot $\mathrm{P}$ uptake.
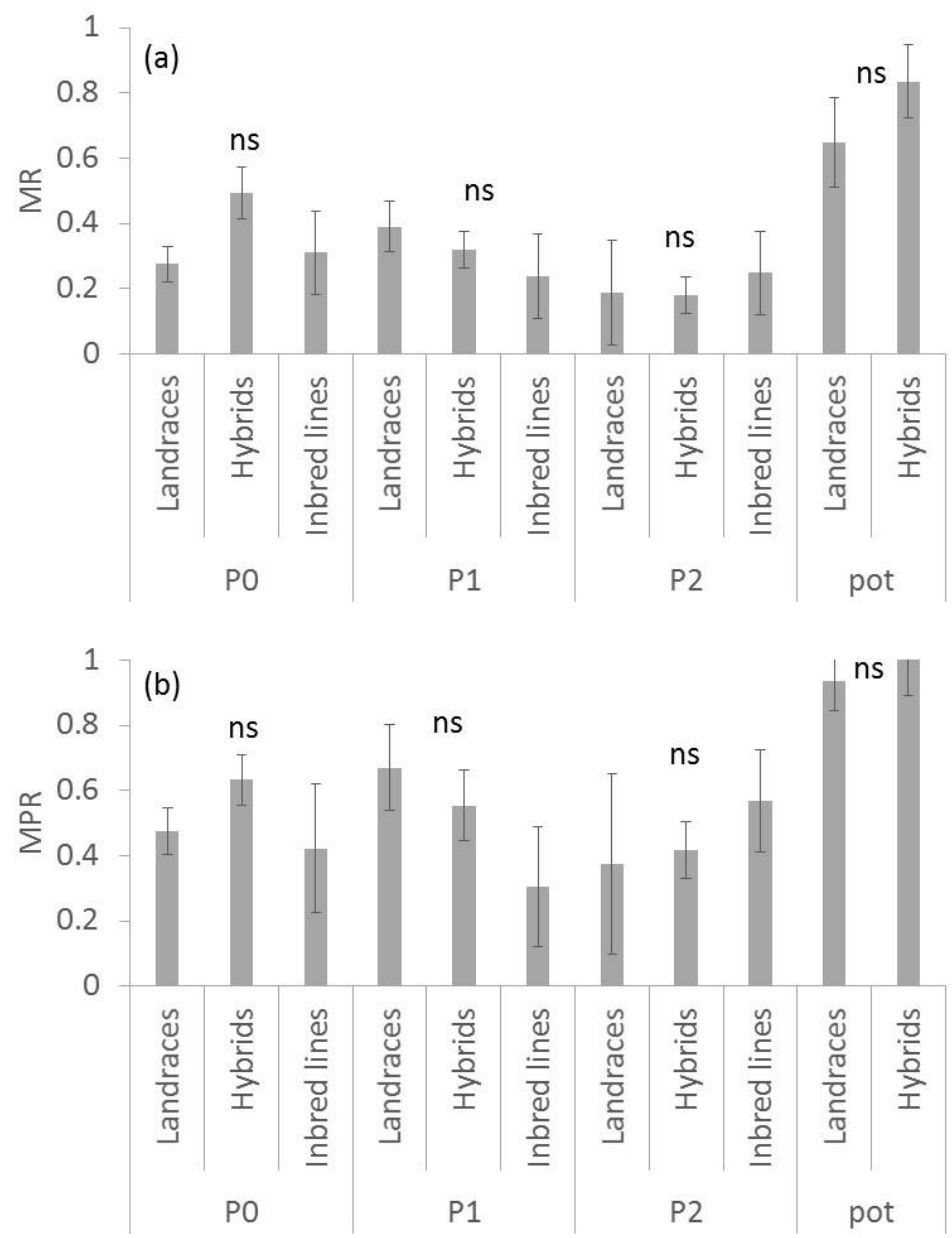

Fig. 2.4. Mycorrhizal responsiveness (a) and mycorrhizal P responsiveness (b) at the three $\mathrm{P}$ levels and in the pot experiment (the data of the pot experiment were from Yang (2009), and shown in Table 2.S1). 


\section{Chapter 2}

\section{Mycorrhizal fungal community}

Molecular identification indicated the occurrence of two families (Glomeraceae and Claroideoglomeraceae) and four genera (Fig. 2.S1). Three genera, Glomus, Rbirophagus and Funneliformis belong to the Glomeraceae; Claroideoglomus to the Claroideoglomeraceae. Phylogenetic analysis indicated four clusters (one species in each genus) and the AMF species at the site were tentatively identified as Glomus etunicatum, Rbizophabus intraradices, Funneliformis mosseae and Claroideoglomus etunicatum. There were small differences in species richness between $\mathrm{P}_{1}$ and $\mathrm{P}_{2}$. There were also small differences in species composition among the four varieties (Fig. 2.S2). Likewise the differences in the two fields $\left(\mathrm{P}_{1}\right.$ and $\left.\mathrm{P}_{2}\right)$ were small.

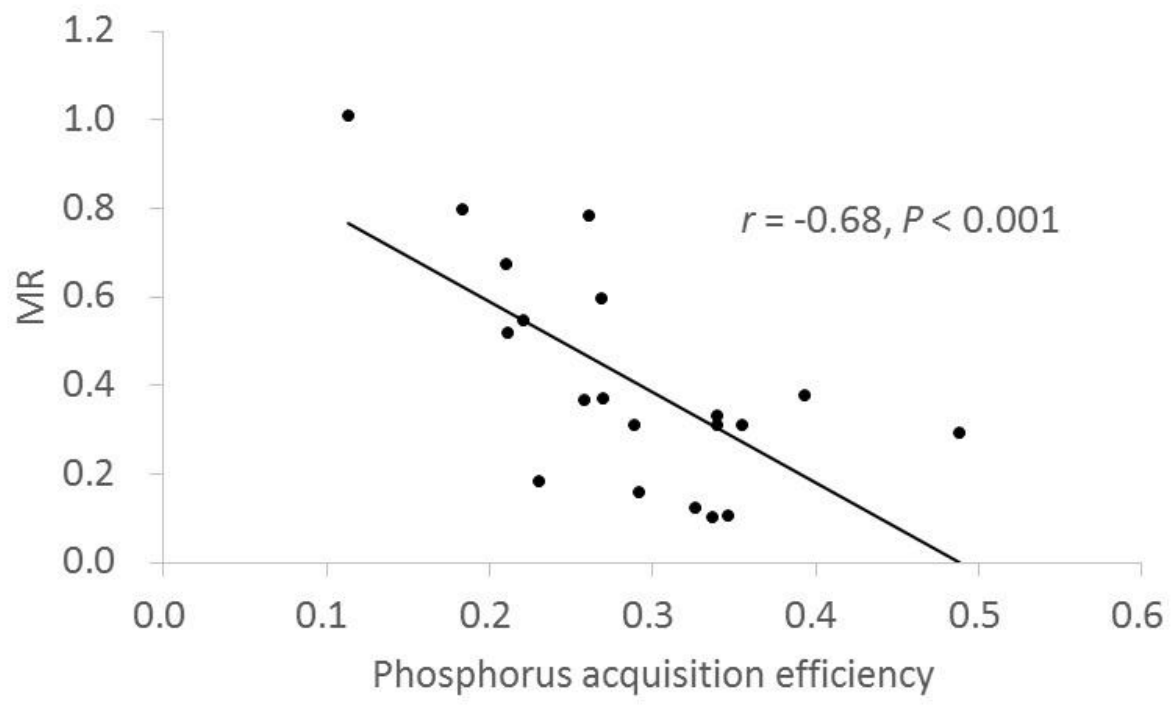

Fig. 2.5. The relation between phosphorus acquisition efficiency (formula 2) and mycorrhizal responsiveness $\left(\mathrm{MR}_{\text {biom; }}\right.$; see formula 1$)$. 


\section{Mycorrhizal field responsiveness and phosphorus acquisition efficiency of maize (Zea mays L.) varieties}

\section{Discussion}

\section{Mycorrhizal colonization and variation in responsiveness among varieties}

The present study showed genetic variation among maize varieties in mycorrhizal colonization (Table 2.2) and mycorrhizal responsiveness (both $\mathrm{MR}_{\text {biom }}$ and $\mathrm{MR}_{\mathrm{P}}$; Fig. 2.3). These data confirm earlier reports on genetic variation in mycorrhizal responsiveness in maize by Kaeppler et al. (2000), Wright et al. (2005) and Chu et al. (2013). Genetic variation in responsiveness has equally been shown for other agricultural crops (Galván et al. 2011; Khalil et al. 1994). Hetrick et al. (1992) and Zhu et al. (2001) claimed that modern genotypes had lower mycorrhizal responsiveness than old genotypes, which would imply that current breeding practices have in fact selected against mycorrhizal responsiveness. However, contrary to Hetrick et al. (1992) and Zhu et al. (2001), we found no evidence that landraces differed from inbred lines and hybrids for mycorrhizal responsiveness (Fig. 2.4), and therefore our data do not confirm the hypothesis for selection against mycorrhizal responsiveness. Similarly we did not observe categorical differences in mycorrhizal colonization (Fig. 2.2), suggesting that also that trait was not systematically selected against during modern breeding. An et al. (2010) also observed that modern hybrids did not show reduced colonization levels compared to older landraces.

A significant correlation that we consistently observed was the negative correlation between mycorrhizal responsiveness $\left(\mathrm{MR}_{\text {biom }}\right.$ and $\left.\mathrm{MR}_{\mathrm{P}}\right)$ and the biomass and $\mathrm{P}$ uptake in the non-mycorrhizal condition. This result confirms earlier studies by Kaeppler et al. (2000) and Galván et al. (2011) who also noted the negative correlation between growth in the non-mycorrhizal condition and mycorrhizal responsiveness. This pattern would imply then that selection for mycorrhizal responsiveness could automatically select for plants with poor performance in the non-mycorrhizal or low-mycorrhizal condition, a result that breeders would unlikely find relevant for novel breeding efforts. Interestingly, we did observe significant categorical differences in $\mathrm{P}$ acquisition efficiency, with landraces having a higher PAE than inbred lines and hybrids. This difference was caused by a higher biomass at $\mathrm{P}_{0}$ in the rotated cores of the landraces $(0.61 \mathrm{~g})$ compared to the two other categories $(0.45-0.47 \mathrm{~g})$, a difference that was just not significant $(\mathrm{P}=0.054)$. Apparently, breeding has had a negative impact on the 


\section{Chapter 2}

ability to acquire $\mathrm{P}$ and grow under low-fertility conditions under low levels of mycorrhizal inoculum. The negative correlation between PAE and mycorrhizal responsiveness (Fig. 2.5) would imply that, together with a lower PAE, the average mycorrhizal responsiveness has rather increased. Our data support the alternative hypothesis by Sawers et al. (2008), who had proposed that actually the symbiotic contribution of AMF to new genotypes could have been strengthened during programs of plant selection. The data by Wright et al. (2005) support that explanation.

Colonization was not correlated with plant biomass at low P, contrary to earlier studies (Chu et al. 2013; Hetrick et al. 1996) and meta-analyses based on earlier studies (Lehmann et al. 2012; Lekberg and Koide 2005). We did notice, though, that in the field with the highest P level, both colonization and mycorrhizal responsiveness were reduced compared to the other fields with no or lower fertilizer-P input, both patterns that are well-known in the mycorrhizal literature (Hao et al. 2008).

\section{Mycorrhizal community of maize varieties}

Only few species were observed on the roots, and these species are known to be almost ubiquitous in agricultural fields. With such a low diversity, possibly due to intensive management of those fields for a long period, it is not surprising that the effects of $\mathrm{P}$ fertilizer and of variety on the native AMF community in our field were small, though both were significant (Fig. 2.S2; MANOVA results: cultivar - P $=0.02$; field $/$ P-level $-\mathrm{P}=0.03$; interaction $-\mathrm{P}=0.52$ ). Our data confirm a previous study by Galván et al. (2009) who noted also species-poor AMF communities in onion (Allium cepa) fields in the Netherlands with small differences in those communities in fields were different degrees of $\mathrm{P}$ availability. Data from Oehl et al. (2004) showing that agricultural intensification resulted in a decrease of AMF species richness are consistent with our results. Our data support the claim that the impact of soil $\mathrm{P}$ on the diversity of AM fungi colonizing plants is broadly similar (Gosling et al. 2013). Oliveira et al. (2009) found that community structure of indigenous AMF in the rhizosphere of tropical maize varieties was variable and related to the $\mathrm{P}$ efficiency of the maize varieties. However, considering that we only observed a small difference in P efficiency among old landraces and modern inbred lines and hybrids, the weak differences in AMF community differentiation may not be surprising. Interestingly, their results also showed that the different $\mathrm{P}$ 


\section{Mycorrhizal field responsiveness and phosphorus acquisition efficiency of maize (Zea mays L.) varieties}

levels in the soil exerted only a small effect on the composition of the AMF communities. Other factors that we did not study may exert a larger influence on AMF communities. AMF communities were affected by soil depth and maize growth stage in the northern China Plain, one of the most important regions for cereal production in China (Tian et al. 2011). Our cores were taken from the upper $22 \mathrm{~cm}$ soil and we may therefore have missed vertical niche differentiation of AMF. Differences in AMF communities with plant growth stage and seasons have been repeatedly reported for agricultural soils (Oehl et al. 2004; Vandenkoornhuyse et al. 2002; Wang et al. 2014).

\section{Assessing field mycorrhizal responsiveness}

An important question is to what extent assessment of mycorrhizal responsiveness under controlled conditions and under field conditions does correlate. From our 20 varieties, 11 were also investigated in the greenhouse under controlled conditions (a non-mycorrhizal control) by Yang (2009) who used soil collected from the $\mathrm{P} 0$ plot in our experiment but mixed with river sand and added $\mathrm{KH}_{2} \mathrm{PO}_{4}$ (the Olsen-P of in her mixed substrate was $5.3 \mathrm{mg} \mathrm{kg}^{-1}$ soil). These data are provided in Table 2.S1.

Interestingly, there was no significant correlation between mycorrhizal responsiveness as assessed in the greenhouse and in the field $(r=0.34, \mathrm{n}=11 ; \mathrm{P}$ $=0.31$. Responsiveness, as determined through the comparison with a nonmycorrhizal control, was higher than field responsiveness, suggesting that even low levels of colonization (5-10\%) bring mycorrhizal benefits in a pot experiment. Further inspection of the data suggested that both the correlation between noncolonized and low-colonized plants and the correlation between mycorrhizal plants in greenhouse and field were not significant, so we currently cannot explain the discrepancy between both assessments of mycorrhizal responsiveness.

In-growth cores with and without rotation to test mycorrhizal responsiveness have both advantages and disadvantages, compared to the classic method with inoculated pots and sterilized, non-mycorrhizal controls. The biggest advantage is that the (non-)rotated cores method assesses the plants' response to root colonization by the native AMF community (Fig. 2S2). Roots of different varieties could be colonized by different AMF species, although we did not find much differences among the four maize varieties (Fig. 2S1). As a result, in-growth cores can also be used to assess the community structure of indigenous AMF (Fig. 


\section{Chapter 2}

$2 \mathrm{~S} 1$ and 2S2). On the other hand, with in-growth cores it is impossible to have a non-mycorrhizal control. Roots in rotated cores were also colonized (Table 2.3), but to a much lower extent than roots in non-rotated cores. This may lead to an underestimation of mycorrhizal responsiveness. Additionally, in the rotated cores AMF hyphae can exploit a limited soil volume, similar to the inoculated treatments in the classic pot experiments. In the non-rotated cores AMF hyphae can exploit a much larger soil volume (outside the cores). This may lead to different results on mycorrhizal responsiveness between the two methods, and this difference may be bigger when the cores' diameter is larger. This is, however, probably not the main explanation for the discrepancy in mycorrhizal responsiveness between in the field (with in-growth cores) and in the pot experiments. The main reason could be the cores' size which was limiting plant growth in the field. It is well-known that mycorrhizal responsiveness is smaller (and can even be negative) in smaller pots (smaller soil volumes) as the potential to explore outside the depletion zone decreases with diminishing pot size (Koide 1991). In earlier studies (Johnson et al. 2001; Zhang et al. 2012), in-growth cores were used for grass (plants with small biomass), and in our study, maize was restricted to have a much smaller soil volume by the cores than maize should have. Thus, how to select a suitable core size for different plant species is crucial. 


\section{Supplementary material}

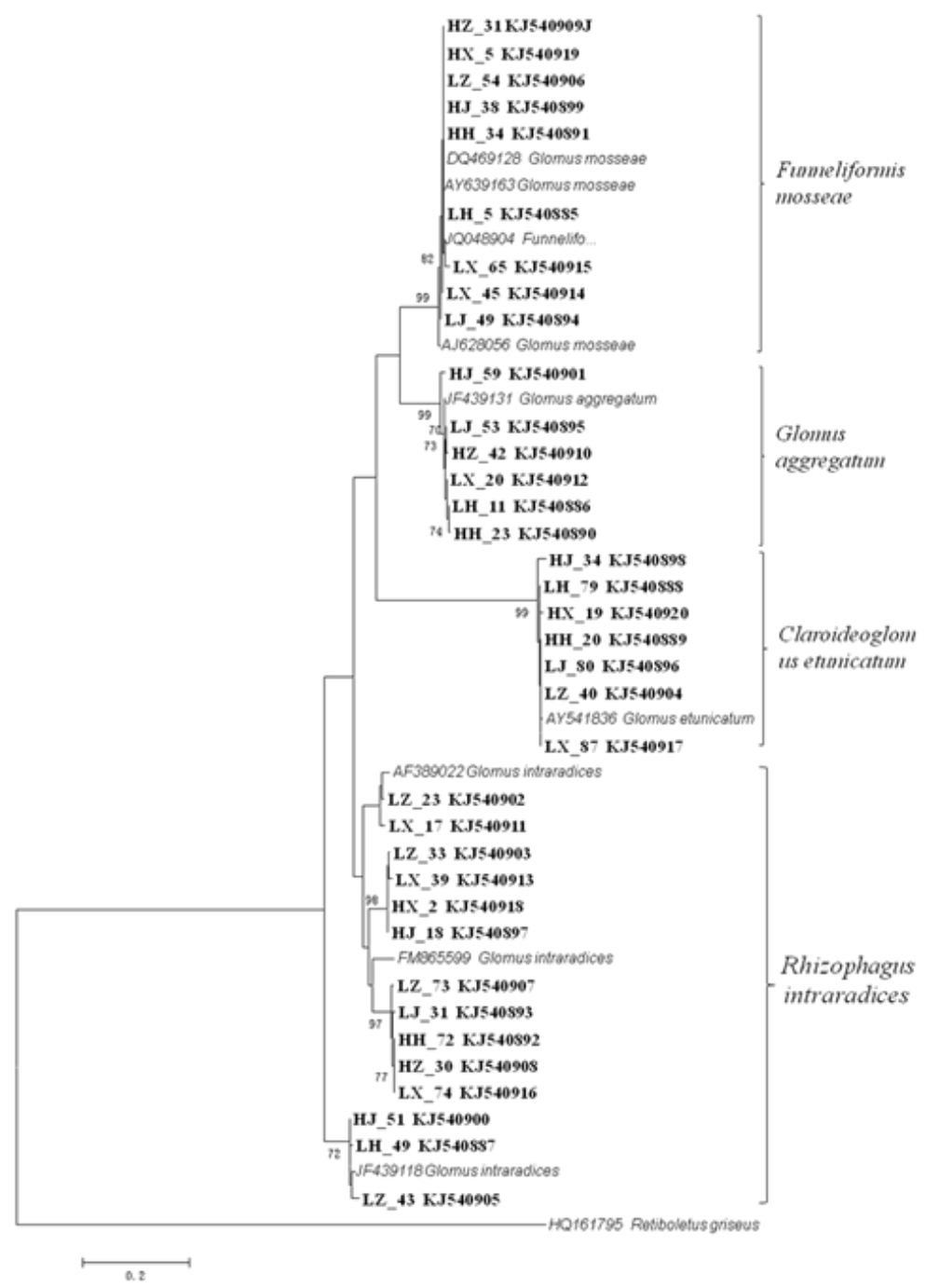

Fig. 2.S1. Phylogenetic affinities of LSU rDNA representing arbuscular mycorrhizal fungi isolated during this work and reference sequences from GenBank (italics). Bootstrap values from 1,000 replications. For the first capital letter, L and $\mathrm{H}$ present $\mathrm{P}_{1}$ and $\mathrm{P}_{2}$, respectively. Abbreviations for the four varieties: $\mathrm{H}$ : Huangmaya (HMY), J: Jinhuanghou (JHH), Z: Zhongdan2 (ZD2), X: Xianyu335 (XY335). 


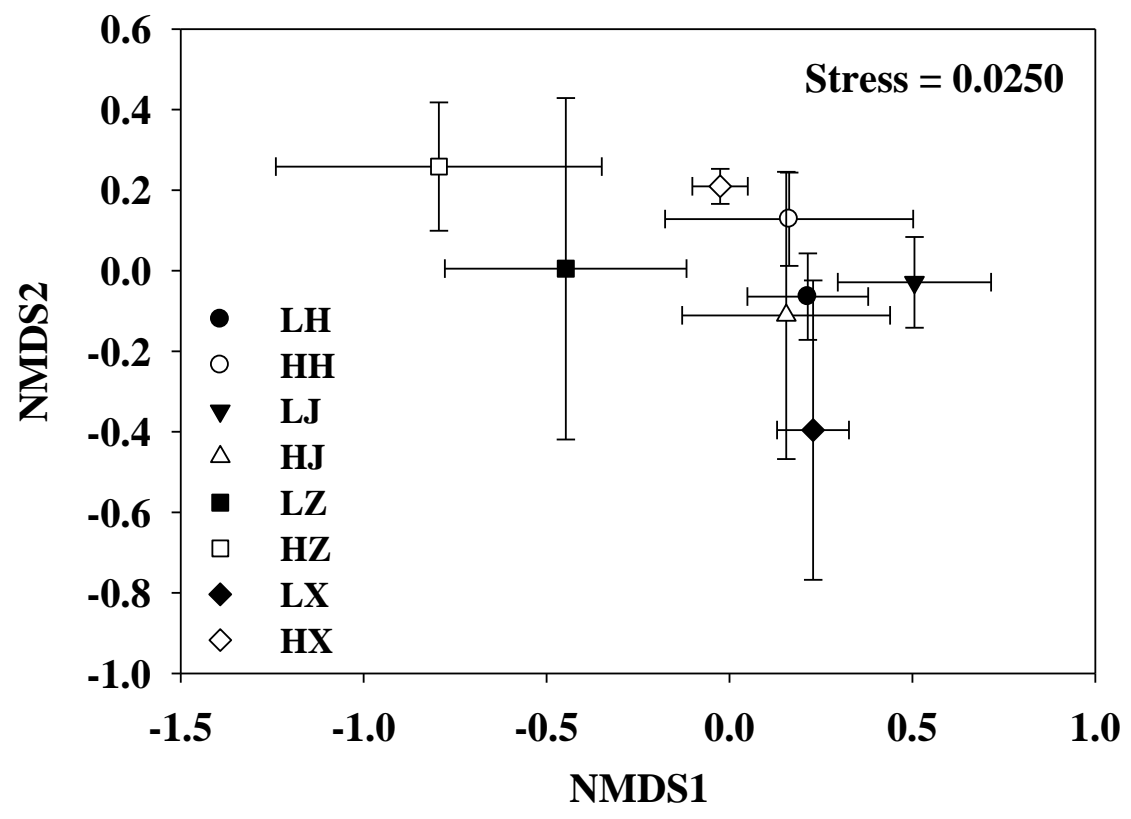

Fig. 2.S2. NMDS ordination of the mycorrhizal species composition on four maize varieties in two fields. Black signs refer to the low-P treatment (P1; L), open signs to the high P-treatment $(\mathrm{P} 2 ; \mathrm{H})$. Abbreviations for the four varieties: H: Huangmaya (HMY), J: Jinhuanghou (JHH), Z: Zhongdan2 (ZD2), X: Xianyu335 (XY335). 
Table 2.S1.The mycorrhizal growth responsiveness of some maize genotypes released in China (Yang 2009).

\begin{tabular}{lllll}
\hline & & \multicolumn{3}{c}{ Shoot biomass $\left(\mathrm{g} \mathrm{pot}^{-1}\right)$} \\
Varieties & Year of release & $\mathrm{NM}$ & $\mathrm{M}$ & $\mathrm{MR}(\%)$ \\
\hline Baimaya (BMY) & 1950 & 3.67 & 5.48 & 33 \\
Jinhuanghou (JHH) & 1950 & 1.96 & 5.15 & 62 \\
Huangmaya (HMY) & 1950 & 3.90 & 5.30 & 26 \\
Yinglizi (YLZ) & 1950 & 2.80 & 4.14 & 32 \\
Zhongda2 (ZD2) & 1973 & 2.74 & 4.31 & 36 \\
Huang417 (H417) & 1977 & 2.26 & 4.40 & 49 \\
Nongda60 (ND60) & 1984 & 1.31 & 4.66 & 72 \\
Yedan13 (YD13) & 1987 & 1.65 & 4.50 & 63 \\
Nongda108 (ND108) & 1991 & 1.75 & 3.76 & 53 \\
Zhengdan958 (ZD958) & 2000 & 1.41 & 3.46 & 59 \\
Nongda368 (ND368) & 2000 & 1.63 & 2.44 & 33 \\
Jinhai5 (JH5) & 2003 & 2.24 & 3.78 & 41 \\
Liyu16 (LY16) & 2003 & 1.57 & 4.65 & 66 \\
Denghai3719 (DH3719) & 2005 & 1.88 & 4.02 & 53 \\
\hline
\end{tabular}

Note: The Olsen-P was $5.3 \mathrm{mg} \mathrm{kg}^{-1}$ in this experiment.

NM: non-mycorrhizal; M: mycorrhizal; MR: mycorrhizal responsiveness calculated as: (shoot biomass of M- shoot biomass of NM) / shoot biomass of $\mathrm{M} \times 100$ 



\section{CHAPTER 3}

Phosphate uptake from phytate by arbuscular mycorrhizal maize

Xinxin Wang, Ellis Hoffland, Gu Feng, Thomas W. Kuyper 


\section{Chapter 3}

\section{Abstract}

Background and aims Phytate is the most abundant form of soil organic phosphorus (P). Increased P nutrition of arbuscular mycorrhizal (AM) plants derived from phytate has been repeatedly reported. Earlier studies assessed acid phosphatase rather than phytase as an indication of mycorrhizal fungi-mediated phytate-P use. These also disregarded the potential effect of phytate addition on mobilization of mineral $\mathrm{P}$, due to phytate-induced desorption of phosphate ions from metal (hydr)oxides. We investigated the effect of mycorrhizal hyphae-mediated phytase activity on $\mathrm{P}$ uptake by two maize varieties and the effect of phytate addition on mobilization of mineral $\mathrm{P}$.

Methods Two maize (Zea mays L.) varieties [Huangmaya (HMY) and Xianyu335 (XY335)], non-inoculated or inoculated with the AM fungi Funneliformis mosseae or Claroideoglomus etunicatum, were grown for 45 days in two-compartment rhizoboxes. The soil in the hyphal compartment was supplemented with 20,100 and $200 \mathrm{mg}$ P $\mathrm{kg}^{-1}$ soil as calcium phytate. We measured activity of phytase and acid phosphatase in the hyphal compartment, hyphal length density, P uptake and plant biomass and calculated the effect of phytate addition on phosphate desorption.

Results Our results showed: (1) phytate addition increased phytase and acid phosphatase activity, and resulted in increased P uptake and plant biomass; (2) increases in $\mathrm{P}$ uptake and biomass were correlated with phytase activity but not with acid phosphatase activity; (3) phytate addition rate initially increased, but at the highest rates decreased hyphal length density; (4) at the higher rate, competitive desorption of phosphate is substantial; (5) HMY was more responsive to Funneliformis mosseae, while XY335 was more responsive to Claroideoglomus etunicatum.

Conclusions Competitive desorption of phosphate can explain the decrease in hyphal length density at high phytate addition. We conclude that P from phytate can be used by arbuscular mycorrhizal plants, but that the phytate contribution to plant nutrition is likely limited.

Keywords: mycelium; phytase; acid phosphatase; maize varieties; competitive sorption 


\section{Phosphate uptake from phytate by arbuscular mycorrhiza maize}

\section{Introduction}

Phosphorus $(\mathrm{P})$ is an essential plant nutrient that limits agricultural production on many soils (Vance 2001). Although the total amount of P in soils often exceeds plant demand, most $\mathrm{P}$ occurs in forms that are unavailable for plant uptake. Plants can take up only orthophosphate from the soil solution. Most of the P in soils, however, is not in the soil solution but is (strongly) adsorbed to mineral surfaces (metal (hydr)oxides) and/or precipitated as poorly soluble phosphate salts. Also a large part of soil P between 30-80\% can be present as organic P (Dalal 1977). Organic $\mathrm{P}$ cannot be taken up by plants. Plants or soil microbes need to hydrolyse organic $\mathrm{P}$, after which the orthophosphate can be taken up. However, the largest part of the organic $\mathrm{P}$ pool is also adsorbed or fixed and thereby inaccessible to these hydrolytic enzymes (Turner et al. 2002). Inositol phosphates (phytate) form a large component of the soil organic $\mathrm{P}$ pool, whereas more simple organic $\mathrm{P}$ forms, such as nucleic acids, sugar phosphates, and phospholipids represent only a small proportion (Stewart and Tiessen 1987). Soil phytate is therefore a potentially important source of $\mathrm{P}$ for plants.

Use of phytate as a $\mathrm{P}$ source depends on the ability to produce the enzymes required for hydrolysis and on the bioavailability of phytate. In order to hydrolyse phytate, organisms use various phosphatases, mainly phytase (myoinositol hexakisphosphate phosphohydrolase) and phosphomonoesterases, often referred to as acid phosphatase. The latter category of enzymes hydrolyses lowerorder inositol phosphates, but not phytate (Nannipieri et al. 2011).

Mechanistic understanding of phytate use by plants is hampered by two problems. First, in all studies published so far, phytate was added to soils without taking into account competitive sorption of phytate and phosphate to metal (hydr)oxides. Phytate addition might lead to desorption and increased availability of orthophosphate (Ognalaga et al. 1994). Enhanced P uptake by plants at higher phytate addition rates may therefore be misinterpreted as a result from phytate mineralization. Second, some studies assessed acid phosphatase rather than phytase activity (Wang et al. 2013; Zhang et al. 2014). Acid phosphatase may hydrolyse only some of the degradation products of phytate, with a lower number of phosphate group and only play an additional role after lower-order inositol phosphates have been formed by phytase (Nannipieri et al. 2011). This hypothesis is supported by the observation that wheat cannot use phytate-P as efficiently as 


\section{Chapter 3}

other organic phosphorus sources due to lack of phytase, even though it produces acid phosphatase (Richardson et al. 2000).

Arbuscular mycorrhizal fungi (AMF) form symbiotic relationships with the roots of more than $80 \%$ of terrestrial plants (Smith and Read 2008). The main benefit for the plant is enhanced access to and uptake of orthophosphate, possibly in conjunction with an enhanced desorption rate of bound $\mathrm{P}$ (Cardoso and Kuyper 2006). Though it was shown that AMF hyphae displayed phosphatase activity (Joner and Johansen 2000), only few studies have addressed the question whether AMF hydrolyse phytate and, as a result, increase plant P uptake. Koide and Kabir (2000) demonstrated that the hyphae of Glomus intraradices (now Rhizophagus intraradices) hydrolysed organic $\mathrm{P}$ and transferred the released $\mathrm{P}$ to the plant. Feng et al. (2003) demonstrated that hyphae acquired P from sodium phytate in a root-free compartment and transferred $\mathrm{P}$ to Trifolium pratense, but they did not demonstrate hyphal production of phytase.

Within plant species, there is genetic variation in dependency on and responsiveness to AMF (Chu et al. 2013; Galván et al. 2011; Gao et al. 2007; Kaeppler et al. 2000). This variation may be used to breed varieties that derive more benefit from the mycorrhizal symbiosis. It is not known, however, whether there is also genetic variation among plant varieties in benefit from mycorrhizal symbioses when the major source of $\mathrm{P}$ is phytate.

The aims of our study were to distinguish the role of AMF-related phytase and acid phosphatase in plant P uptake from phytate. We applied increasing rates of phytate to a root-free hyphal compartment, taking into account potential desorption of orthophosphate from metal (hydr)oxide surfaces. To test whether there is interaction between maize varieties and AMF species in acquiring $\mathrm{P}$ from phytate, we selected an old variety and a new hybrid variety of maize (see also Chapter 2) and two AMF species.

\section{Materials and methods}

\section{Soil and microcosms}

A calcareous loamy soil was collected from field plots at the Changping LongTerm Fertilizer Station of China Agricultural University in Beijing, China. The soil contained $17.8 \mathrm{~g} \mathrm{~kg}^{-1}$ organic C, $2.9 \mathrm{mg} \mathrm{kg}^{-1}$ Olsen-P, $87.2 \mathrm{mg} \mathrm{kg}^{-1} \mathrm{~N}, 155.7 \mathrm{mg} \mathrm{kg}$ 


\section{Phosphate uptake from phytate by arbuscular mycorrhiza maize}

1 exchangeable $\mathrm{K}$, and had a $\mathrm{pH}$ value (in $\mathrm{CaCl}_{2}$ ) of 7.8 . The soil was passed through a 2 -mm sieve and sterilized by $\gamma$-radiation with ${ }^{60} \mathrm{Co}$ at $10 \mathrm{kGy}$.

Ammonium oxalate-extractable $\mathrm{P}, \mathrm{Al}$, and Fe were determined prior to the experiment according to (Schwertmann 1970), by inductively coupled plasmaatomic emission spectroscopy. The unamended soil contained $667 \mathrm{mg} \mathrm{Al} \mathrm{kg-1}, 505$ $\mathrm{mg} \mathrm{Fe} \mathrm{kg-1}$ and $175 \mathrm{mg} \mathrm{P} \mathrm{kg}^{-1}$. For the phytate-amended soil it was assumed that all phytate-P added would end up in the oxalate-extractable $\mathrm{P}$ pool. These results were used to calculate the degree of $\mathrm{P}$ saturation $\alpha$ of a soil (eq.1) assuming that sorption of orthophosphate is dominated by metal (hydr)oxides (Van der Zee and van Riemsdijk 1988) and to estimate water-extractable $\mathrm{P}\left(\mathrm{P}_{\mathrm{w}}\right.$, eq. 2; Koopmans et al. 2007):

$\alpha=\mathrm{P}_{\mathrm{ox}} /(\mathrm{Al}+\mathrm{Fe})_{\mathrm{ox}}$

$\mathrm{P}_{\mathrm{w}}=\alpha / 0.19(0.5-\alpha)$

where $\alpha$ means $\mathrm{P}$ saturation status and $\mathrm{P}_{\mathrm{ox}}$ and $[\mathrm{Al}+\mathrm{Fe}]_{\mathrm{ox}}$ are expressed in mmol $\mathrm{kg}^{-1} \cdot \mathrm{P}_{\mathrm{w}}$ (in $\mathrm{mg} \mathrm{kg}^{-1}$ ) is water-extractable $\mathrm{P}$ at a soil/solution ratio of 1:60 [v/v]. Equation 1 was originally developed for a noncalcareaous sandy soil, but was shown to be valid for other soils as well (Koopmans et al. 2007; Schoumans and Chardon 2015).

Rhizoboxes (microcosms) were set up as described by Wang et al. (2013). Every box had two compartments (a root compartment and a hyphal compartment), separated by $30 \mu \mathrm{m}$ nylon mesh that hyphae but not roots could pass. In the hyphal compartment, a buffer zone of $2 \mathrm{~cm}$ width from the mesh window was set up to minimize the influence of roots on the hyphal compartment. Soil was added to the rhizoboxes in the following amounts: $750 \mathrm{~g}$ in the root compartment with $20 \mathrm{mg} \mathrm{P} \mathrm{kg}^{-1}$ (as $\mathrm{KH}_{2} \mathrm{PO}_{4}$; previous research had shown extremely poor maize growth without any $\mathrm{P}$ fertilizer); $300 \mathrm{~g}$ in the buffer zone without any additional $\mathrm{P}$, and $450 \mathrm{~g}$ in the hyphal compartment with 20, 100 and $200 \mathrm{mg}$ P (as calcium phytate; Sigma-Aldrich, St. Louis, MO, USA) per kg soil. Because of the extremely low available $\mathrm{P}$, we did not include any control without phytate in the hyphal compartment. The other nutrients $\left(\mathrm{kg}^{-1}\right.$ soil) were added uniformly only to the root compartment: $200 \mathrm{mg} \mathrm{N}$ (as $\mathrm{KNO}_{3}$ ), $50 \mathrm{mg} \mathrm{Mg}$ (as $\mathrm{MgSO}_{4}$ ), $5 \mathrm{mg} \mathrm{Zn} \mathrm{(as} \mathrm{ZnSO}_{4}$ ), and $2 \mathrm{mg} \mathrm{Cu}$ (as $\mathrm{CuSO}_{4}$ ). The nutrients were mixed with the soil before filling of the pots. Three weeks after sowing, another $100 \mathrm{mg}$ $\mathrm{N}$ (as $\mathrm{KNO}_{3}$ ) $\mathrm{kg}^{-1}$ soil was added to every root compartment. 


\section{Chapter 3}

\section{Host plant and mycorrhizal fungal inoculum}

Two maize varieties were used: Huangmaya (HMY), an open-pollinated, earlysenescing variety, which was bred in the 1950s (Chu et al. 2013); and Xianyu335 (XY335), a modern hybrid (Chapter 2). In each root compartment, two maize seeds (surface-sterilized for $10 \mathrm{~min}$ in $10 \% \mathrm{H}_{2} \mathrm{O}_{2}$ followed by $3 \mathrm{~min}$ in $70 \%$ ethanol) were sown; they were thinned to one plant after germination. Soil moisture was kept at $18-20 \%(\mathrm{w} / \mathrm{w}$, i.e. $70 \%$ of water holding capacity) as determined gravimetrically by weighing the pots every 2 days during the experiment and adding tap water when necessary. The glasshouse temperature range was $23-31{ }^{\circ} \mathrm{C}$.

The AMF species Funneliformis mosseae (formerly Glomus mosseae, reference number BGC HEB07B, 1511C0001BGCAM0049) and Claroideoglomus etunicatum (formerly Glomus etunicatum, BGC HEB07A, 1511C0001BGCAM0048) were used in this experiment. Both were obtained from the Bank of Glomeromycota of China, Institute of Plant Nutrition and Resources, Beijing Academy of Agriculture and Forestry Research. The two AMF species colonized both maize varieties in previous experiments (unpublished), resulting in a significant growth response. They also occur abundantly in maize fields (Chapter 2). The fungi were propagated in a 5:1 mixture (w/w) of zeolite and river sand with maize for 4 months in a greenhouse. Inoculum consisted of soil containing spores, mycelium, and fine root fragments. Forty g inoculum was added to each mycorrhizal root compartment, and $40 \mathrm{~g}$ of sterilized inoculum (a mixture of both AMF species) was added to non-mycorrhizal root compartments. To minimize differences in microbial communities of mycorrhizal and non-mycorrhizal treatments, $10 \mathrm{ml}$ of AMF-free filtrate from the inoculum was added to each non-mycorrhizal compartment, and $10 \mathrm{ml}$ of deionized water was added to each mycorrhizal pot.

\section{Harvest and sample analysis}

Plants were harvested 45 days after sowing. At harvest, plant roots were carefully removed from the soil and shaken gently to remove loosely adhering soil, which was regarded as bulk soil. Soils in the root compartment, the buffer compartment and the hyphal compartment were collected separately. The top $2 \mathrm{~cm}$ of soil from the hyphal compartment was discarded to eliminate any surface effects. Soil from the buffer section was also discarded. The remainder was mixed in a blender to obtain a uniform matrix for subsequent analyses. 


\section{Phosphate uptake from phytate by arbuscular mycorrhiza maize}

Soil solution for enzyme assays was obtained by gently shaking about $0.5 \mathrm{~g}$ of moist soil with $2 \mathrm{ml}$ deionized water for $1 \mathrm{~min}$. After settling, the suspension was collected for assays and the sediment was dried at $90{ }^{\circ} \mathrm{C}$ for $24 \mathrm{~h}$ to determine dry weight as a reference base.

Plants were separated into shoots and roots. The shoots were oven-dried at $105{ }^{\circ} \mathrm{C}$ for $30 \mathrm{~min}$ to cease metabolic activity and then at $72{ }^{\circ} \mathrm{C}$ for $48 \mathrm{~h}$ and finally ground to a fine powder. Roots were washed with deionized water and then preserved at $-20^{\circ} \mathrm{C}$.

Frozen roots were cut into $1-\mathrm{cm}$ segments and thoroughly mixed. A $0.5-\mathrm{g}$ subsample was cleared with $10 \%$ (w/v) $\mathrm{KOH}$ at $90{ }^{\circ} \mathrm{C}$ for $2 \mathrm{~h}$ and stained with trypan blue for quantification of mycorrhizal colonization (Trouvelot et al. 1986). Extraradical hyphae were extracted from two 5-g soil sub-samples from the hyphal compartment using the membrane filter technique (Jakobsen et al. 1992b). Hyphal length was assessed using the gridline intercept method at $200 \times$ magnification and then converted to hyphal length density ( $\mathrm{m} \mathrm{g}^{-1} \mathrm{dw}$ soil). Shoot $\mathrm{P}$ concentration was determined by the standard vanado-molybdate method (Murphy and Riley 1962), after digestion in a $\mathrm{H}_{2} \mathrm{SO}_{4}-\mathrm{H}_{2} \mathrm{O}_{2}$ mixture at $360{ }^{\circ} \mathrm{C}$ for 2 h.

Phytase activity was assessed according to Richardson et al. (2000): 0.5 $\mathrm{mL}$ soil suspension was mixed with $2 \mathrm{ml}$ of $30 \mathrm{mM}$ MES [2-(N-morpholino) ethanesulfonic acid] buffer ( $\mathrm{pH}$ 5.5) with $0.5 \mathrm{ml}$ of $2 \mathrm{mM}$ EDTA (ethylenediaminetetraacetic acid) and with $0.5 \mathrm{ml}$ of $20 \mathrm{mM}$ Na-phytate (Sigma, St. Louis, MO, USA). The mixture was incubated for $1 \mathrm{~h}$ at $37^{\circ} \mathrm{C}$ and the reaction terminated by addition of $1 \mathrm{ml} \mathrm{25 \%}$ trichloroacetic acid (TCA). Solutions were subsequently centrifuged at $12000 \times \mathrm{g}$ for $10 \mathrm{~min}$ to remove soil particles. To the controls TCA was added prior to incubation. The orthophosphate concentration in the supernatant was determined by measuring absorbance at $882 \mathrm{~nm}$ using the molybdenum-blue reaction.

Acid phosphatase (phosphomonoesterase) activity in hyphal and root compartments was assayed according to (Neumann 2006): $0.5 \mathrm{~mL}$ soil suspension was transferred into $2 \mathrm{~mL}$ Eppendorf reaction vials, to which $0.4 \mathrm{~mL}$ of $200 \mathrm{mM}$ acetate buffer $(\mathrm{pH}$ 5.2) and $0.1 \mathrm{~mL}$ of $150 \mathrm{mM}$ substrate [pNPP (pnitrophenylphosphate); Sigma St. Louis, MO, USA] were added. The mixture was incubated for $30 \mathrm{~min}$ at $30^{\circ} \mathrm{C}$, after which the reaction was terminated by addition of $0.5 \mathrm{ml}$ of $0.5 \mathrm{M} \mathrm{NaOH}$ and centrifugation for $10 \mathrm{~min}$ at $12000 \times \mathrm{g}$, which also 


\section{Chapter 3}

removed soil particles. In controls the substrate was added after incubation. The concentration of pNP in the supernatant was measured spectrophotometrically at $405 \mathrm{~nm}$ (Joner and Johansen 2000).

\section{Experimental design and statistical analysis}

The experiment was set up in a randomized complete full factorial block design with three factors: (1) Phytate - three levels in the hyphal compartment, 20, 100 and $200 \mathrm{mg} \mathrm{kg}^{-1} \mathrm{P}$ as Ca-phytate; (2) Variety - two maize varieties, HMY and XY335; (3) AMF - three treatments, without AMF, and inoculated with F. mosseae or C. etunicatum. The experiment was carried out with four replicates, giving 72 rhizoboxes in total. The 18 rhizoboxes within a block were arranged randomly in the glasshouse, with the positions re-randomized every week.

Statistical analyses were performed with SPSS software, version 19.0 (SPSS Inc., Chicago, IL, USA). All data met the requirements of homogeneity of variance (Levene's test) after log transformation. Three-way analysis of variance was performed to test for significant sources of variation in dependent variables. Where necessary, we report results of ANOVA both including and excluding the non-mycorrhizal treatment. Means were compared with Turkey's Honestly Significant Differences test at the 5\% level of probability. Correlation between variables was tested using Pearson's correlation coefficient with log-transformed data $(P<0.05)$.

\section{Results}

\section{Soil $P$ status after phytate addition}

The P saturation status ( $\alpha$ value) of the original soil was 0.17 . Addition of 20,100 and $200 \mathrm{mg}$ phytate- $\mathrm{P} \mathrm{kg}^{-1}$ soil increased $\mathrm{P}_{\mathrm{ox}}$ from 5.65 to $6.06,7.80$ and 9.95 mmol kg-1 and $\alpha$ values from 0.17 to $0.18,0.23$ and 0.29 , respectively. Using the formula of Koopmans et al. (2007), this implied that $\mathrm{P}_{\mathrm{w}}$ was $2.7 \mathrm{mg} \mathrm{P} \mathrm{kg}{ }^{-1}$ in the original soil and increased after addition of 20,100 or 200 mg phytate- $\mathrm{P} \mathrm{kg}^{-1}$ to 3.0 , 4.5 and $7.6 \mathrm{mg} \mathrm{P} \mathrm{kg}^{-1}$, respectively.

\section{Enzyme activities}

The effects of phytate addition, variety and mycorrhizal treatment on phytase activity in the hyphal compartment were not straightforward: all interactions were significant (Table 3.1). Maize variety had no main effect on phytase activity. 
Table 3.1. ANOVA results with phytase activity in the hyphal compartment as dependent variable, and phytate addition $(\mathrm{P})$, varieties (CV) and mycorrhizal treatments $(M)$ as independent variables. The dataset was analysed twice: once including the non-mycorrhizal control and once excluding this treatment.

\begin{tabular}{lcccccc}
\hline \multirow{2}{*}{ Independent variable } & \multicolumn{3}{l}{ With non-AM control } & \multicolumn{4}{c}{ Without non-AM control } \\
\cline { 2 - 7 } & $\mathrm{df}$ & $\mathrm{F}$ & $P$ value & $\mathrm{df}$ & $\mathrm{F}$ & $P$ value \\
\hline $\mathrm{P}$ & 2 & 98.8 & $<0.001$ & 2 & 28.8 & $<0.001$ \\
$\mathrm{CV}$ & 1 & 0.004 & 0.95 & 1 & 0.3 & 0.57 \\
$\mathrm{M}$ & 2 & 92.8 & $<0.001$ & 1 & 11.5 & 0.002 \\
$\mathrm{P} \times \mathrm{CV}$ & 2 & 18 & $<0.001$ & 2 & 21.6 & $<0.001$ \\
$\mathrm{P} \times \mathrm{M}$ & 4 & 9.4 & $<0.001$ & 2 & 0.6 & 0.56 \\
$\mathrm{CV} \times \mathrm{M}$ & 2 & 5.8 & 0.005 & 1 & 9.4 & 0.004 \\
$\mathrm{P} \times \mathrm{CV} \times \mathrm{M}$ & 4 & 5.6 & 0.001 & 2 & 4.3 & 0.02 \\
\hline
\end{tabular}

Acid phosphatase activity in both the hyphal and root compartment was significantly affected by phytate addition and variety, and their interaction (Table 3.2). Phytase activity was significantly higher with $200 \mathrm{mg} \mathrm{P} \mathrm{kg}^{-1}$ than with 20 and $100 \mathrm{mg} \mathrm{P} \mathrm{kg}^{-1}$ for XY335, but for HMY phytase activity was significantly higher with 100 and $200 \mathrm{mg} \mathrm{P} \mathrm{kg}^{-1}$ than with $20 \mathrm{mg} \mathrm{P} \mathrm{kg}^{-1}$ (Fig. 3.1). Effects of the two AMF species on acid phosphatase activity were similar for both maize varieties and across the three phytate levels. Acid phosphatase activity in the root compartment and in the hyphal compartment were significantly positively correlated regardless of whether the non-mycorrhizal treatment was included ( $r=$ 0.82; $P<0.001$; Fig. 3.S1) or excluded $(r=0.83 ; P<0.001)$ in the correlation analysis. The activity was significantly higher in the root compartment than in the hyphal compartment (Fig. 3.S1). 


\section{Chapter 3}

Table 3.2 ANOVA results with acid phosphatase activity in root and hyphal compartments as dependent variable, and phytate addition $(\mathrm{P})$, varieties $(\mathrm{CV})$ and mycorrhizal treatments $(\mathrm{M})$ as independent variables. The non-mycorrhizal control was not included in the analysis.

\begin{tabular}{|c|c|c|c|c|c|}
\hline \multirow{2}{*}{$\begin{array}{l}\text { Independent } \\
\text { Variable }\end{array}$} & \multirow[t]{2}{*}{$\mathrm{df}$} & \multicolumn{2}{|c|}{ Root compartment } & \multicolumn{2}{|c|}{ Hyphal compartment } \\
\hline & & $\mathrm{F}$ & $P$ value & F & $P$ value \\
\hline $\mathrm{P}$ & 2 & 3.9 & 0.05 & 14.1 & $<0.001$ \\
\hline $\mathrm{CV}$ & 1 & 11.2 & 0.001 & 13.3 & 0.002 \\
\hline M & 1 & 0.1 & 0.87 & 0.04 & 0.79 \\
\hline $\mathrm{P} \times \mathrm{CV}$ & 2 & 1.7 & 0.23 & 4.7 & 0.04 \\
\hline $\mathrm{P} \times \mathrm{M}$ & 2 & 0.4 & 0.60 & 0.2 & 0.72 \\
\hline $\mathrm{CV} \times \mathrm{M}$ & 1 & 3.4 & 0.10 & 0.5 & 0.47 \\
\hline $\mathrm{P} \times \mathrm{CV} \times \mathrm{M}$ & 2 & 1.1 & 0.36 & 0.6 & 0.58 \\
\hline
\end{tabular}

Phytase activity and acid phosphatase activity in the hyphal compartment correlated significantly positively $(r=0.72 ; P<0.001$; Fig. 3.2). Phytase activity ranged between $1 \%$ and $5 \%$ (average $3 \%$ ) of acid phosphatase activity. Although the phytate effects on phytase (Table 3.1) and acid phosphatase (Table 3.2) activities were variety-dependent, they both tended to increase with phytate addition (Figs. 3.1 and 3.2). 


\section{Phosphate uptake from phytate by arbuscular mycorrhiza maize}

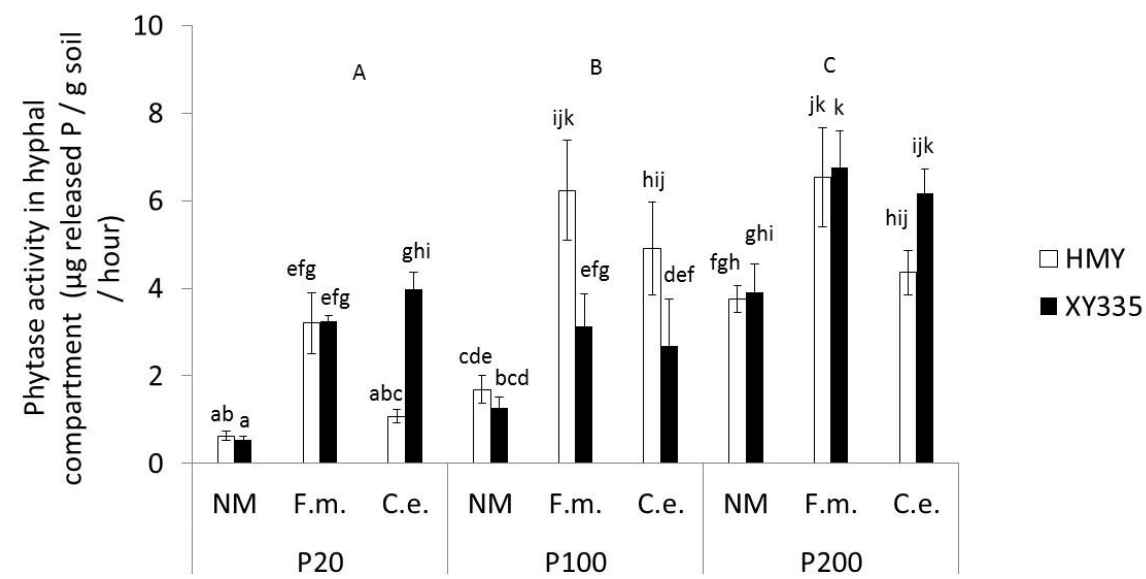

Fig. 3.1. Phytase activity in the hyphal compartment of two maize varieties (HMY and XY335) grown with 20,100 or $200 \mathrm{mg}$ phytate-P per $\mathrm{kg}$ soil in the hyphal compartment. The plants were non-mycorrhizal (NM) or inoculated with F. mosseae (F.m.) or C. etunicatum (C.e.). Bars represent means $\pm \mathrm{SE}(\mathrm{n}=4)$. Treatments with the same lowercase letter are not significantly differences (Tukey: $P<0.05$ ); uppercase letters refer to main effects of phytate additions.

\section{Hyphal length density and root colonization}

Hyphal length density was significantly affected by phytate, AMF, and most interactions (Table 3.3). There were no differences between both varieties. It was about $10 \%$ higher at $100 \mathrm{mg} \mathrm{kg}^{-1}$ phytate-P $\left(2.7 \mathrm{~m} \mathrm{~g}^{-1}\right.$ soil $)$ than at $20 \mathrm{mg} \mathrm{kg}^{-1}(2.4$ $\mathrm{m} \mathrm{g}^{-1}$ soil; $\left.P=0.014\right)$ and $200 \mathrm{mg} \mathrm{kg}^{-1}$ treatments $\left(2.3 \mathrm{~m} \mathrm{~g}^{-1}\right.$ soil; $P<0.001$; Fig. 3.S2).

The effect of AMF species on mycorrhizal root colonization was similar for all phytate-P levels, but it was variety-dependent (Table 3.3): A 10\% larger fraction of the HMY roots was colonized HMY by F. mosseae (56\%) compared to C. etunicatum (46\%), whereas XY335 showed the opposite pattern (Fig. 3.S3). 


\section{Chapter 3}

Table 3.3 ANOVA results with hyphal length density in the hyphal compartment, root colonization and root length as dependent variable, and phytate addition $(\mathrm{P})$, varieties (CV) and mycorrhizal treatments $(\mathrm{M})$ as independent variables, considering the AMFinoculated treatments, only.

\begin{tabular}{|c|c|c|c|c|c|c|c|}
\hline \multirow[t]{2}{*}{$\begin{array}{l}\text { Independent } \\
\text { Variable }\end{array}$} & \multirow[t]{2}{*}{$\mathrm{df}$} & \multicolumn{2}{|c|}{$\begin{array}{l}\text { Hyphal length } \\
\text { density }\end{array}$} & \multicolumn{2}{|c|}{$\begin{array}{l}\text { Root } \\
\text { colonization }\end{array}$} & \multicolumn{2}{|c|}{$\begin{array}{l}\text { Root } \\
\text { length }\end{array}$} \\
\hline & & $\mathrm{F}$ & $P$ value & F & $P$ value & F & $P$ value \\
\hline $\mathrm{P}$ & 2 & 5.3 & 0.01 & 0.8 & 0.47 & 13.5 & $<0.001$ \\
\hline $\mathrm{CV}$ & 1 & 1.5 & 0.23 & 10.3 & 0.003 & 64.2 & $<0.001$ \\
\hline M & 1 & 34.1 & $<0.001$ & 17.8 & $<0.001$ & 0.6 & 0.45 \\
\hline $\mathrm{P} \times \mathrm{CV}$ & 2 & 25.4 & $<0.001$ & 3.6 & 0.04 & 5.3 & 0.01 \\
\hline $\mathrm{P} \times \mathrm{M}$ & 2 & 10.5 & $<0.001$ & 0.5 & 0.63 & 0.2 & 0.79 \\
\hline $\mathrm{CV} \times \mathrm{M}$ & 1 & 0.01 & 0.98 & 22.0 & $<0.001$ & 13.1 & 0.001 \\
\hline $\mathrm{P} \times \mathrm{CV} \times \mathrm{M}$ & 2 & 9.9 & $<0.001$ & 1.9 & 0.16 & 4.1 & 0.03 \\
\hline
\end{tabular}

\section{Shoot biomass and shoot $P$ content}

Shoot biomass and P content of the non-mycorrhizal treatments were not affected by phytate addition (Fig. 3.3), confirming that plant roots could not take up any $\mathrm{P}$ from phytate added to the hyphal compartment. Shoot biomass and P content of the AMF-inoculated treatments increased with increasing phytate addition in both varieties (although less strong for XY335; Fig. 3.3). The mycorrhizal response increased with phytate addition for both varieties. Variety HMY responded more strongly to F. mosseae than C. etunicatum, whereas XY335 tended to show the opposite response (Table 3.4, Fig. 3.3), similar to the pattern found for mycorrhizal colonization. 


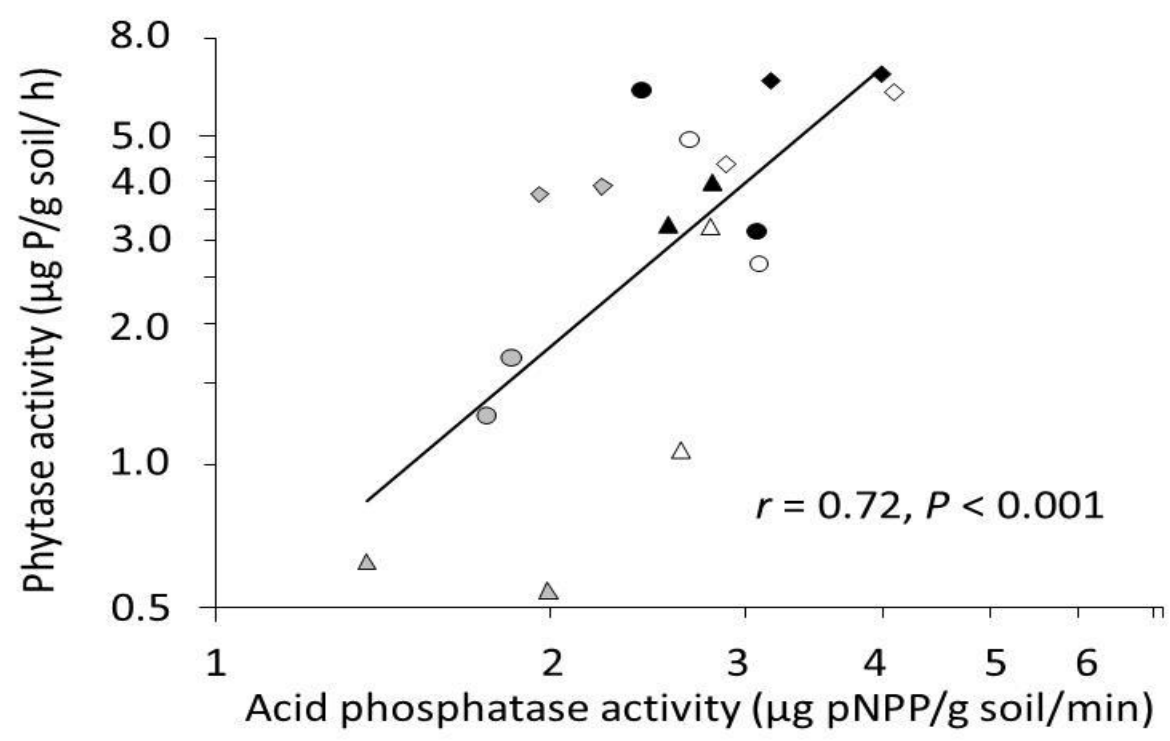

Fig. 3.2. The relation between acid phosphatase activity and phytase activity in the hyphal compartment. Triangle, circle and diamond indicate the 20, 100 and $200 \mathrm{mg}$ phytate-P per kg soil in hyphal compartment, respectively. Grey, white and black marks indicate control, F. etunicatum and C. mosseae treatment, respectively. Each symbol represents one variety and the means of four replicates.

Phytate addition of 100 and $200 \mathrm{mg} \mathrm{P} \mathrm{kg}^{-1}$ resulted in average increases of 1 and $2 \mathrm{mg} \mathrm{P}$ in shoots, respectively, compared to $20 \mathrm{mg} \mathrm{P} \mathrm{kg}{ }^{-1}$. In some cases, however, phytate addition did not result in increased $\mathrm{P}$ uptake; for example, XY335 did not respond to $\mathrm{P}$ addition from 20 to $100 \mathrm{mg} \mathrm{kg}^{-1}$. The increase in shoot $\mathrm{P}$ content (compared to the treatment with $20 \mathrm{mg}$ phytate- $\mathrm{P} \mathrm{kg}{ }^{-1}$ ) correlated significantly and positively with increases in phytase activity in the hyphal compartment $(r=0.50 ; P=0.002$; Fig. 3.4). Changes in acid phosphatase activity did not correlate with changes in P uptake $(r=0.26 ; P=0.16)$. 

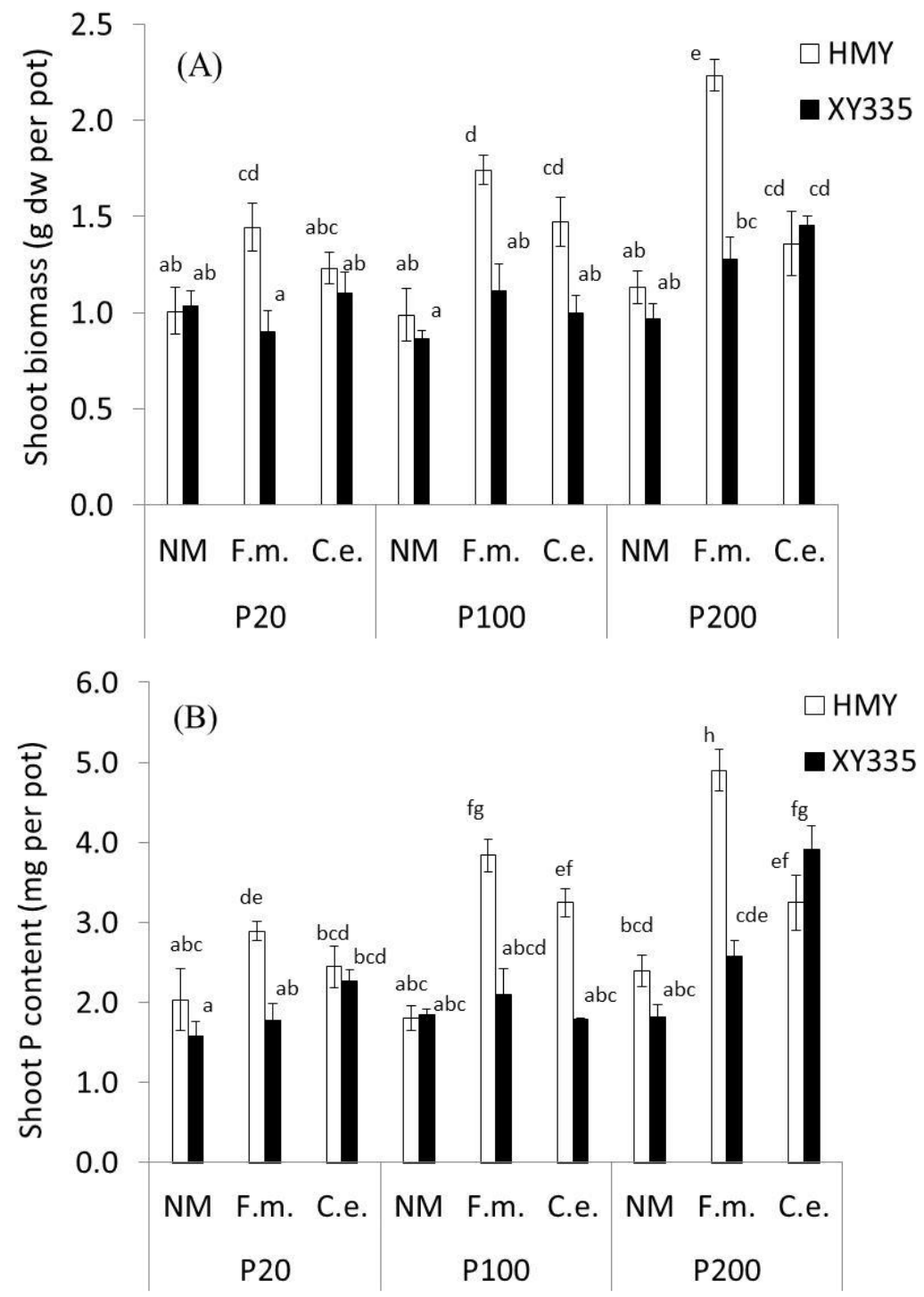

Fig. 3.3. Shoot biomass (A) and shoot P content (B) of two maize varieties (HMY and XY335) grown with 20,100 or $200 \mathrm{mg}$ phytate-P per $\mathrm{kg}$ soil in the hyphal compartment. The plants were nonmycorrhizal (NM) or inoculated with F. mosseae (F.m.) or C. etunicatum (C.e.). Bars represent means \pm SE $(\mathrm{n}=4)$. Bars with the same letter are not significantly different (Tukey: $P<0.05$ ). 


\section{Phosphate uptake from phytate by arbuscular mycorrhiza maize}

\section{Discussion}

\section{Soil $P$ status after phytate addition}

When phytate is added to soil, it competes with orthophosphate for binding sites on metal (hydr)oxides. Our calculations show that additions of 20 and $100 \mathrm{mg}$ P as phytate $\mathrm{kg}^{-1}$ had a minor effect on mineral $\mathrm{P}$ availability in the loamy soil we used; however, at an addition of $200 \mathrm{mg}$ phytate- $\mathrm{P} \mathrm{kg}^{-1}$, competitive desorption (and increased mineral $\mathrm{P}$ availability) was likely important because predicted available $\mathrm{P}$ increased almost threefold. We also observed a reduction in hyphal length density with additions of $200 \mathrm{mg}$ phytate-P $\mathrm{kg}^{-1}$ (Fig. 3.S2), a result consistent with an earlier described negative effect of soil solution $\mathrm{P}$ on mycorrhizal functioning (Olsson et al. 1997). Our observations suggest that at high phytate addition, orthophosphate availability increased both due to chemical processes (competitive sorption of orthophosphate and phytate) and to hydrolysis by phytase and acid phosphatase produced by hyphae. Future studies on the role of phytate in plant nutrition should therefore include low metal (hydr)oxide soils or artificial substrates that do not contain any adsorbed phosphate.

\section{Phytase and acid phosphatase activities}

The lower activity of acid phosphatase and phytase in the hyphal compartment of the non-mycorrhizal control treatment compared to the AMF-inoculated treatments confirms that mycorrhizal fungi or bacteria associated with the mycorrhizal mycelium produced these enzymes (Tarafdar and Claassen 1988). Our study cannot unequivocally assign enzymatic activity to the fungus, so the contradictory results of transcriptomic studies (that suggest that AM fungi do not possess the genes for phytase; Tisserant et al. 2012) and earlier experiments (that indicated hydrolysis in an axenic system; Koide and Kabir 2000) cannot be resolved.

Indirect evidence of the role of AMF in acid phosphatase production comes from the positive correlation between acid phosphatase in the root (without phytate addition) and hyphal (with phytate addition) compartments, with higher amounts of acid phosphatase activity in the root compartment (Fig. 3.S1). Higher phosphatase activity (independent of the actual presence of the relevant organic P source) is consistent with a higher hyphal density close to roots ( $\mathrm{Li}$ et al. 1991). The higher acid phosphatase activity in the root compartment compared to 


\section{Chapter 3}

the hyphal compartment could, however, also hint at a higher contribution by the root compared to AMF hyphae in mobilizing $\mathrm{P}$ from lower-order inositol phosphates.

Table 3.4 ANOVA results with shoot biomass and shoot $\mathrm{P}$ content as dependent variables, and phytate addition $(\mathrm{P})$, varieties $(\mathrm{CV})$ and mycorrhizal treatments $(\mathrm{M})$ as independent variables, with the non-mycorrhizal control included.

\begin{tabular}{|c|c|c|c|c|c|}
\hline \multirow{2}{*}{$\begin{array}{l}\text { Independent } \\
\text { Variable }\end{array}$} & \multirow[t]{2}{*}{ df } & \multicolumn{2}{|c|}{ Biomass } & \multicolumn{2}{|c|}{ Shoot P content } \\
\hline & & F & $P$ value & $\mathrm{F}$ & $P$ value \\
\hline $\mathrm{P}$ & 2 & 5.8 & 0.005 & 27.3 & $<0.001$ \\
\hline $\mathrm{CV}$ & 1 & 30.6 & $<0.001$ & 32.6 & $<0.001$ \\
\hline M & 2 & 20.5 & $<0.001$ & 21.8 & $<0.001$ \\
\hline $\mathrm{P} \times \mathrm{CV}$ & 2 & 0.2 & 0.78 & 4.3 & 0.02 \\
\hline $\mathrm{P} \times \mathrm{M}$ & 4 & 1.3 & 0.27 & 5.5 & 0.001 \\
\hline $\mathrm{CV} \times \mathrm{M}$ & 2 & 12.5 & $<0.001$ & 26.3 & $<0.001$ \\
\hline $\mathrm{P} \times \mathrm{CV} \times \mathrm{M}$ & 4 & 1.5 & 0.21 & 5.3 & 0.001 \\
\hline
\end{tabular}

Activities of acid phosphatase and phytase were correlated and increased after phytate addition to the hyphal compartment (Fig. 3.1). Other studies have also observed a significantly positive correlation between activities of both enzymes. A similar correlation was found for 16 plant species grown at Pdeficiency and P-sufficiency ( $\mathrm{Li}$ et al. 1997). However, whereas increases in phytase activity correlated positively with increased P-uptake by the maize varieties (Fig. 3.2), no such correlation was found for increases in acid phosphatase and increased P-uptake. This, in combination with the fact that acid phosphatase may not hydrolyse phytate, suggests that measurement of acid phosphatase provides only indirect information for phytate utilization. We agree with Hayes et al. (1999) and Richardson et al. (2005) that researchers should work on unification and standardization of enzymatic measurements when researching hydrolysis of organic P. Since both phytase and acid phosphatase are able to hydrolyze pNPP (Li et al. 1997), the activity assayed with pNPP as substrate includes the co-hydrolyzing activity of both enzymes (but with phytase making only a minor contribution because of its low activity compared to acid phosphatase). Our observation that phytase activity was only around 3\% of acid phosphatase activity is consistent with earlier observations by Hayes et al. (1999), 
who observed that phytase activity was less than $5 \%$ of acid phosphatase activity; and by Barrett-Lennard et al. (1993), who found that phytase activity was on average $7 \%$ of total acid phosphatase activity in excised root segments.

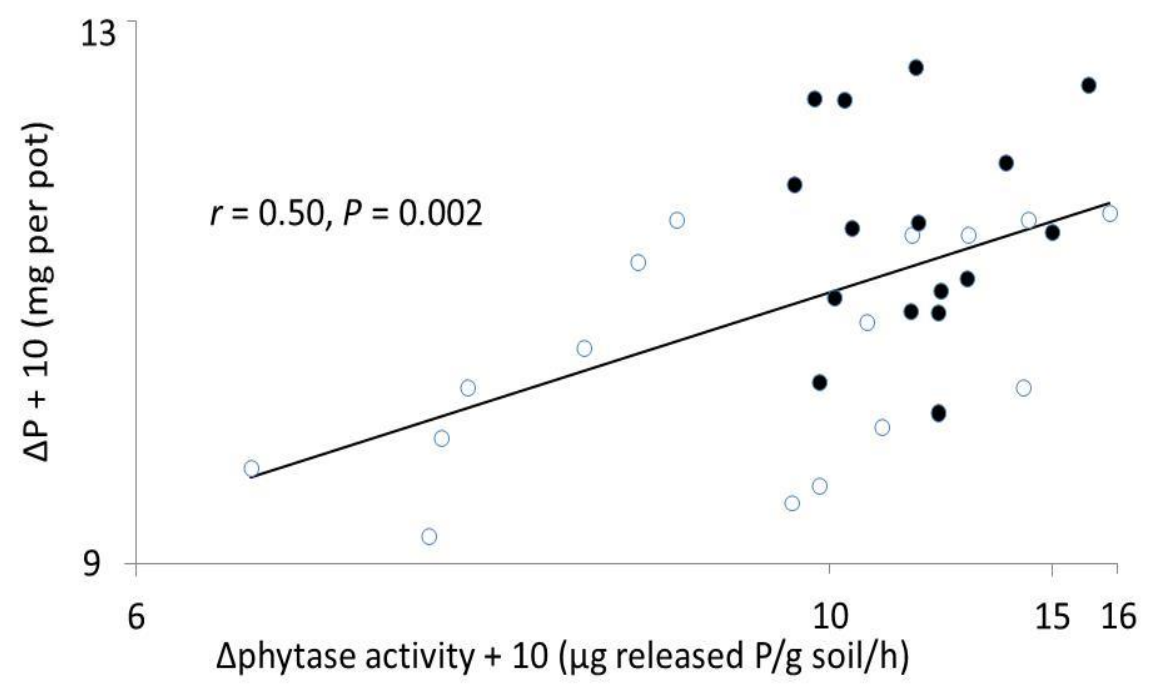

Fig. 3.4. The relation between the increase ( $\Delta$ phytase) in phytase activity (compared to the addition of $\left.20 \mathrm{mg} \mathrm{P} \mathrm{kg}^{-1}\right)$ and the increase in $\mathrm{P}$ uptake $(\Delta \mathrm{P})$ in the mycorrhizal treatments. Open symbols represent the difference between 100 and $20 \mathrm{mg}$ phytate $\mathrm{P}$ $\mathrm{kg}^{-1}$ soil; black markers represent the difference between 200 and $20 \mathrm{mg}$ phytate $\mathrm{P} \mathrm{kg}^{-1}$ soil. To allow log transformation, negative values were avoided by adding up 10 to the original data. Each symbol represents one variety and the means of four replicates.

\section{Differential plant performance}

The two maize varieties tested responded differently to AMF inoculation and phytate supply (Table 3.4). The old variety HMY was more responsive to AMF than XY335 (Fig. 3.3), which is consistent with a previous study showing higher responsiveness of HMY when grown on a low-P soil (Chu et al. 2013). ANOVA results on phytate, AMF species and variety effects on root colonization and hyphal length density (Table 3.3) showed complicated interaction effects, which make it hard to explain the differential shoot biomass and shoot $\mathrm{P}$ content response by the two varieties mechanistically. This interaction between maize 


\section{Chapter 3}

varieties and AMF species on hyphal $\mathrm{P}$ uptake from phytate may imply that breeders need to consider plant variation and fungal functional diversity in breeding efficient maize varieties using organic P (Rengel and Marschner 2005; Wolfe et al. 2008) .

A small fraction ( $2 \%$ at maximum) of $\mathrm{P}$ from phytate was taken up by the hyphae and transferred to the shoot. The question is whether this conclusion then translates into a general conclusion that phytate can only make a minor addition to plant $\mathrm{P}$ use. This may not necessarily be the case. We need to compare this number with $\mathrm{P}$ recovery from other sources. For the soil that we used, Chu et al. (2013) determined P recovery (after addition of $100 \mathrm{mg} \mathrm{P} \mathrm{kg}^{-1}$ soil) of $4.4 \%$ for non-mycorrhizal maize and $7.5 \%$ for mycorrhizal maize. So within this framework $2 \%$ may not necessarily be low, also taking into account that the quantitatively most important contribution of the AMF symbiosis was likely at the end of the growing period, due to the slow growth of AMF hyphae. Therefore, care must be taken when extrapolating these results to other soils, where P-recovery may be higher, or to other experiments where (mycorrhizal) plant roots and hyphae can all contribute to P mobilization from phytate. 


\section{Supplementary material}

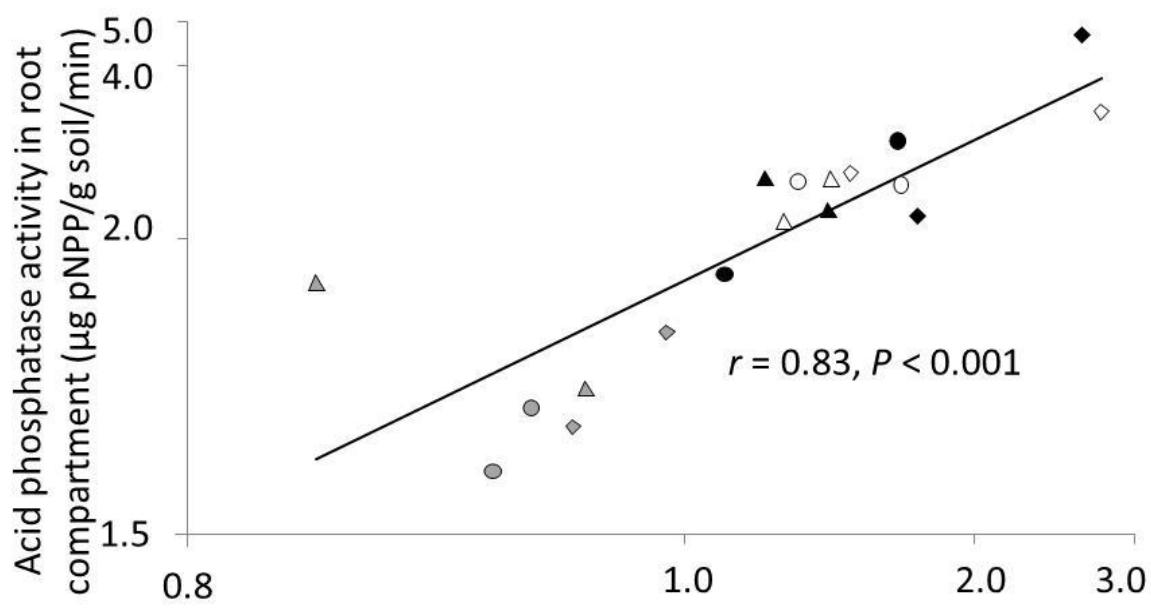

Acid phosphatase activity in hyphal compartment ( $\mu \mathrm{g}$ pNPP /g soil /min)

Fig. 3.S1. Correlation between acid phosphatase activity in hyphal compartment and root compartment. Triangle, circle and square markers indicate the three levels of phytate (20, 100 or $200 \mathrm{mg}$ phytate $\left.\mathrm{P} \mathrm{kg}^{-1}\right)$, respectively. Grey, white and black refer to the non-mycorrhizal control and F. etunicatum and C. mosseae inoculated treatments, respectively. Each marker represents one variety and the means of four replicates. 


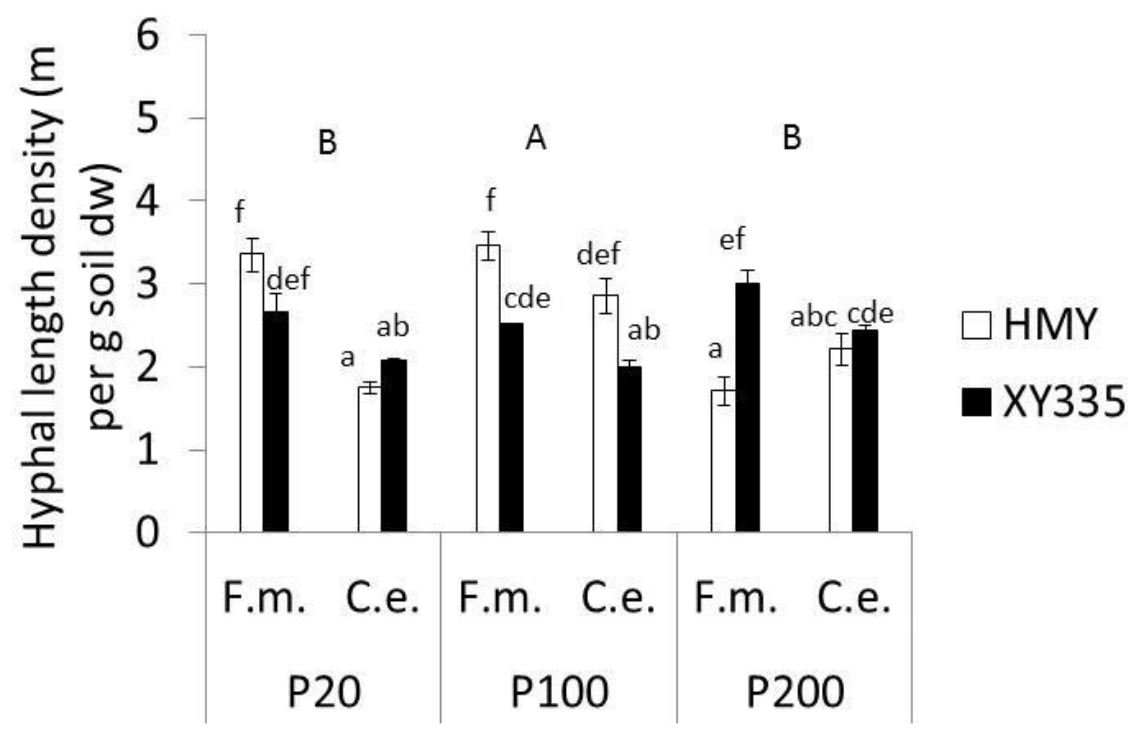

Fig. 3.S2. Hyphal length density in hyphal compartments of two maize varieties (HMY and XY335). P20, P100 and P200 mean 20, 100 and $200 \mathrm{mg}$ phytate-P per kg soil treatment in the hyphal compartment, respectively. The AMF were F. mosseae (F.m.), C. etunicatum (C.e.). Bars represent means $\pm \mathrm{SE}(\mathrm{n}=4)$. Treatments with the same lowercase letter are not significantly different (Tukey: $P<0.05$ ); uppercase letters refer to main effects of phytate additions. 


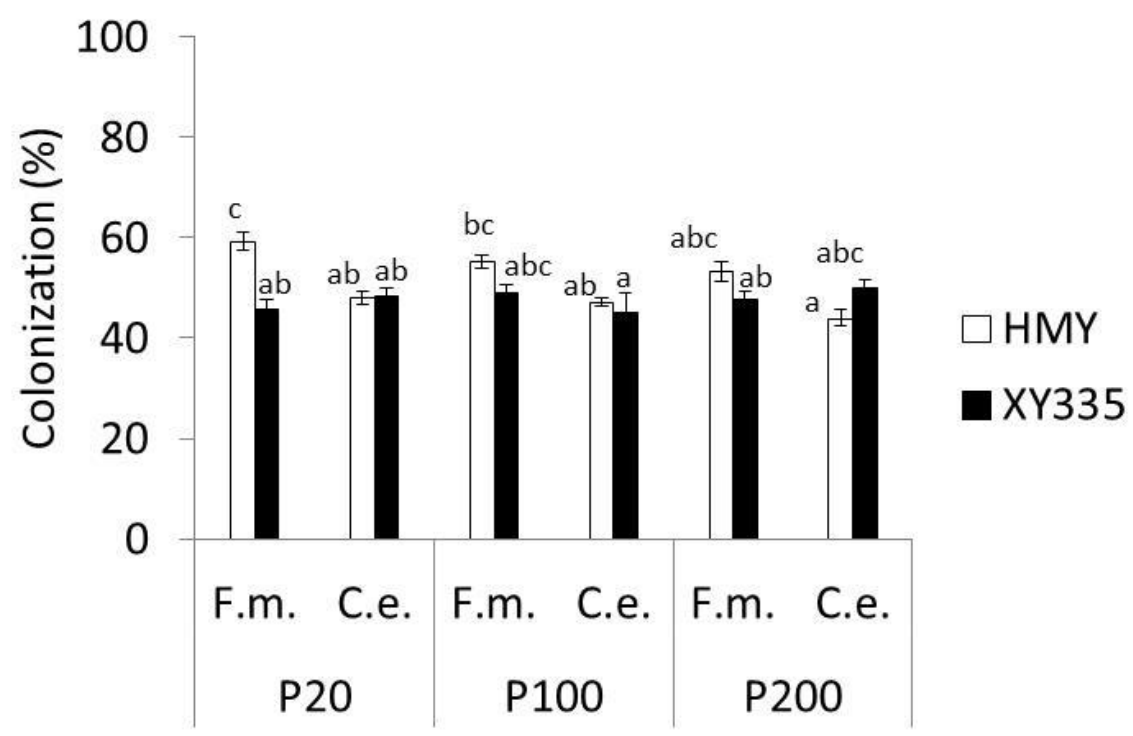

Fig. 3.S3. Fractional mycorrhizal root colonization for two maize varieties (HMY and XY335). P20, P100 and P200 mean 20, 100 and $200 \mathrm{mg}$ phytate-P per $\mathrm{kg}$ soil treatment in the hyphal compartment, respectively. The AMF were F. mosseae (F.m.), C. etunicatum (C.e.). Bars represent means $\pm \mathrm{SE}(\mathrm{n}=4)$. Treatments with the same letter are not significantly different (Tukey: $P<0.05$ ). 



\section{CHAPTER 4}

The arbuscular mycorrhizal symbiosis enhances $\mathrm{P}$ uptake and increases productivity by mixtures of maize varieties compared to monocultures

Xinxin Wang, Ellis Hoffland, Gu Feng, Thomas W. Kuyper 


\section{Chapter 4}

\section{Abstract}

Arbuscular mycorrhizal fungi can play a key role in enhancing plant productivity (overyielding) in multispecies natural ecosystems; however, their role in enhancing crop productivity in mixed cropping systems is still poorly known. We grew monocultures and mixtures of maize varieties in a greenhouse and in a field experiment. Variety mixtures (intercropping) showed overyielding and enhanced P-uptake in the pot experiment when mycorrhizal but not when non-mycorrhizal. The increase in relative yield total was due to complementarity effects, implying that relative overyielding and enhanced $\mathrm{P}$ uptake were not due to enhanced competitive ability by the larger variety. Variety mixing also increased hyphal length. Increased P uptake and hyphal length density in mixtures compared to monocultures occurred both in the greenhouse (with Funneliformis mosseae) and in the field with a mixed-species inoculum. Our results suggest that mixing maize varieties may be beneficial for enhancing productivity and $\mathrm{P}$ acquisition efficiency.

Keywords: maize; mixture; arbuscular mycorrhizal fungi; hyphal length density; overyielding; common mycorrhizal network 


\section{The arbuscular mycorrhizal symbiosis enhances $P$ uptake and increases productivity by mixtures of maize varieties compared to monocultures}

\section{Introduction}

The relationship between biological diversity and ecosystem functioning (e.g., productivity) has been one of the major issues in ecology. The consensus view (Hooper et al. 2005) is that the scientific community has high confidence in the claim that certain combinations of plant species show complementarity in resource use and thereby increase average rates of ecosystem productivity compared to single plant species. In ecosystems, including agro-ecosystems, the positive relation between biodiversity and ecosystem productivity is manifested in the phenomenon of overyielding, where the combination of species produces more biomass than expected from the average production of the component species grown in monoculture. Overyielding has been repeatedly observed in grassland experiments (Hooper and Vitousek 1997; Tilman et al. 2006). Overyielding also occurs in intercropping, i.e. the simultaneous cultivation of multiple crop species in a single field (Li et al. 2014).

Two mechanisms for overyielding in mixtures have been proposed, viz., selection and complementarity. Mathematical models have been developed (Loreau and Hector 2001) to partition overyielding into both components. Selection effects are due to the increased likelihood of including species in multi-species mixtures that are more-than-average productive. In intercropping, where the farmer selects the crop mixture, a positive selection effect can be due to competitive release from intraspecific competition by the better performing crop species. In that case the more competitive species will largely dominate the mixture. Complementarity refers to the part of overyielding that cannot be explained by the selection effect; it is due to positive interactions between species. Complementarity includes complementarity in a strict sense and facilitation (Hinsinger 2001; Hinsinger et al. 2011). Examples of complementarity in a strict sense include vertical niche differentiation (shifts in rooting depth in multi-species mixtures resulting in a larger volume of soil that can be exploited), temporal niche shifts (phenological changes in physiological activity during species interactions) or specialization on separate nitrogen sources $\left(\mathrm{N}_{2-}\right.$ fixation, uptake of ammonium or nitrate). Complementarity in $\mathrm{P}$ use from organic $\mathrm{P}$ sources has been hypothesized by Turner (2008), but no evidence has been reported to support that hypothesis. Examples of facilitation include production of root exudates (low-molecular-weight organic anions such as citrate, malate or oxalate) that increase $\mathrm{P}$ availability to both the plant that produces those exudates and to 


\section{Chapter 4}

neighbouring plants. Negative plant - soil feedback can cause overyielding (or rather a lack of underyielding) due to 'dilution' of pathogenic rhizosphere biota (Mangan et al. 2010; Schnitzer et al. 2011); mathematically it is part of complementarity in partitioning models. Separating complementarity in a strict sense and facilitation is difficult, and for that reason these mechanisms are treated together in the partitioning model by Loreau and Hector (2001).

In agriculture, overyielding has been frequently reported for mixtures of cereals (Poaceae) and legumes (Fabaceae); both complementarity (access to different $\mathrm{N}$ sources) and facilitation (mobilization of $\mathrm{P}$, and in some cases also of $\mathrm{Fe}$ ) play a role (Li et al. 2004; Li et al. 2014; Li et al. 2004).

Most studies have addressed the issue of biodiversity and overyielding by studying different plant species. However, intraspecific variability could also be a cause for overyielding. Relatively few studies to that effect have been published and these were recently summarized (Brooker et al. 2015; Brooker et al. 2016; Schöb et al. 2015). In mixtures of susceptible and resistant blast disease rice varieties, the disease incidence in the susceptible variety was reduced compared to the sole variety, due to pathogen dilution, resulting in overyielding (Garrett and Mundt 1999; Zhu et al. 2000).

Using different plant species or different varieties or varieties of a (crop) species in order to increase yield may be an attractive and promising route, as stacking different plant traits that maximize nutrient uptake (and hence increase productivity) may be impossible in one species or variety, due to inherent trade-offs during evolution (Denison 2012).

Arbuscular mycorrhizal fungi (AMF) form mutualistic relationships with about $80 \%$ of higher plants (Smith and Read 2008). AMF play a major role in enhancing uptake of immobile nutrients, such as $\mathrm{P}$, from the soil, transferring these to plants in exchange for photosynthetic $\mathrm{C}$ from the plant. AMF diversity can increase productivity of plant communities (Maherali and Klironomos 2007). The role of the arbuscular mycorrhizal symbiosis in complementarity has been investigated by Montesinos-Navarro et al. (2012). They concluded that complementarity occurred because different plant species associated with different AMF and hence that niche differentiation by AMF species is a driver for overyielding, consistent with the results of an earlier study by Maherali and Klironomos (2007). A corollary of that mechanism is that overyielding would less likely occur in case plants are connected to the same mycorrhizal fungus in a 


\section{The arbuscular mycorrhizal symbiosis enhances $P$ uptake and increases productivity by mixtures of maize varieties compared to monocultures}

common mycorrhizal network. Only few studies investigated whether single AMF species impacted on the relation between plant species richness and productivity. Klironomos et al. (2000) studied that relationship and concluded that curves that describe the relation between plant species richness and productivity saturate at a lower level of plant species diversity when plants are mycorrhizal than in the case of non-mycorrhizal plants. They hypothesized that this result was due to increased niche overlap of plant species that are connected in a common mycorrhizal network, and hence to increased redundancy of individual plant species. But results from other studies with two plant species interconnected by one mycorrhizal fungus are not consistent. Walder et al. (2012) grew sorghum and flax, connected by a common mycorrhizal network, and observed increased relative yield total. In their system the carbon for the fungus was primarily delivered by sorghum, while the nutrient benefits were primarily for flax. However, due to the large size inequality between both plants, even in the mycorrhizal condition, sorghum did not show a significant yield depression in the mixture. Cases where differential $\mathrm{C}$ supply to the fungus and nutrient provision by the fungus were coordinated, have also been reported (Fellbaum et al. 2014).

In this study we tested whether combining maize varieties can generate overyielding due to enhanced $\mathrm{P}$ uptake and utilization. We also tested whether the AMF symbiosis influenced the magnitude of overyielding and calculated whether differential effects between mycorrhizal and non-mycorrhizal plants were due to selection effects or complementarity effects. We applied different $\mathrm{P}$ sources to test whether the soil $\mathrm{P}$ status impacted on the interaction between these varieties. We used a pot experiment to test the influence of one AMF species compared to a nonmycorrhizal control on performance of monocultures and mixtures; and a field experiment to test the consistency of our results under agricultural conditions with multiple fungal species.

We hypothesized that (i) AMF increase biomass and $\mathrm{P}$ uptake (positive mycorrhizal responsiveness) relative to non-mycorrhizal plants; (ii) there is complementarity between maize varieties due to differences in root morphology and physiology in the non-mycorrhizal condition and hence overyielding; (iii) AMF increase below-ground similarity due to a shared mycorrhizal network and in combination with enhanced $\mathrm{P}$ acquisition will reduce overyielding; (iv) the addition of an easily available $\mathrm{P}$ source decreases overyielding whereas the addition of a $\mathrm{P}$ source that is more difficult to access increases overyielding due to genetic 


\section{Chapter 4}

differences between both maize varieties in P-mobilizing capacity. Our third hypothesis, which stated that the presence of arbuscular mycorrhiza would reduce overyielding, seems a logical corollary from the first two hypotheses.

\section{Materials and Methods}

\section{Pot experiment}

A calcareous loamy soil was collected from field plots at the Changping LongTerm Fertilizer Station of China Agricultural University in Beijing. The soil contained $17.8 \mathrm{~g}$ organic $\mathrm{C} \mathrm{kg}^{-1}$ soil, $2.9 \mathrm{mg}$ Olsen- $\mathrm{P} \mathrm{kg}^{-1}$ soil, $87.2 \mathrm{mg} \mathrm{N} \mathrm{kg}-1$ soil, $156 \mathrm{mg}$ ammonium acetate-exchangeable $\mathrm{K} \mathrm{kg}^{-1}$ soil, and had a $\mathrm{pH}$ (in $0.01 \mathrm{M}$ $\left.\mathrm{CaCl}_{2}\right)$ of 7.8 . The soil was sieved $(2 \mathrm{~mm})$ and sterilized by $\gamma$-radiation with ${ }^{60} \mathrm{Co}$ at $10 \mathrm{kGy}$.

The following mineral nutrients at the indicated rates $\left(\mathrm{kg}^{-1}\right.$ soil $)$ were added uniformly: $200 \mathrm{mg} \mathrm{N}$ (as $\mathrm{KNO}_{3}$ ), $50 \mathrm{mg} \mathrm{Mg}$ (as $\mathrm{MgSO}_{4}$ ), $5 \mathrm{mg} \mathrm{Zn}$ (as $\mathrm{ZnSO}_{4} \cdot 7 \mathrm{H}_{2} \mathrm{O}$ ), and $2 \mathrm{mg} \mathrm{Cu}\left(\mathrm{as} \mathrm{CuSO}_{4}\right)$. To achieve the same soil $\mathrm{K}$ level among all treatments, $\mathrm{K}_{2} \mathrm{SO}_{4}$ was supplied at 25,25 and $0 \mathrm{mg} \mathrm{K} \mathrm{kg}^{-1}$ soil, depending on the $\mathrm{P}$ treatments (P-control, P-phytate and $\mathrm{P}-\mathrm{KH}_{2} \mathrm{O}_{4}$, respectively). Three weeks after sowing, another $100 \mathrm{mg}$ of $\mathrm{N}$ (as $\mathrm{KNO}_{3}$ ) was added to every pot. The nutrients were mixed with the soil before pot filling. The soil was then placed in plastic pots (4 kg of soil per pot).

The experiment was executed twice, in 2012 and 2013. In 2012, three Chinese maize varieties that were bred in the last 60 years were selected based on previous screening experiments (Chu et al. 2013; Chapter 2): Huangmaya (HMY), an open-pollinated, early-senescing variety; Zhongdan 2 (ZD2), a moderatesenescing hybrid; and 197, an inbred line, known to be P-inefficient (Liu et al. 2004). In 2013, we tested one additional maize variety in the pot experiment, Xianyu 335 (XY335), which was once popular in China. Data on mycorrhizal (P) responsiveness and $\mathrm{P}$ acquisition efficiency of those four varieties are provided in Chapter 2.

The AMF species Funneliformis mosseae was used in pot experiments. The inoculum was obtained from Bank of Glomeromycota of China, Institute of Plant Nutrition and Resources, Beijing Academy of Agriculture and Forestry Research, Beijing. The fungus was propagated in a 5:1 mixture (w/w) of zeolite and river sand with maize for 4 months in a greenhouse. Inoculum consisted of soil 


\section{The arbuscular mycorrhizal symbiosis enhances $P$ uptake and increases productivity by mixtures of maize varieties compared to monocultures}

containing spores ( $140 \mathrm{~g}^{-1}$ soil), mycelium, and fine root fragments. Forty gram of the inoculum was added to pots of the mycorrhizal treatment before pot filling, and $40 \mathrm{~g}$ of the sterilized inoculum was added to pots of the non-mycorrhizal treatment. To minimize differences in microbial communities of mycorrhizal and non-mycorrhizal treatments, $10 \mathrm{ml}$ of AMF-free filtrate from the inoculum was added to each pot of the non-mycorrhizal treatment, and $10 \mathrm{ml}$ of deionized water was added to each pot of the mycorrhizal treatment.

The experiment in 2012 was a three-factor experiment: mycorrhizal treatment (absent or present) $\times$ maize variety (three monocultures, HMY, ZD2, 197; three mixtures) $\times \mathrm{P}$ (no $\mathrm{P}, \mathrm{KH}_{2} \mathrm{PO}_{4}$ or phytate). Phosphorus treatments consisted of a control (no P added), addition of an easily available P source $(20 \mathrm{mg}$ $\mathrm{P} \mathrm{kg}^{-1}$ soil as $\left.\mathrm{KH}_{2} \mathrm{PO}_{4}\right)$, and addition of a sparingly available P source $(20 \mathrm{mg} \mathrm{P} \mathrm{kg-}$ 1 soil as Ca-phytate (Sigma-Aldrich, St. Louis, MO, USA). There were four replicates for each treatment, giving 144 pots in total in four blocks.

The experiment in 2013 was a two-factor experiment: mycorrhiza (present or absent) $\times$ variety combination (four monocultures, HMY, ZD2, 197, XY335; six mixtures). All pots received $20 \mathrm{mg} \mathrm{P} \mathrm{kg}^{-1}$ soil as Ca-phytate (SigmaAldrich, St. Louis, MO, USA). Addition of other nutrients was the same as in 2012. There were four replicates, giving 80 pots in four blocks.

Seeds of maize were surface-sterilized in $10 \%$ (v/v) $\mathrm{H}_{2} \mathrm{O}_{2}$ for $10 \mathrm{~min}$ and rinsed in deionized water. In the monoculture treatments, four seeds were sown in each pot which were thinned to two seedlings per pot after emergence. In the mixed treatment, two seeds of each variety were sown in each pot which were thinned to one seedling per variety after emergence. Tap water was supplied daily, and the pots were weighed twice per week to adjust soil moisture content to $18 \%$ $(\mathrm{w} / \mathrm{w})$; differences in plant weight among treatments were ignored. The glasshouse temperature range was $23-31{ }^{\circ} \mathrm{C}$. The natural light was given without supplementary light.

Plants were harvested about 6.5 weeks after sowing in both years (47 days, sowing date $12^{\text {th }}$ July in 2012; 45 days, sowing date $7^{\text {th }}$ July in 2013). At harvest, roots were carefully removed from the soil and shaken gently to remove loosely adhering soil, and finally washed under running water. Roots were cut into $1-\mathrm{cm}$ segments and thoroughly mixed. A $0.5-\mathrm{g}$ sub-sample was cleared with $10 \%$ (w/v) $\mathrm{KOH}$ at $90{ }^{\circ} \mathrm{C}$ for $2 \mathrm{~h}$ and stained with Trypan blue. Mycorrhizal colonization was assessed by the method of (Trouvelot et al. 1986). Hyphal length density (HLD) 


\section{Chapter 4}

was determined by the method described by (Jakobsen et al. 1992b). The shoots were oven-dried at $70{ }^{\circ} \mathrm{C}$ for 3 days, and dry weights recorded. The shoots were ground to a fine powder. Plant $\mathrm{P}$ concentration was determined by the standard vanado-molybdate method (Murphy and Riley 1962)

\section{Field experiment}

A field experiment was conducted to test for consistency of the effects observed in the greenhouse in the presence of a naturally occurring mixed AMF inoculum. The same three maize varieties as used in the 2012 pot experiment were used as monoculture and as mixed culture in the field experiment in 2012. Three (197, ZD2, and XY335) maize varieties used in the pot experiment in 2013 were also used in the field experiment, but HMY was replaced by Nongda108 (ND108), because lodging-resistance of HMY was poor in 2012. The field experiment was conducted at the experimental station in Shangzhuang (North China). Application rates of nutrients in each treatment were as follows: $65 \mathrm{~kg} \mathrm{~N} \mathrm{ha}^{-1}$ (as urea, $\mathrm{CO}\left(\mathrm{NH}_{2}\right)_{2}$ ), $80 \mathrm{~kg} \mathrm{~K}_{2} \mathrm{O} \mathrm{ha}{ }^{-1}$ (as $\mathrm{KCl}$ ) and $3.4 \mathrm{~kg} \mathrm{Zn} \mathrm{ha}^{-1}$ (as $\mathrm{ZnSO}_{4} \cdot 7 \mathrm{H}_{2} \mathrm{O}$ ). Fertilizer application rates and timing were the same in both years, and fertilizers were applied before the experiments started. Soil samples were taken for the assessment of available N, P and $\mathrm{K}$ before the experiment started. As the experiments took place in different fields of the experimental station, soils were analysed in both years. Soil samples were taken from the topsoil $(0-30 \mathrm{~cm})$ prior to setting up the field experiment. Soil mineral nitrogen concentration $\left(\mathrm{N}_{\min }\right)$ was determined by continuous flow analysis (TRACS 2000 system, Bran and Luebbe, Norderstedt, Germany) after extracting fresh soil with $0.01 \mathrm{M} \mathrm{CaCl} 2(1: 20$, soil : water) by shaking for $1 \mathrm{~h}$ at $25{ }^{\circ} \mathrm{C}$. Available soil $\mathrm{P}$ (Olsen-P) was determined using the vanado-molybdate method based on extraction of air-dried soil with $0.5 \mathrm{M} \mathrm{NaHCO}_{3}$ at $\mathrm{pH} 8.5$ (Fixen et al. 1990). Available soil $\mathrm{K}$ was determined using the flame spectrometry method based on extraction of air-dried soil with ammonium acetate (Westerman 1990). Soil properties in the soils used in 2012 and 2013 respectively were: bulk density 1.28 and $1.37 \mathrm{~g} \mathrm{~cm}^{-3}, \mathrm{pH}(1: 50.01 \mathrm{M}$ $\left.\mathrm{CaCl}_{2}\right) 7.8$ and 7.9, organic C 11.01 and $7.30 \mathrm{~g} \mathrm{~kg}^{-1}$, available $\mathrm{N} 29$ and $38 \mathrm{mg} \mathrm{kg}^{-1}$, available P 8.9 and $14.6 \mathrm{mg} \mathrm{kg}^{-1}$, and available $\mathrm{K} 85$ and $108 \mathrm{mg} \mathrm{kg}^{-1}$ (Westerman 1990).

The design was a randomized complete block design with three blocks and six treatments (three monocultures, three mixed cultures) in 2011 and four 


\section{The arbuscular mycorrhizal symbiosis enhances $P$ uptake and increases productivity by mixtures of maize varieties compared to monocultures}

blocks and ten treatments (four monocultures and six mixed cultures) in 2012. In 2012 plot size (dependent on total used field size) was $5 \times 5 \mathrm{~m}^{2}$, with row width $50 \mathrm{~cm}$ and interplant width $28 \mathrm{~cm}$; in 2013 plot size was $4 \times 8 \mathrm{~m}^{2}$, with row width $50 \mathrm{~cm}$ and interplant width $28 \mathrm{~cm}$. Plants were collected from Row 3 and Row 4 from west to east in both years. In the monoculture treatments, one variety was sown, and in the mixture treatment the two varieties were sown row by row. Per plot six plants were sampled in 2012 and four in 2013 (83 DAS [days after seeding] in 2012 and 85 DAS in 2013). Plants were separated into roots and shoots in order to determine dry weight and nutrient content. Shoot samples were ovendried at $70{ }^{\circ} \mathrm{C}$ for $72 \mathrm{~h}$. P content was determined by the method as mentioned above.

Soil samples for AMF analyses were collected on both sides of Row 4. Soil cores $(4 \mathrm{~cm}$ diameter $\times 15 \mathrm{~cm}$ depth, two cores per plot) were collected. Soil cores were taken at 0-30 cm depth. Root colonization and hyphal length density (HLD) were determined by the same methods as in the pot experiment.

\section{Statistics}

Relative Yield Total was used to evaluate the effect of variety mixing on shoot biomass or shoot $\mathrm{P}$ content in pot and field experiments. The RYT $\mathrm{T}_{\text {biom }}$ or $\mathrm{RY} \mathrm{T}_{\mathrm{P}}$ was calculated as:

$\mathrm{RYT}=\mathrm{Y} 1 / \mathrm{M} 1+\mathrm{Y} 2 / \mathrm{M} 2$

where $\mathrm{Y} 1$ is the biomass of variety 1 in mixture, and M1 is the biomass of variety 1 in monoculture (Gliessman 1985). For P content the same formula was applied.

The relative mycorrhizal responsiveness $\left(\mathrm{MR} ; \mathrm{MR}_{\mathrm{P}}\right)$ refers to mycorrhizainduced increases in shoot biomass and shoot $\mathrm{P}$ content. $\mathrm{M}(\mathrm{P}) \mathrm{R}$ was calculated according to:

$\mathrm{M}(\mathrm{P}) \mathrm{R}=(\mathrm{M}-\mathrm{NM}) / \mathrm{M} \times 100$

where $\mathrm{M}$ and $\mathrm{NM}$ refer to the shoot biomass or shoot P content of mycorrhizal and non-mycorrhizal plants, respectively (Plenchette et al. 1983).

We tested for significant overyielding for every variety combination in every year by calculating, per block, the predicted yield or P uptake of the mixture and compared that with the actual yield of the mixture. We subsequently tested, through a t-test with $\mathrm{n}=4$, whether the difference between observed and predicted yield or $\mathrm{P}$ uptake was significant. We subsequently evaluated the role of 


\section{Chapter 4}

mycorrhiza in overyielding in two ways. First, we tested, through Fisher's exact test, whether there was an association between mycorrhiza and significant overyielding (based on $n=15$ ). Then we tested whether the RYTs for all 15 combinations, for either biomass yield or P uptake, was significantly different between the non-mycorrhizal and mycorrhizal treatment.

For the field experiment we applied the same calculations, except that we did not apply Fisher's exact test. We had three treatments in 2012 and six in 2013; there were six replicates in 2012 and four in 2013 that we used to calculate the predicted and actually measured biomass and shoot $\mathrm{P}$ content.

For mycorrhizal colonization and hyphal length density, we calculated RYT as described above. We also applied t-tests to test for significant differences (based on the average of four replicates) between monoculture and mixtures.

We partitioned overyielding in two components, following the formula of Loreau and Hector (2001). We did this partitioning for every mixture (15 for the pot experiment and 9 for the field experiment):

$\Delta \mathrm{Y}=\mathrm{Y}_{\mathrm{O}}-\mathrm{Y}_{\mathrm{E}}=\mathrm{N} \Delta \mathrm{RYM}+\mathrm{N}_{\mathrm{cov}}(\Delta \mathrm{RY}, \mathrm{M})$

In this equation, $Y_{O}$ and $Y_{E}$ mean observed yield and expected yield, respectively; N $\Delta R Y M$ measures the complementarity effect, and $\mathrm{N}_{\operatorname{cov}}(\Delta \mathrm{RY}, \mathrm{M})$ measures the selection effect. We calculated $\Delta \mathrm{Y}, \mathrm{N} \Delta \mathrm{RYM}$ and $\mathrm{N}_{\mathrm{cov}}(\Delta \mathrm{RY}, \mathrm{M})$ for the average of the pot and field experiments in 2012 and 2013.

All data met the requirements on homogeneity of variance (Levene's test), except hyphal length density in 2013 (where data were log-transformed). Statistical analyses were performed with SPSS 22.0 (SPSS, Inc., Chicago, IL, USA). We used the $5 \%$ level of probability to judge whether effects were statistically significant.

\section{Results}

\section{Pot experiment}

Averaged over the different $\mathrm{P}$ treatments, mixing did not affect biomass in the non-mycorrhizal condition in both years $(P=0.85$, in 2012; $P=0.36$, in 2013), but increased biomass $(P=0.07$, in 2012; $P=0.04$, in 2013) in the mycorrhizal condition (Fig. 4.1a). Shoot $\mathrm{P}$ content was also not affected by mixtures in the non-mycorrhizal condition $(P=0.79$, in 2012; $P=0.12$, in 2013). In the mycorrhizal condition shoot $\mathrm{P}$ content was significantly increased by mixing $(P=$ 0.001 , in 2012; $P=0.05$, in 2013; Fig. 4.1b). Based on all 15 combinations in the 


\section{The arbuscular mycorrhizal symbiosis enhances $P$ uptake and increases productivity by mixtures of maize varieties compared to monocultures}

non-mycorrhizal condition, both the complementarity effect and the selection effect were not significantly different from zero for biomass and P content. Based on all 15 combinations the biomass increase in the mycorrhizal condition was 1.10 $\mathrm{g}$, and the increase in P uptake $3.28 \mathrm{mg}$. Application of the formula by Loreau and Hector indicated that the complementarity effect (CE) was much larger than the selection effect. (SE) For biomass CE was $0.92 \pm 0.55 \mathrm{~g}$ (95\% confidence interval) and SE $0.18 \pm 0.17 \mathrm{~g}$. For P content CE was $2.86 \pm 1.34 \mathrm{mg}$ (SD) and SE $0.42 \pm$ $0.46 \mathrm{mg}$.

Averaged over both years, non-mycorrhizal mixtures showed significant overyielding in three out of fifteen cases (and one case of significant underyielding). Average RY $\mathrm{T}_{\text {biom }}$ was 1.09. Plant $\mathrm{P}$ content was significantly higher than predicted in four non-mycorrhizal mixtures compared to the corresponding monocultures; average RYT $\mathrm{T}_{\mathrm{P}}$ was 1.12. Mycorrhizal mixtures showed significant overyielding in ten out of fifteen mixtures and significantly increased P content in eleven mixtures (Fig. 4.S1 and 4.S2 for shoot biomass; Fig. 4.S3 and Fig. 4.S4 for shoot $\mathrm{P}$ content). Average RYT $\mathrm{T}_{\text {biom }}$ was 1.18 and average RYT 1.25 . For both biomass and $\mathrm{P}$ content significant overyielding occurred more frequently in mycorrhizal mixtures than in non-mycorrhizal mixtures $(P<0.03$ in both cases). The difference in average $\mathrm{RYT}_{\text {biom }}$ and $\mathrm{RYT}_{\mathrm{P}}$ between non-mycorrhizal and mycorrhizal treatments was not significant $(\mathrm{P}=0.21$ and $\mathrm{P}=0.18$, respectively).

Mycorrhizal colonization in the mixtures was significantly higher than expected from the monoculture pots in $2012(P=0.04)$ (Fig. 4.S4). Hyphal length density was similar for monoculture and mixture treatments in $2012(P=0.43)$, but was higher in the mixtures in 2013 ( $P=0.05$; Fig. 4.2). For mycorrhizal treatments, RYT $\mathrm{T}_{\text {biom }}$ and $\mathrm{RY}_{\mathrm{P}}$ were positively correlated with $\mathrm{RY} \mathrm{T}$ based on mycorrhizal colonization $(r=0.40, P=0.015$ and $r=0.40, P=0.015$, respectively; Fig. 4.4).

Overyielding occurred mainly in pots with phytate as $\mathrm{P}$ source (all three cases of non-mycorrhizal plants; seven out of nine cases with mycorrhizal plants in both years). Plant size (and P content) followed the pattern $\mathrm{P}-\mathrm{KH}_{2} \mathrm{PO}_{4}>\mathrm{P}$ phytate $>$ P-control (Fig. 4.S1). Average mycorrhizal responsiveness differed as a function of $\mathrm{P}$ source; averaged over the three varieties it was highest for the control (56\%), followed by phytate-P (45\%) and mineral-fertilizer P (33\%). For individual varieties, mycorrhizal responsiveness in monoculture varied among varieties in $2012(197,51 \%$; ZD2, 46\%; HMY, 37\%: the average in $3 \mathrm{P}$ sources 


\section{Chapter 4}

treatments) and also varied in 2013 (197, 59\%; ZD2, 45\%; HMY, 62\%; XY335, $51 \%)$. Mycorrhizal responsiveness and mycorrhizal $\mathrm{P}$ responsiveness were higher in mixtures than in monocultures in 2012 (Fig. 4.S8).
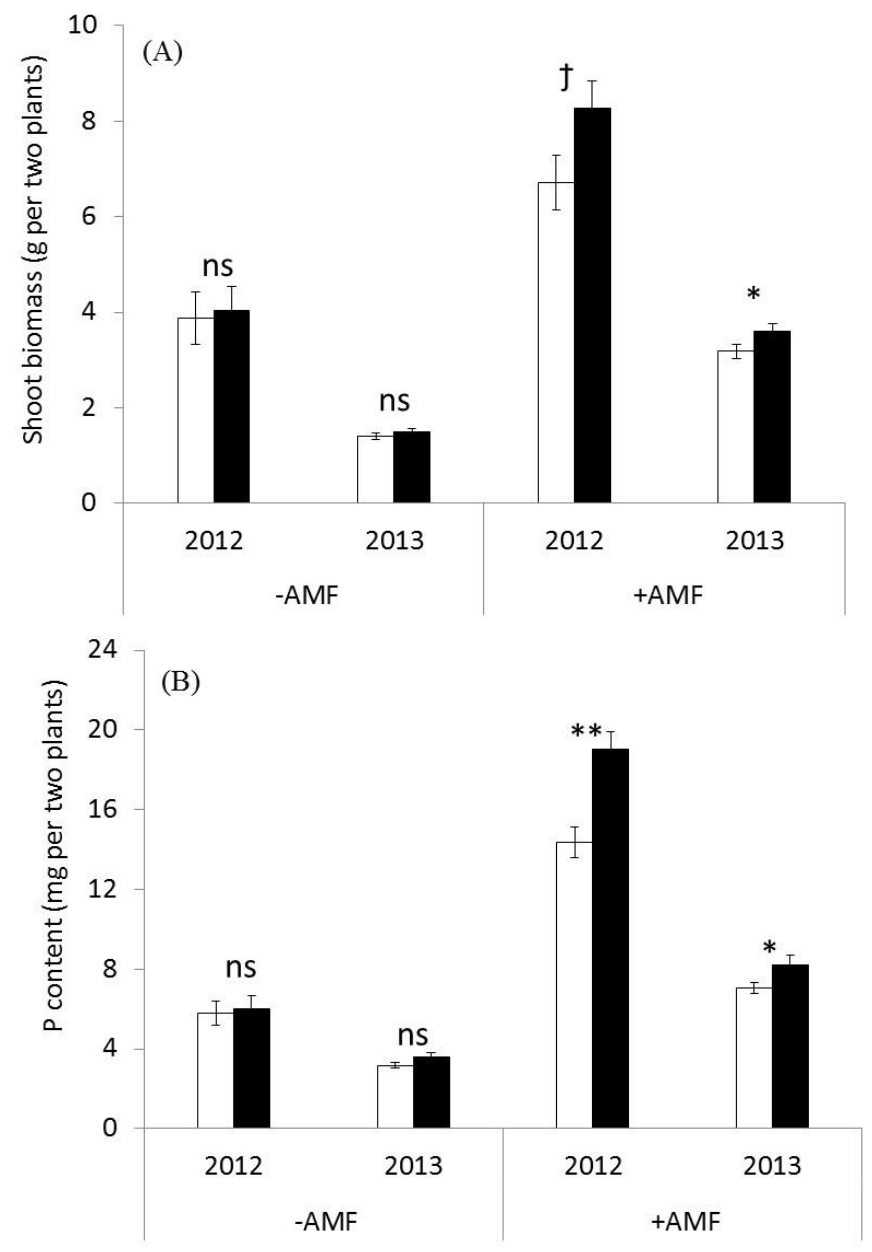

Fig.4.1. Biomass production (A) and plant $\mathrm{P}$ content (B) in mixtures of maize varieties in pot experiments performed in 2012 and 2013, dependent on inoculation with arbuscular mycorrhizae $(-/+\mathrm{AM})$. White bars refer to expected biomass / P uptake, black bars to observed biomass / $\mathrm{P}$ uptake. Bars represent means \pm SE ( $\mathrm{n}=9$ in 2012; $\mathrm{n}=6$ in 2013). $\Phi$ indicates significant differences at $P<0.1 .{ }^{*}$ or $* *$ indicates significant differences at $P<0.05$ or $P<0.01$. 


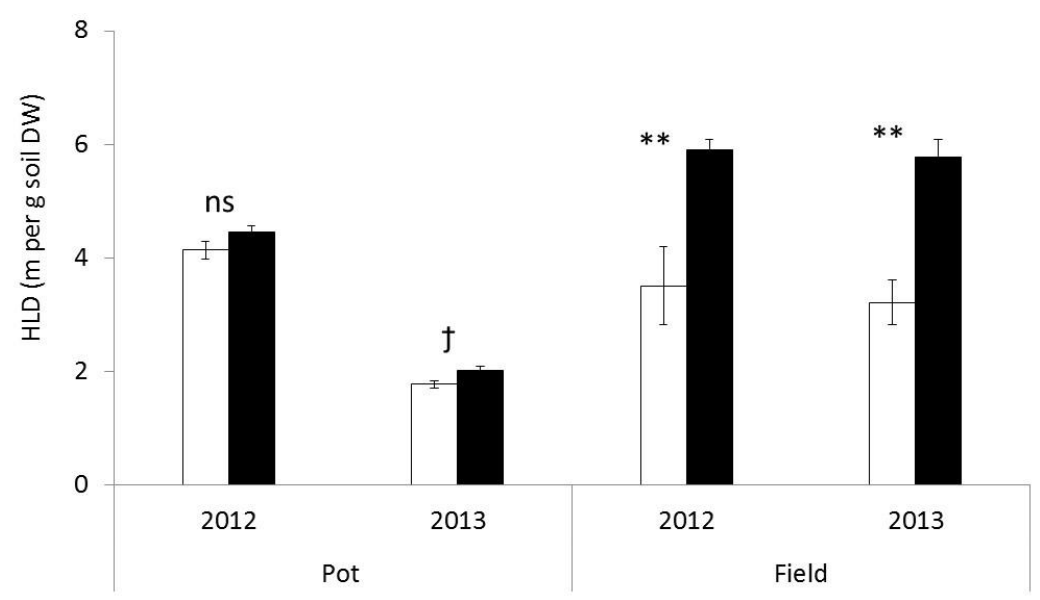

Fig.4.2. Hyphal length density (HLD) in monoculture and mixture treatments in pot and field experiments performed in 2012 and 2013. White bars refer to expected HLD, black bars to observed HLD. Bar presents mean \pm SE $(n=9$ for both monoculture and mixture in pot experiment in 2012; $n=4$ for monoculture and $n=6$ for mixture in pot experiment in 2013; $\mathrm{n}=3$ for both monoculture and mixture in field experiment in 2012; $n=4$ for monoculture and $n=6$ for mixture in field experiment in 2013). $T$ indicates significant differences at $P<0.1$. ${ }^{*}$ or $* *$ indicates significant differences at $P<0.05$ or $P<0.01$.

\section{Field experiment}

Averaged over all combinations, mixing did not affect biomass in any of the two years $(P=0.23$, in 2013), but did affect $P$ content in $2013(P=0.01, \mathrm{n}=6$; Fig. 4.3).

Among all nine mixtures tested in 2012 and 2013, significant biomass overyielding occurred in three combinations and significant underyielding occurred in one combination (Fig. 4.S3). P uptake was significantly higher than predicted, based on the component monocultures, in five out of nine mixtures, and a significant reduction occurred in one mixture (Fig. 4.S6). RYT $\mathrm{T}_{\text {biom }}$ was 1.05 and $\mathrm{RYT}_{\mathrm{P}}$ was 1.08. Both values were smaller than those observed in the pot experiments. Increase in biomass in mixtures was $19.7 \mathrm{~g}$; partitioning showed that the contribution by the complementarity effect $(14.2 \pm 18.7$ [95\% confidence interval] g) was larger than the selection effect $(5.4 \pm 5.6 \mathrm{~g})$. Increase in P uptake in mixtures was $66 \mathrm{mg}$; again CE $(54.0 \pm 43.0 \mathrm{mg})$ was much larger than SE $(12.3$ $\pm 15.8 \mathrm{mg}$; Table. 4.S4). 


\section{Chapter 4}

Hyphal length density in mixtures was significantly higher than in monocultures in both years $(P=0.007$, in 2012; $P=0.004$, in 2013) (Fig. 4.2). By mixing varieties HLD increased with around 70\% in 2012 and with 50\% in 2013. Averaged over both years HLD increased from $3.5 \mathrm{~m} \mathrm{~g}^{-1}$ soil to $6 \mathrm{~m} \mathrm{~g}^{-1}$ soil if two varieties were planted in mixtures. Differences in AM hyphal length density among different varieties in monoculture were generally small (variety 197 showed lowest HLD in monoculture in 2012, but highest HLD in monoculture in 2013). Mycorrhizal colonization was not increased in mixtures compared to the expected values based on the monocultures in $2012(P=0.26)$.

\section{Discussion}

\section{Significance of the study}

To the best of our knowledge, our study is the first to show a mycorrhizamediated role in overyielding of mixtures of different varieties of the same crop species. A mycorrhizal role in the case of overyielding of species mixtures has been shown before by Scheublin et al. (2007) and Walder et al. (2012). But in previous studies of variety mixing in one crop species (Finckh et al. 2000; Zhu et al. 2000), overyielding was attributed to enhanced pathogen resistance through dilution. In both pot and field experiments, the partitioning of overyielding indicated a major role for the complementarity effect, and a much smaller role for the selection effect. Our study did show variation in overyielding and in the relative contribution of complementarity and selection effects. This variation indicates the importance of specific traits and trait combinations (including traits related to mycorrhizal functioning) of the various varieties for the explanation of overyielding and the balance between competition (as indicated by the small positive selection effect) and niche differentiation (as indicated by the much larger complementarity effect). 
The arbuscular mycorrhizal symbiosis enhances $P$ uptake and increases productivity by mixtures of maize varieties compared to monocultures
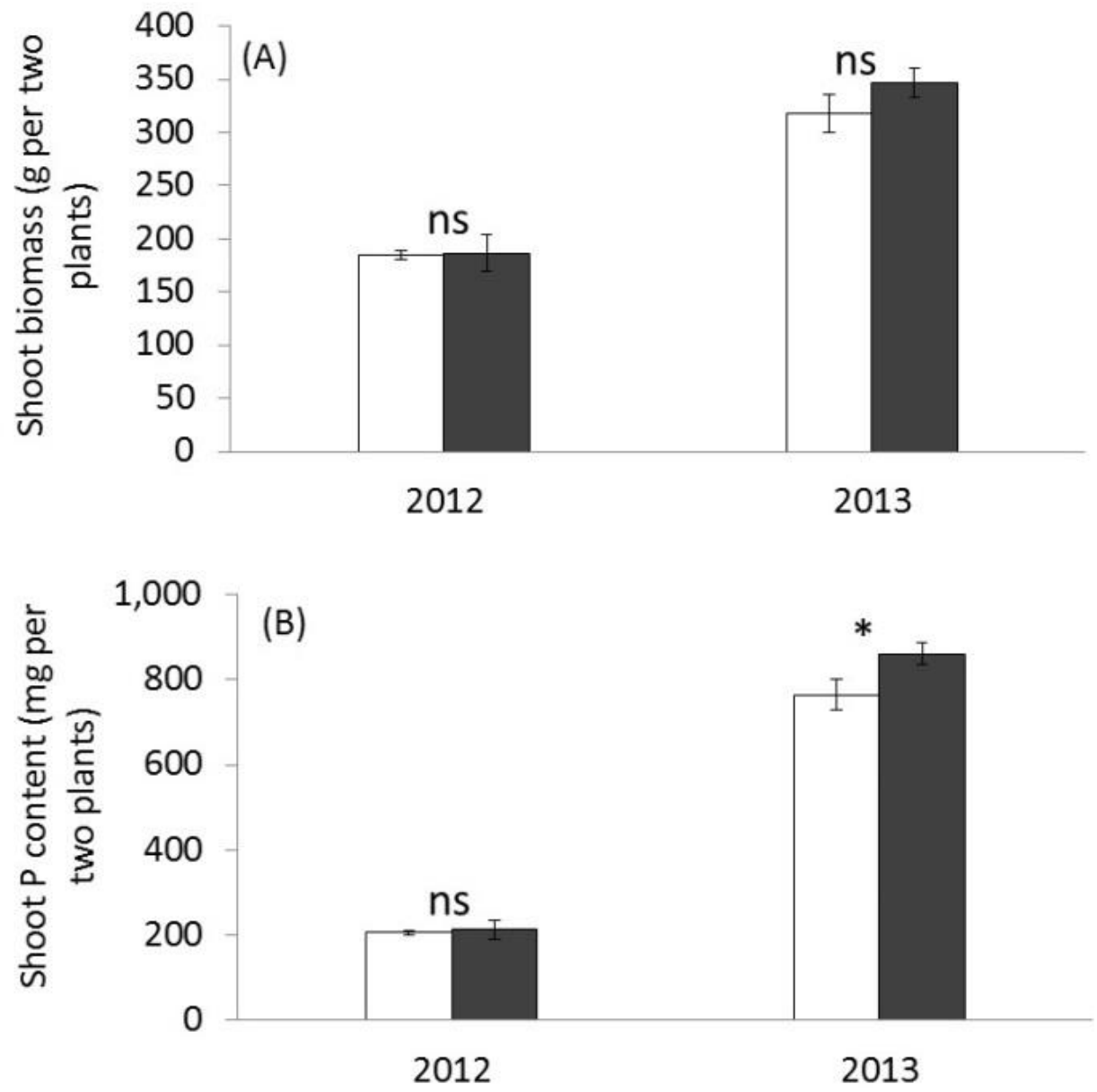

Fig. 4.3. Biomass production (A) and plant $\mathrm{P}$ content (B) in mixtures of maize varieties in field experiments performed in 2012 and 2013. White bars refer to expected biomass and shoot $\mathrm{P}$ content, black bars to observed biomass and shoot $\mathrm{P}$ content. Bar presents mean \pm SE $(n=3$ in 2012; $n=6$ in 2013). * indicates significant differences at $P<0.05$. 


\section{Chapter 4}

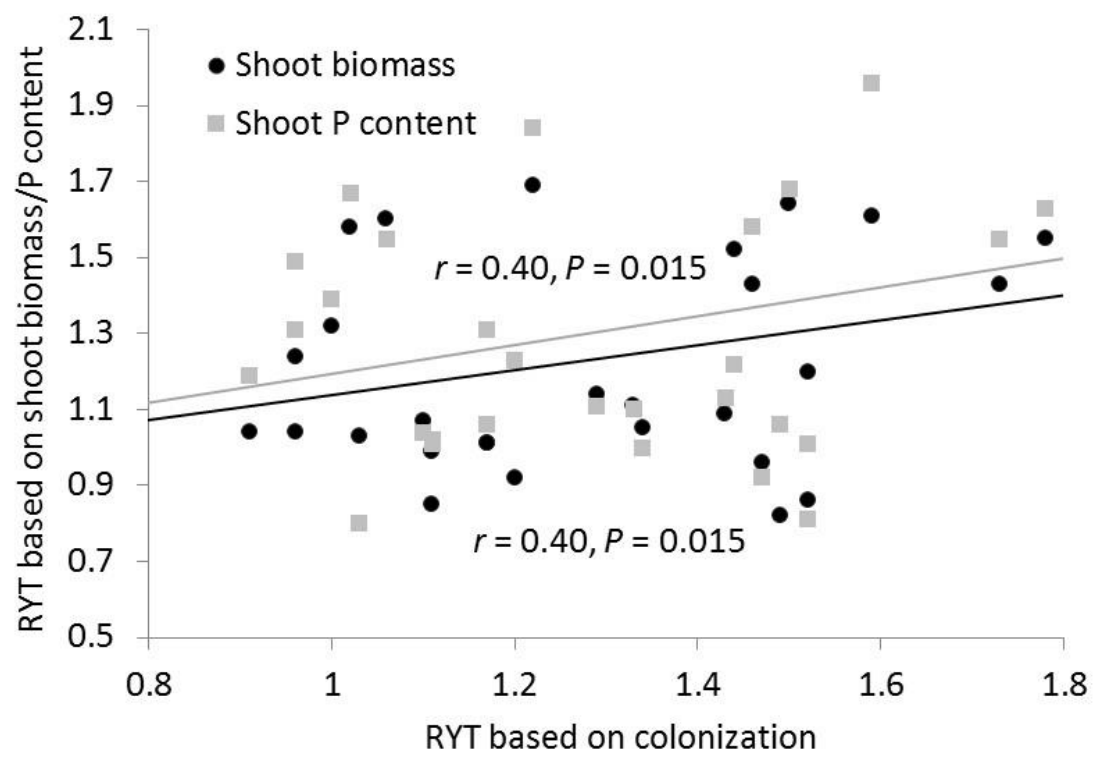

Fig. 4.4. The relationship between RYT based on colonization and RYT shoot biomass/ shoot P content (data from 2012 pot experiment; Pearson coefficient, $P<$ $0.05)$.

\section{Mycorrhizal, but not non-mycorrhizal mixtures, show overyielding}

We observed, when averaged over all treatments in both years, overyielding in terms of biomass and shoot $\mathrm{P}$ uptake in mycorrhizal mixtures and not or hardly so in non-mycorrhizal mixtures. At the same time we observed increases in hyphal length density in mixtures compared with monocultures. It seems therefore logical to explain the mechanism of overyielding by a mixture-induced increase in mycorrhizal abundance (as evidenced by higher hyphal length density and/or fractional root colonization; Fig. 4.2), which translated into increased P-uptake (Fig. 4.1b and 4.3b), which translated to a somewhat smaller extent into increased shoot biomass (Fig. 4.1a and 4.1b). The positive correlation between increases in AM colonization and overyielding in biomass and P uptake (Fig. 4.4) and the observation that mycorrhizal $(\mathrm{P})$ responsiveness was higher in mixtures than predicted from the monocultures further support the causal role of mycorrhiza in overyielding. The positive relation between HLD and P uptake (resulting in higher 


\section{The arbuscular mycorrhizal symbiosis enhances $P$ uptake and increases productivity by mixtures of maize varieties compared to monocultures}

biomass) had been earlier described by Jakobsen et al. (1992a) and Munkvold et al. (2004). In our interpretation therefore, the mycorrhizal symbiosis was the driver of overyielding, not the response variable whereby larger plants provided more $\mathrm{C}$ below-ground that alleviated C-limitation by the AMF (see also Chapter 5 for an analogous argument). These results validate the first hypothesis but, more importantly, invalidate both our second and third hypothesis.

In the 15 cases of non-mycorrhizal plants we noted one instance of significant underyielding (where $\mathrm{KH}_{2} \mathrm{PO}_{4}$ was added) and three cases of overyielding in mixtures compared to monocultures. Apparently the differences among maize varieties were too small to result in differential ability to acquire $\mathrm{P}$ (the growth-limiting element in our study) and there was therefore no complementarity. However, cases of overyielding in the non-mycorrhizal condition in pots where phytate-P has been added, do not exclude the possibility that there is genetic variation among maize varieties in the ability to acquire $\mathrm{P}$ from phytate (see also Chapter 3).

Somewhat unexpectedly, overyielding occurred both in pot experiments with one species of AMF (Funneliformis mosseae), where the common mycorrhizal network was hypothesized to reduce niche differentiation between varieties and in the field with a more diverse AMF assemblage, where different AMF species may have contributed to niche differentiation (Montesinos-Navarro et al. 2012). In cases of pot experiments with only one mycorrhizal fungus, Klironomos et al. (2000) hypothesized less overyielding in species-rich plant communities because of increased niche overlap due to the common mycorrhizal network. Under such conditions of reduced niche overlap, competitive inequality between different species or varieties would become more important. The literature only partly confirms that hypothesis. While some studies found a coordinated response between plant investment in the mycorrhizal network and plant benefit from that network, thereby amplifying competitive inequalities (Fellbaum et al. 2014; Weremijewicz and Janos 2013), other studies summarized by Van der Heijden and Horton (2009) noted a more variable outcome in how mycorrhizal networks could modify competitive relationships. We are currently analysing the fungi on the roots of the various varieties of the field experiment, to test to what extent plant selectivity (that allows varieties to select their own AMF assemblage, see Chapter 2) played a role. Preliminary data from the field experiment indicate that variety mixtures had a higher AMF richness than monocultures (on average 7 molecular 


\section{Chapter 4}

taxa in monocultures versus 10 in mixtures; Fei, unpublished results), supporting complementarity in mycorrhizal functioning.

\section{Practical implications}

In order to partition the overyielding in selection and complementarity effects, we applied the formula of Loreau and Hector (2001). Mathematically, application of that formula is straightforward in the case of a two-species or two-variety mixture where the experimenter has full control over plant species or variety choice. However, we admit that the biological interpretation of that partitioning may not be straightforward in such cases (Fox 2005) and that the terminology, especially with regard to the term selection effect, is potentially confusing.

As RYT may provide a biased picture (in case there are large size differences between plants a higher RYT may not be agronomically attractive, because of lower absolute yields if the higher relative yield is especially due to the subordinate species, hence in cases of a negative selection effect), we also assessed the occurrence of transgressive ( $=$ absolute) overyielding. Cases of transgressive overyielding were never significant $(P>0.05$ in all cases) in the greenhouse and in the field. In the pot experiments, there were 8 cases of 15 showing transgressive overyielding in terms of shoot biomass, and 12 cases of 15 in terms of $\mathrm{P}$ content in the presence of AMF; without AMF, 4 cases and 5 cases in terms of shoot biomass and P content, respectively. Applying Fisher's exact test indicated that for biomass there was no difference between the non-mycorrhizal and mycorrhizal treatments, but that transgressive overyielding in terms of $\mathrm{P}$ content occurred significantly more frequently in mycorrhizal mixtures than in non-mycorrhizal mixtures $(P<0.03)$. In the field experiment, there were 4 cases of 9 showing transgressive overyielding in terms of shoot biomass, and 5 cases showing transgressive overyielding in terms of $\mathrm{P}$ uptake. From these data we conclude that it is highly unlikely that there is a yield penalty (in terms of absolute yield) when combining different crop varieties in the same field. As interplant distances, as used by us in the field experiments, are similar to these distances in China's agriculture, we conclude that our design realistically mimicked competition and facilitation between varieties of the same species.

However, we cannot yet predict the outcome of specific variety mixtures based on a mechanistic understanding of the effects of various trait combinations. 
The arbuscular mycorrhizal symbiosis enhances $P$ uptake and increases productivity by mixtures of maize varieties compared to monocultures

Further studies in that direction are therefore important in order to translate these observations into recommendations for agricultural management practices. 


\section{Chapter 4}

\section{Supplementary material}
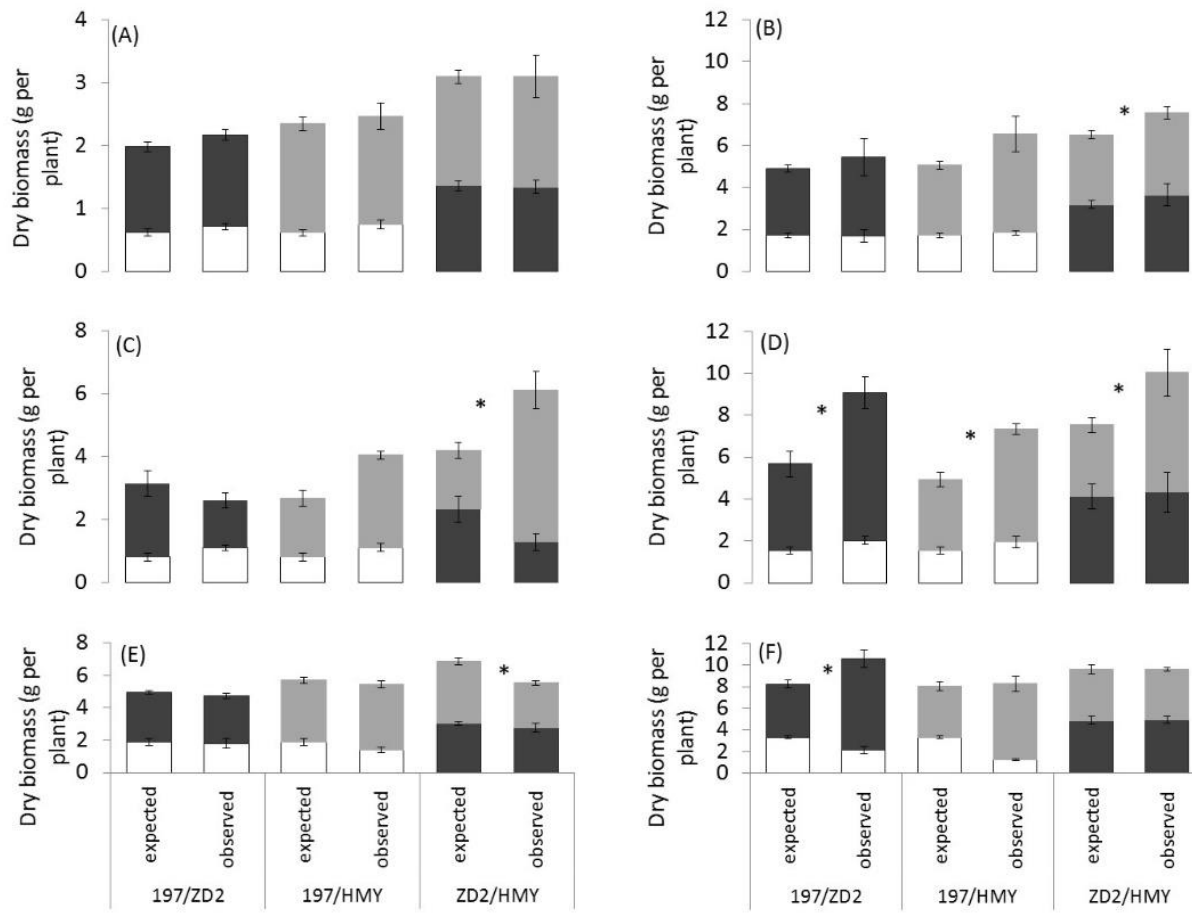

Fig. 4.S1. Dry biomass of maize genotypes (197, open bars; HMY, grey bars; ZD2, black bars) in pot experiment in 2012 without (A, C, E) and with $\mathrm{AMF}(\mathrm{B}, \mathrm{D}, \mathrm{F})$ in Pcontrol treatment (A, B), P-phytate treatment (C, D), and $\mathrm{P}_{-} \mathrm{KH}_{2} \mathrm{PO}_{4}(\mathrm{E}, \mathrm{F})$. "observed" refers to results from the mixtures. "expected" refers to the expected biomass based on the results of the corresponding monocultures. Bar presents mean $\pm \mathrm{SE}(\mathrm{n}=4) . *$ indicates significant differences between expected and observed values at $\mathrm{P}<0.05$. 

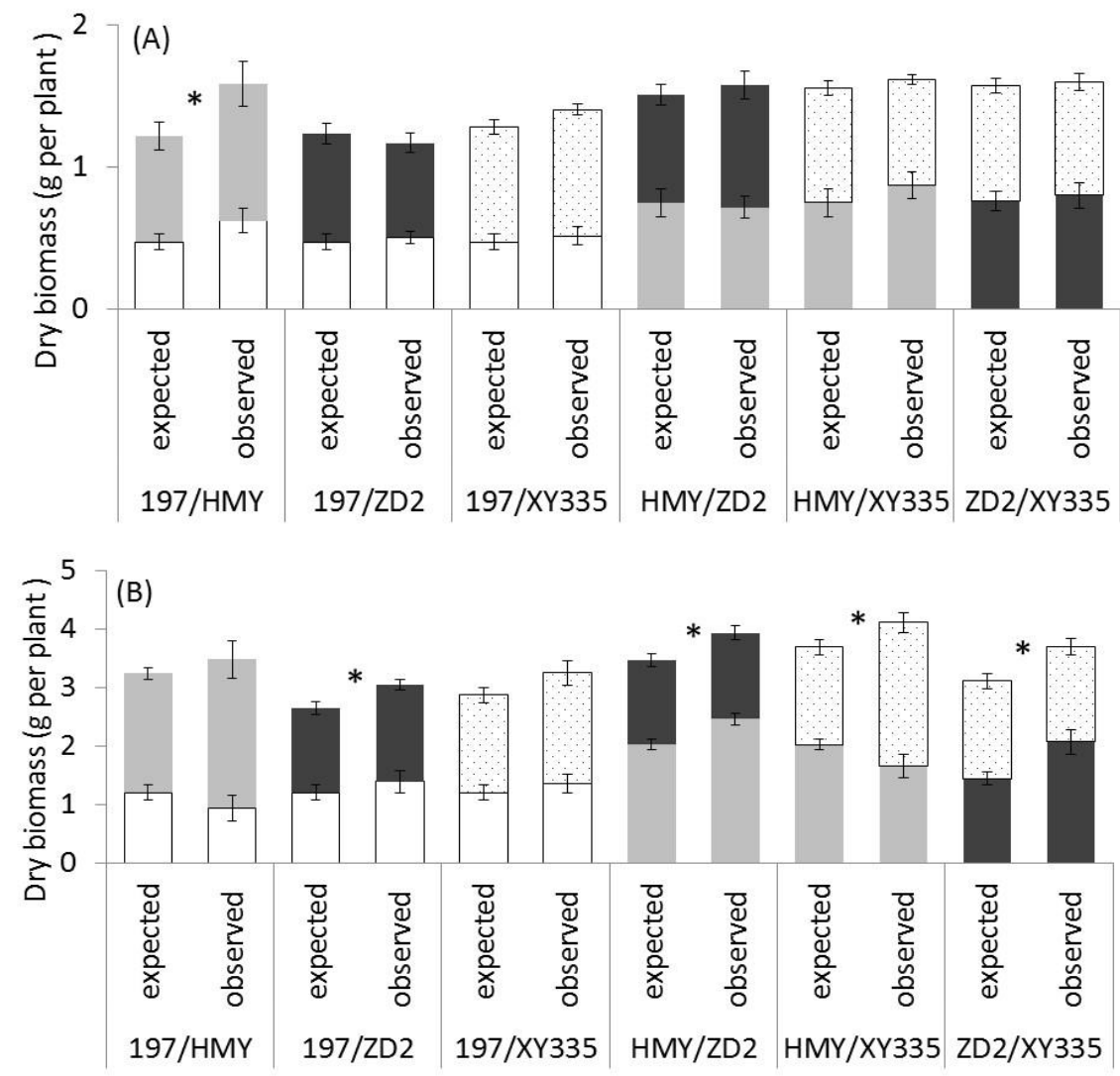

Fig. 4.S2. Dry biomass of maize genotypes (197, open bars; HMY, grey bars; ZD2, black bars; XY335, dotted bars) in pot experiment in 2013 without (A) and with (B) AMF. "observed" refers to results from the mixtures. "expected" refers to the expected biomass based on the results of the corresponding monocultures. Bar presents mean $\pm \mathrm{SE}(\mathrm{n}=4)$. * indicates significant differences between expected and observed values at $P<0.05$. 


\section{Chapter 4}
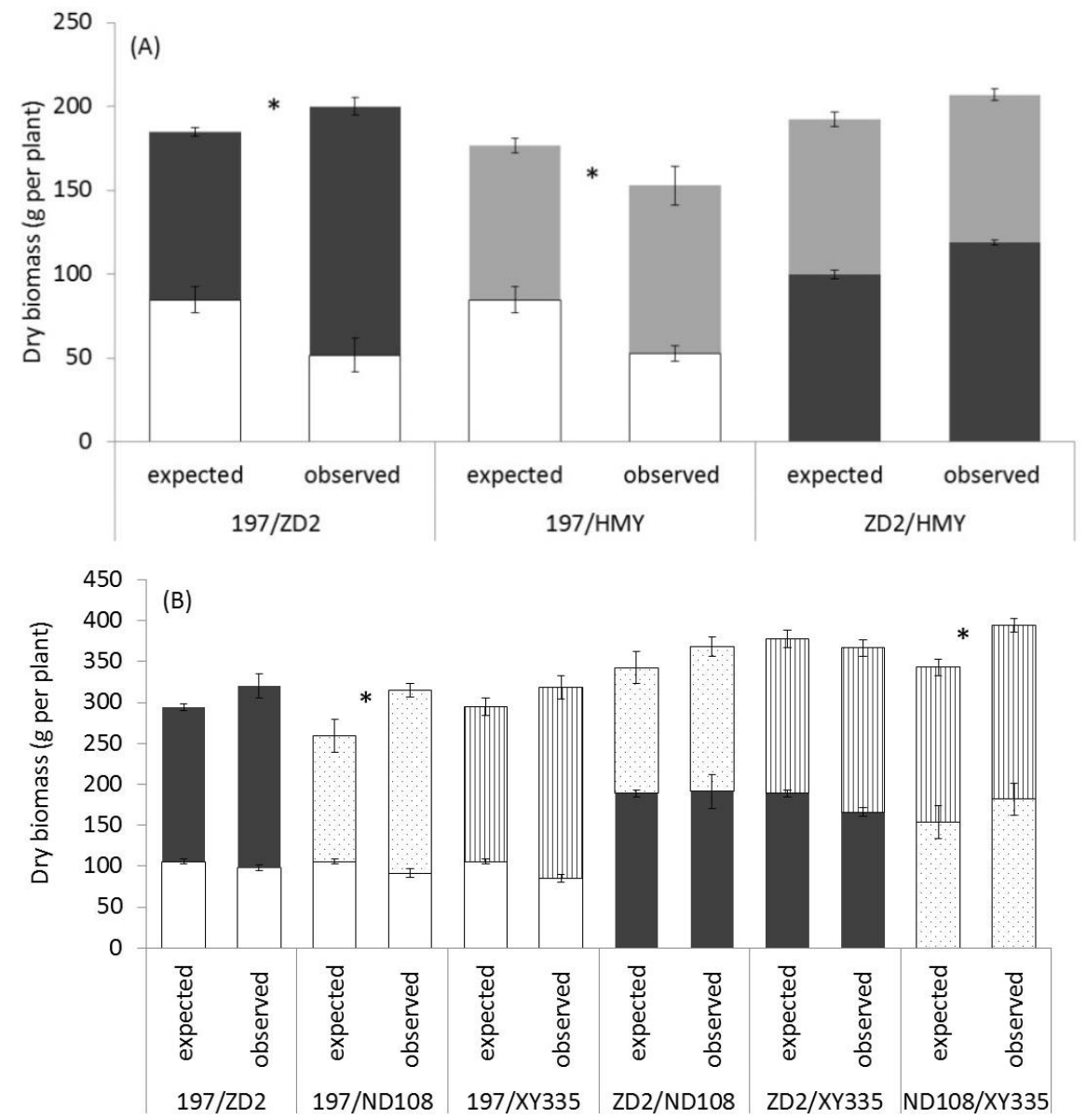

Fig. 4.S3. Dry biomass of maize genotypes (197, open bars; HMY, grey bars; ZD2, black bars; XY335, dotted bars; ND108, hatched) in field experiment in 2012 (A) and 2013 (B). "observed" refers to results from the mixtures. "expected" refers to the expected biomass based on the results of the corresponding monocultures. Bar presents mean $\pm \mathrm{SE}(\mathrm{n}=3,2012 ; \mathrm{n}=4,2013)$. * indicates significant differences between expected and observed values at $P<0.05$. 


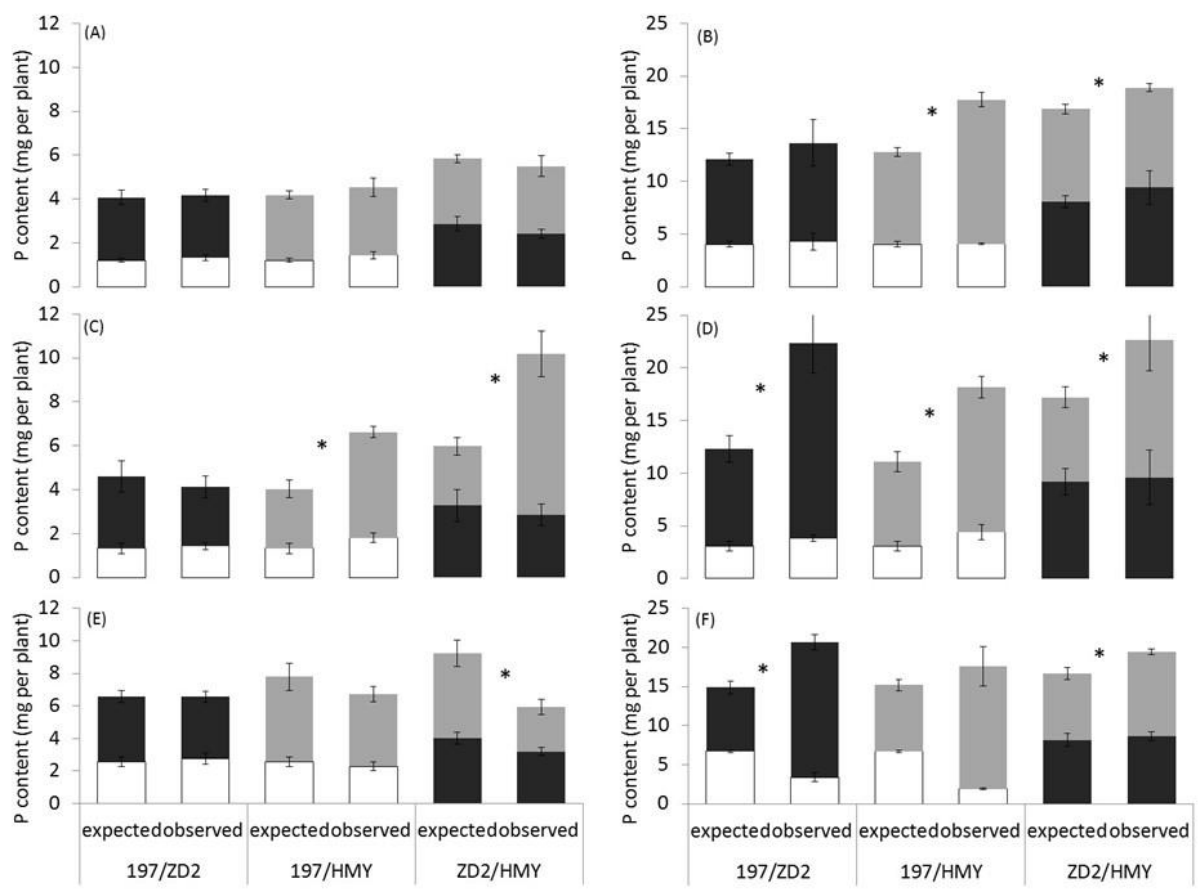

Fig. 4.S4. Shoot P content of maize genotypes (197, open bars; HMY, grey bars; ZD2, black bars) in pot experiment in 2012 without (A, C, E) and with AMF (B, D, F) in Pcontrol treatment (A, B), P-phytate treatment $(\mathrm{C}, \mathrm{D})$, and $\mathrm{P}_{-} \mathrm{KH}_{2} \mathrm{PO}_{4}(\mathrm{E}, \mathrm{F})$. "observed" refers to results from the mixtures. "expected" refers to the expected biomass based on the results of the corresponding monocultures. Bar presents mean $\pm \mathrm{SE}(\mathrm{n}=4) . *$ indicates significant differences between expected and observed values at $P<0.05$. 


\section{Chapter 4}
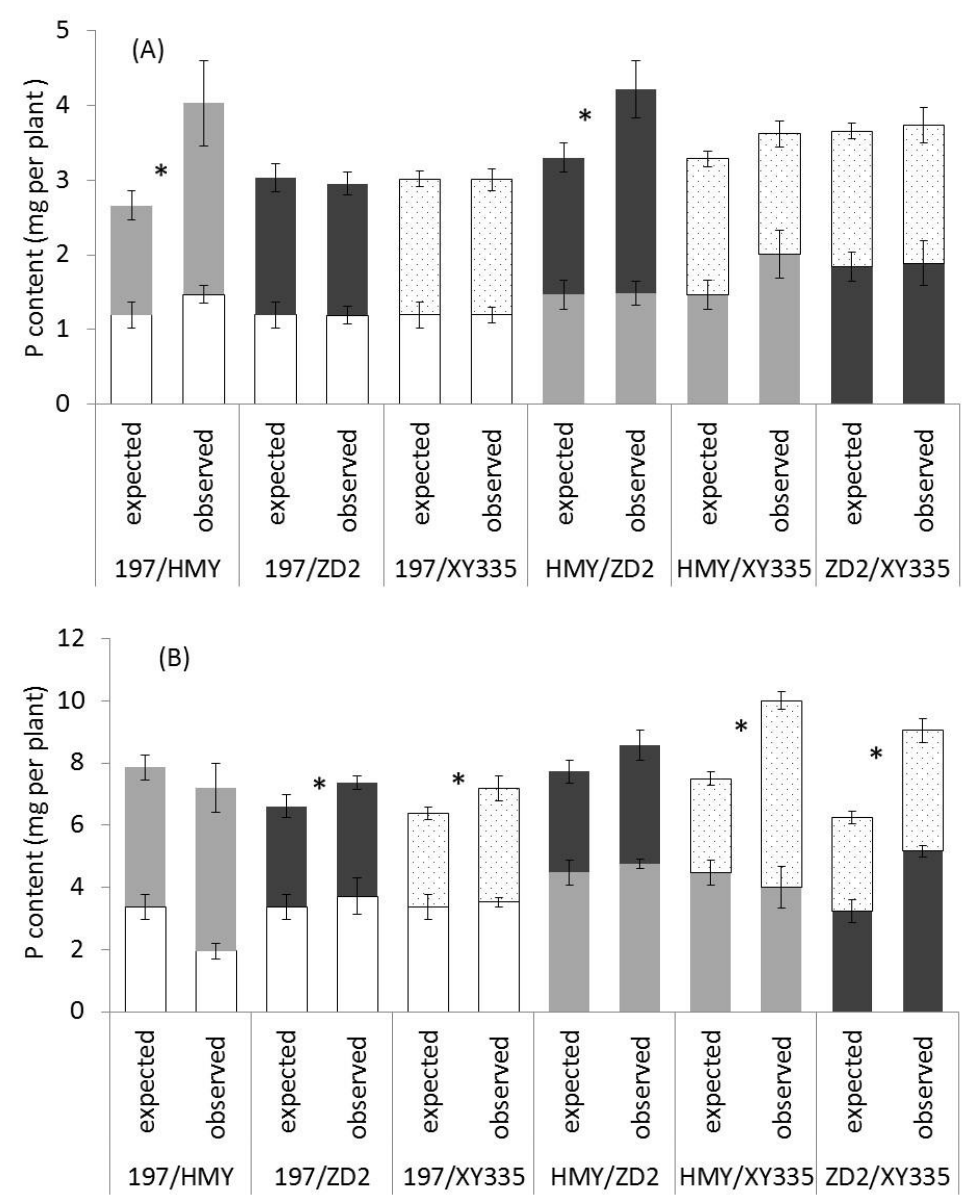

Fig. 4.S5. Shoot P content of maize genotypes (197, open bars; HMY, grey bars; ZD2, black bars; XY335, dotted bars) in pot experiment in 2013 without (A) and with (B) AMF. "observed" refers to results from the mixtures. "expected" refers to the expected biomass based on the results of the corresponding monocultures. Bar presents mean $\pm \mathrm{SE}(\mathrm{n}=4)$. * indicates significant differences between expected and observed values at $P<0.05$. 


\section{productivity by mixtures of maize varieties compared to monocultures}
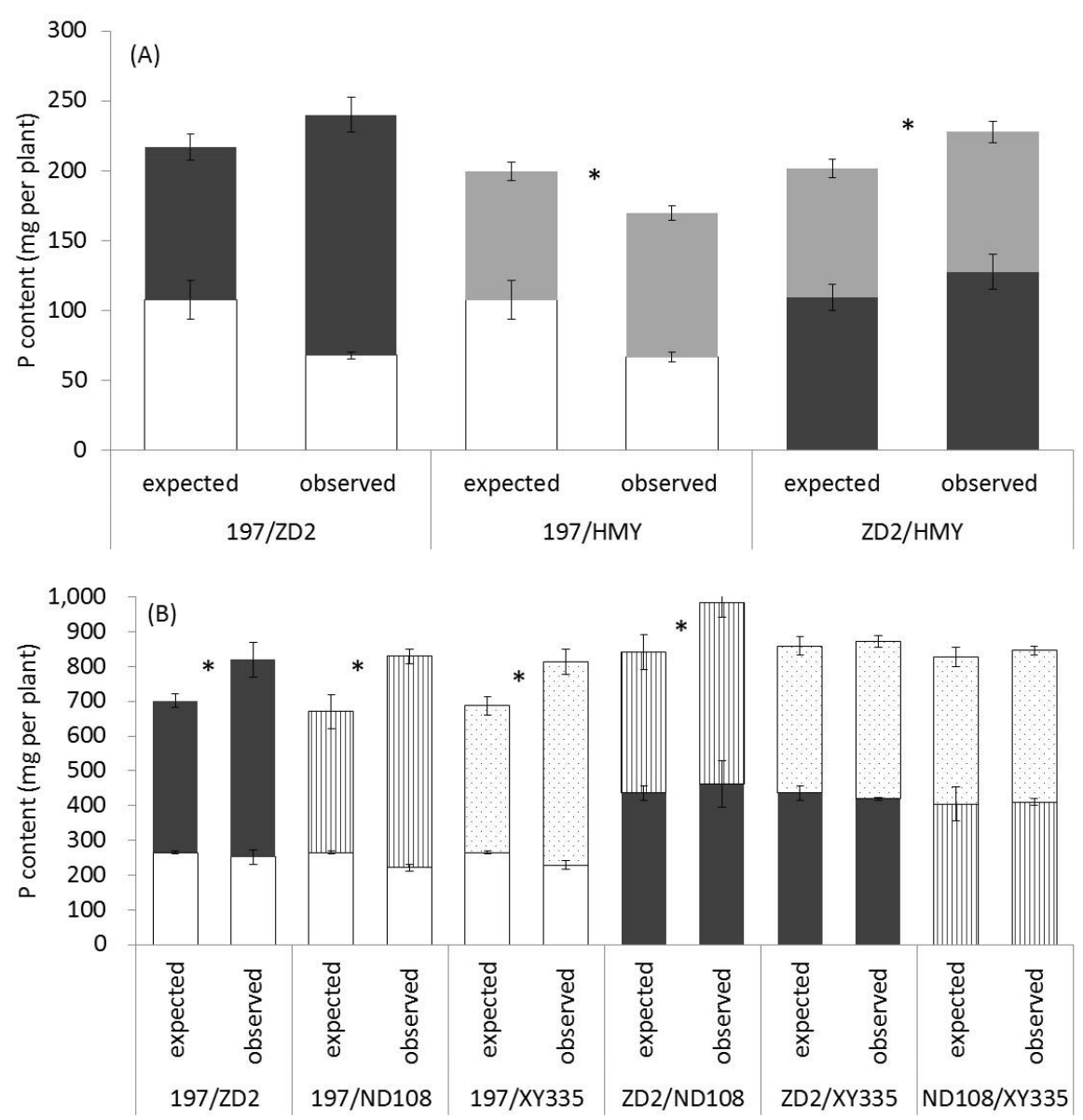

Fig. 4.S6. Shoot P content of maize genotypes (197, open bars; HMY, grey bars; ZD2, black bars; XY335, dotted bars; ND108, hatched) in field experiment in 2012 (A) and 2013 (B). "observed" refers to results from the mixtures. "expected" refers to the expected biomass based on the results of the corresponding monocultures. Bar presents mean $\pm \mathrm{SE}(\mathrm{n}=3,2012 ; \mathrm{n}=4,2013)$. * indicates significant differences between expected and observed values at $P<0.05$. 


\section{Chapter 4}

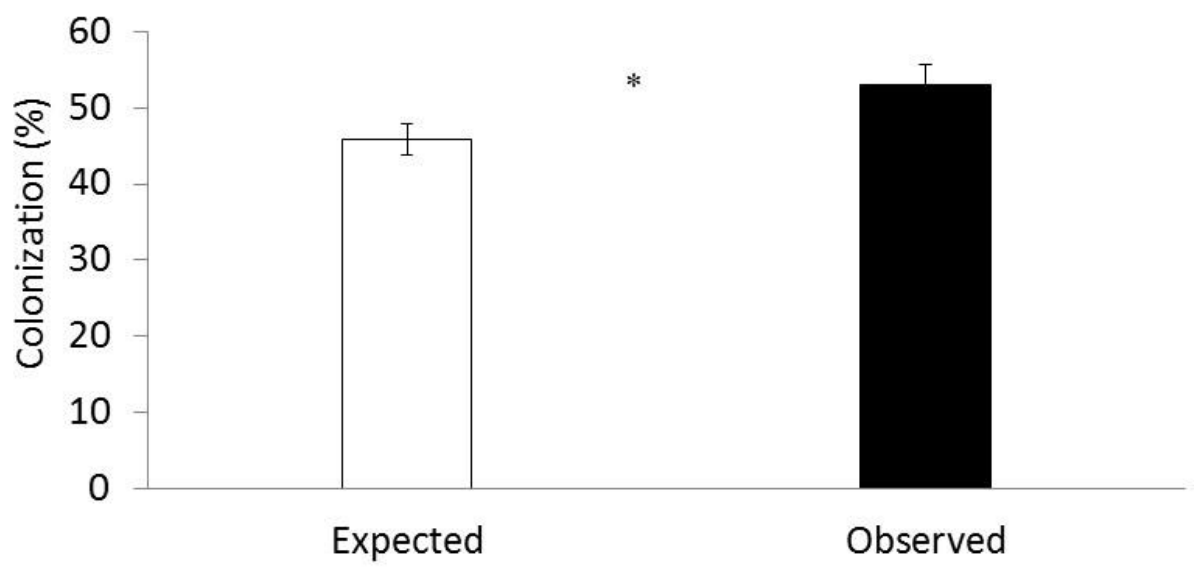

Fig. 4.S7. Mycorrhizal colonization in 2012 pot experiment. White bars refer to expected colonization, black bars to observed colonization. Bar presents mean $\pm \mathrm{SE}$ $(\mathrm{n}=9)$. * indicate significant differences between expected and observed at $P<0.05$. 
The arbuscular mycorrhizal symbiosis enhances $P$ uptake and increases productivity by mixtures of maize varieties compared to monocultures
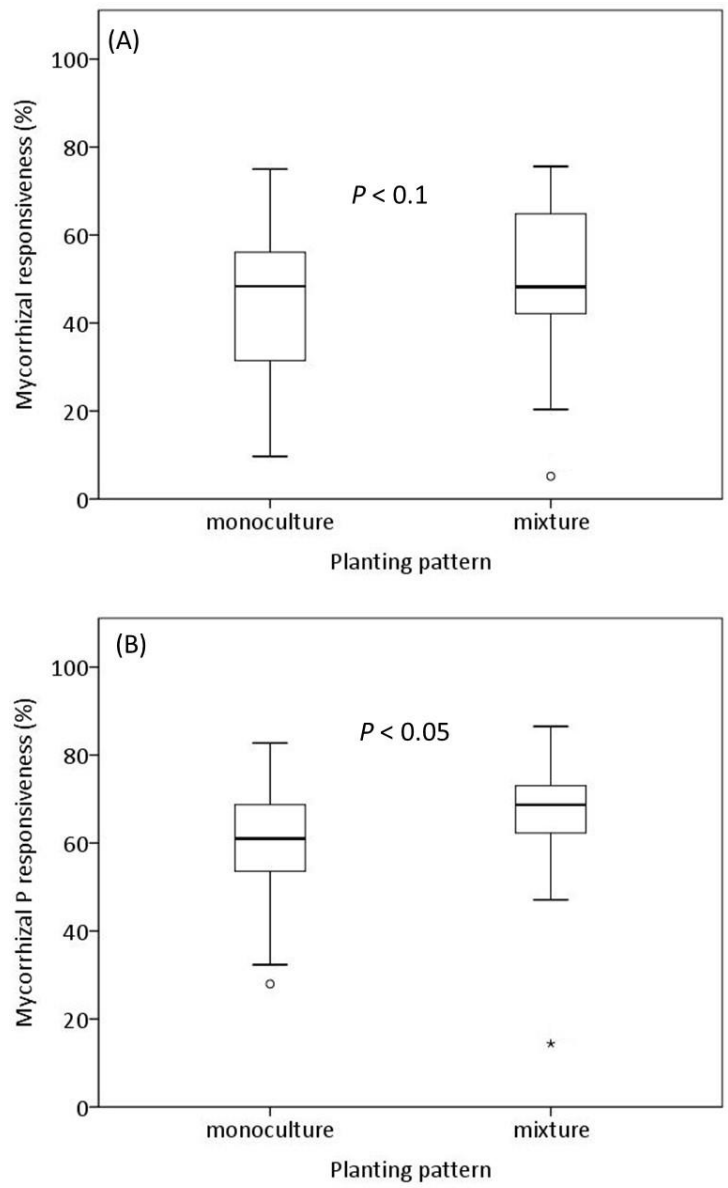

Fig. 4.S8. Mycorrhizal responsiveness (A) and mycorrhizal P responsiveness (B) in monoculture or in mixture (data from 2012 pot experiment; $P<0.05$ ). 


\section{Chapter 4}

Table 4S1. Relative yield total $( \pm \mathrm{SE})$ based on shoot biomass or shoot $\mathrm{P}$ content for different maize varieties combinations with (AMF) or without (non) mycorrhiza in 2012 and 2013 pot experiments.

\begin{tabular}{|c|c|c|c|c|c|}
\hline Year & Combination & P source & Mycorrhiza & $\mathrm{RY}_{\mathrm{biom}}$ & $\mathrm{RYT}_{\mathrm{P}}$ \\
\hline 2012 & 197/ZD2 & No P & non & $1.14 \pm 0.09$ & $1.08 \pm 0.11$ \\
\hline \multirow[t]{17}{*}{ Pot } & 197/HMY & No P & non & $1.13 \pm 0.06$ & $1.14 \pm 0.07$ \\
\hline & ZD/HMY & No P & non & $0.99 \pm 0.09$ & $0.95 \pm 0.06$ \\
\hline & 197/ZD2 & No P & AMF & $1.09 \pm 0.18$ & $1.11 \pm 0.18$ \\
\hline & 197/HMY & No P & AMF & $1.24 \pm 0.15$ & $1.17 \pm 0.15$ \\
\hline & ZD/HMY & No P & $\mathrm{AMF}$ & $1.16 \pm 0.07$ & $1.14 \pm 0.09$ \\
\hline & 197/ZD2 & $\mathrm{KH}_{2} \mathrm{PO}_{4}$ & non & $0.99 \pm 0.09$ & $1.07 \pm 0.12$ \\
\hline & 197/HMY & $\mathrm{KH}_{2} \mathrm{PO}_{4}$ & non & $0.93 \pm 0.09$ & $0.90 \pm 0.10$ \\
\hline & ZD/HMY & $\mathrm{KH}_{2} \mathrm{PO}_{4}$ & non & $0.83 \pm 0.02$ & $0.69 \pm 0.05$ \\
\hline & 197/ZD2 & $\mathrm{KH}_{2} \mathrm{PO}_{4}$ & $\mathrm{AMF}$ & $1.20 \pm 0.13$ & $1.33 \pm 0.12$ \\
\hline & 197/HMY & $\mathrm{KH}_{2} \mathrm{PO}_{4}$ & $\mathrm{AMF}$ & $0.94 \pm 0.05$ & $1.05 \pm 0.07$ \\
\hline & ZD/HMY & $\mathrm{KH}_{2} \mathrm{PO}_{4}$ & $\mathrm{AMF}$ & $1.02 \pm 0.08$ & $1.21 \pm 0.12$ \\
\hline & 197/ZD2 & Phytate & non & $1.09 \pm 0.15$ & $1.06 \pm 0.17$ \\
\hline & 197/HMY & Phytate & non & $1.56 \pm 0.12$ & $1.68 \pm 0.13$ \\
\hline & ZD/HMY & Phytate & non & $1.74 \pm 0.30$ & $1.97 \pm 0.25$ \\
\hline & 197/ZD2 & Phytate & $\mathrm{AMF}$ & $1.54 \pm 0.08$ & $1.69 \pm 0.05$ \\
\hline & 197/HMY & Phytate & AMF & $1.47 \pm 0.13$ & $1.62 \pm 0.18$ \\
\hline & ZD/HMY & Phytate & AMF & $1.35 \pm 0.17$ & $1.30 \pm 0.24$ \\
\hline 2013 & 197/HMY & Phytate & non & $1.40 \pm 0.25$ & $1.79 \pm 0.31$ \\
\hline \multirow[t]{11}{*}{ Pot } & 197/ZD2 & Phytate & non & $1.03 \pm 0.18$ & $1.05 \pm 0.16$ \\
\hline & 197/XY335 & Phytate & non & $1.47 \pm 0.22$ & $1.34 \pm 0.16$ \\
\hline & HMY/ZD2 & Phytate & non & $1.10 \pm 0.15$ & $1.24 \pm 0.18$ \\
\hline & HMY/XY335 & Phytate & non & $1.10 \pm 0.11$ & $1.21 \pm 0.21$ \\
\hline & ZD2/XY335 & Phytate & non & $1.02 \pm 0.03$ & $1.05 \pm 0.09$ \\
\hline & 197/HMY & Phytate & AMF & $1.07 \pm 0.23$ & $1.02 \pm 0.21$ \\
\hline & 197/ZD2 & Phytate & AMF & $1.15 \pm 0.04$ & $1.13 \pm 0.09$ \\
\hline & 197/XY335 & Phytate & AMF & $1.57 \pm 0.07$ & $1.50 \pm 0.12$ \\
\hline & $\mathrm{HMY} / \mathrm{ZD} 2$ & Phytate & $\mathrm{AMF}$ & $1.12 \pm 0.08$ & $1.21 \pm 0.17$ \\
\hline & HMY/XY335 & Phytate & $\mathrm{AMF}$ & $1.16 \pm 0.09$ & $1.45 \pm 0.18$ \\
\hline & ZD2/XY335 & Phytate & $\mathrm{AMF}$ & $1.21 \pm 0.07$ & $1.47 \pm 0.05$ \\
\hline
\end{tabular}


The arbuscular mycorrhizal symbiosis enhances $P$ uptake and increases productivity by mixtures of maize varieties compared to monocultures

Table S2. Relative yield total ( \pm SE) based on shoot biomass or shoot P content for different maize varieties combinations in 2012 and 2013 field experiments.

\begin{tabular}{llll}
\hline \multicolumn{1}{c}{ Year } & Combination & $\mathrm{RY}_{\text {biom }}$ & $\mathrm{RYT}_{\mathrm{P}}$ \\
\hline 2012 Field & 197/ZD2 & $1.07 \pm 0.09$ & $1.13 \pm 0.14$ \\
& 197/HMY & $0.99 \pm 0.18$ & $0.97 \pm 0.19$ \\
& ZD2/HMY & $1.08 \pm 0.06$ & $1.15 \pm 0.14$ \\
\hline 2013 Field & $197 /$ ZD2 & $1.06 \pm 0.03$ & $1.13 \pm 0.10$ \\
& $197 / \mathrm{ND} 108$ & $1.20 \pm 0.11$ & $1.20 \pm 0.07$ \\
& $197 / \mathrm{XY} 335$ & $1.26 \pm 0.11$ & $1.41 \pm 0.10$ \\
& ZD2/ND108 & $1.12 \pm 0.11$ & $1.16 \pm 0.12$ \\
& ZD2/XY335 & $0.98 \pm 0.03$ & $1.03 \pm 0.02$ \\
& ND108/XY335 & $1.18 \pm 0.06$ & $1.05 \pm 0.07$ \\
\hline
\end{tabular}




\section{Chapter 4}

Table S3. Partitioning of overyielding $(\Delta \mathrm{Y})$ in terms of shoot biomass ( $\mathrm{g}$ ) into complementarity effect (CE) and selection effect (SE) in the pot experiments.

\begin{tabular}{|c|c|c|c|c|c|c|c|c|}
\hline \multirow{2}{*}{ Year } & \multirow[b]{2}{*}{ Combination } & \multirow[b]{2}{*}{ Fertilizer } & \multicolumn{3}{|c|}{-AMF } & \multicolumn{3}{|c|}{$+\mathrm{AMF}$} \\
\hline & & & $\Delta \mathrm{Y}$ & $\mathrm{CE}$ & SE & $\Delta \mathrm{Y}$ & CE & SE \\
\hline \multirow[t]{9}{*}{2012} & 197/ZD2 & No P & 0.19 & 0.22 & -0.04 & 0.53 & 0.41 & 0.13 \\
\hline & 197/HMY & No P & 0.11 & 0.24 & -0.13 & 1.48 & 1.21 & 0.27 \\
\hline & ZD2/HMY & No P & 0.01 & 0.00 & 0.01 & 1.04 & 1.04 & 0.00 \\
\hline & 197/ZD2 & Phytate & -0.53 & 0.00 & -0.53 & 3.40 & 2.89 & 0.52 \\
\hline & 197/HMY & Phytate & 1.37 & 1.26 & 0.11 & 2.40 & 2.10 & 0.29 \\
\hline & ZD2/HMY & Phytate & 1.92 & 2.38 & -0.47 & 2.50 & 2.73 & -0.23 \\
\hline & 197/ZD2 & $\mathrm{KH}_{2} \mathrm{PO}_{4}$ & -0.23 & -0.23 & 0.00 & 2.37 & 1.52 & 0.85 \\
\hline & 197/HMY & $\mathrm{KH}_{2} \mathrm{PO}_{4}$ & -0.23 & -0.54 & 0.31 & 0.24 & -0.52 & 0.76 \\
\hline & ZD2/HMY & $\mathrm{KH}_{2} \mathrm{PO}_{4}$ & -1.30 & -1.24 & -0.06 & 0.05 & 0.04 & 0.00 \\
\hline \multirow[t]{6}{*}{2013} & 197/HMY & Phytate & 0.37 & 0.37 & 0.00 & 0.24 & 0.05 & 0.19 \\
\hline & 197/ZD2 & Phytate & -0.06 & -0.04 & -0.03 & 0.39 & 0.39 & 0.00 \\
\hline & 197/XY335 & Phytate & 0.12 & 0.12 & 0.00 & 0.38 & 0.38 & 0.00 \\
\hline & HMY/ZD2 & Phytate & 0.06 & 0.06 & 0.00 & 0.46 & 0.40 & 0.06 \\
\hline & HMY/XY335 & Phytate & 0.06 & 0.06 & -0.01 & 0.42 & 0.53 & -0.12 \\
\hline & ZD2/XY335 & Phytate & 0.03 & 0.03 & 0.00 & 0.59 & 0.64 & -0.05 \\
\hline
\end{tabular}


The arbuscular mycorrhizal symbiosis enhances $P$ uptake and increases productivity by mixtures of maize varieties compared to monocultures

Table S4. Partitioning of overyielding $(\Delta \mathrm{Y})$ in terms of shoot biomass (g) into complementarity effect (CE) and selection effect (SE) in the field experiments.

\begin{tabular}{lllll}
\hline Year & Combinations & $\Delta \mathrm{Y}$ & $\mathrm{CE}$ & $\mathrm{SE}$ \\
\hline 2012 & 197/ZD2 & 15.27 & 8.64 & 6.62 \\
& 197/HMY & -24.09 & -25.80 & 1.71 \\
& ZD2/HMY & 14.83 & 13.92 & 0.90 \\
2013 & 197/ZD2 & 26.10 & 15.70 & 10.39 \\
& 197/ND108 & 55.26 & 41.06 & 14.21 \\
& 197/XY335 & 24.00 & 6.16 & 17.84 \\
& ZD2/ND108 & 25.61 & 27.95 & -2.34 \\
& ZD2/XY335 & -11.24 & -11.25 & 0.01 \\
& ND108/XY335 & 51.58 & 52.55 & -0.98
\end{tabular}





\section{CHAPTER 5}

Influence of maize varieties and arbuscular mycorrhizal fungi on intraspecific plant - soil feedback

Xinxin Wang, Ellis Hoffland, Gu Feng, Thomas W. Kuyper 


\section{Chapter 5}

\section{Abstract}

1. Our aim was to explore plant - soil feedback dynamics by two different maize varieties and the role of arbuscular mycorrhizal fungi in this feedback.

2. We carried out a two-phase experiment in a greenhouse, including conditioning phase and feedback phase to determine plant - soil feedbacks in the absence and presence of different arbuscular mycorrhizal fungal (AMF) species.

3. In the conditioning phase sterilized soil was conditioned with a maize variety in the absence or presence of different AMF inocula; in the feedback phase each soil community created by the two varieties was used to grow each variety in its own (home) and in the other (away) soil. We calculated a scaled pairwise interaction coefficient, based on biomass and P uptake, to quantify feedback strength caused by the various soil communities.

4. In the conditioning phase, both maize varieties were differentially influenced by different AMF species compared to non-mycorrhizal controls.

5. In the feedback phase for the non-mycorrhizal condition the interaction coefficient was negative for both biomass and P uptake, whereas it was positive in the mycorrhizal condition for $\mathrm{P}$ uptake. For biomass, it was positive for three AMF treatments, but negative for the treatment with Gigaspora margarita. The interaction coefficient was largest in the mixture of three AMF species.

5. Conclusion: Positive intraspecific feedback dynamics in mycorrhizal and negative intraspecific feedback dynamics in non-mycorrhizal maize plants raise questions how maize varieties may select more beneficial AMF.

Keywords: maize varieties; AMF species; plant - soil feedback; soil conditioning; scaled interaction coefficient; selectivity 


\section{Introduction}

Plant - soil feedback (PSF) as a driver of plant community dynamics and of diversity - productivity relationships has received increasing attention (Harrison and Bardgett 2010; Ravenek et al. 2014; Van de Voorde et al. 2011). Plant - soil feedbacks originate because the growth of a plant species affects its soil, including biological, chemical and physical characteristics (Bezemer et al. 2006; Ehrenfeld et al. 2005; Klironomos 2002). These soil factors can generate either positive or negative feedback dynamics (Bever et al. 1997). A positive feedback implies that a plant species alters its soil environment in a way that increases its own fitness or growth relative to that of other plant species; a negative feedback implies that a plant species alters its soil environment in a way that decreases its own fitness or growth relative to that of other plant species (Bever 2003; Bever et al. 1997).

Most studies on PSF have shown that soil biota play a crucial role in determining the direction and magnitude of that feedback (Bais et al. 2006; Van der Putten et al. 1993; Zobel and Öpik 2014). Up to now, studies have tested PSF dynamics by pairwise comparisons of plant growth on their own soils and on soils conditioned by different plant species (de Kroon et al. 2012). It is still unknown to what extent intraspecific PSF dynamics are similar to interspecific PSF dynamics. Especially, for agricultural crops the sign of the feedback in temporal sequences of different varieties of the same crop can be important for crop management. Compared to the increasing interest in the role of intraspecific variation for complementarity and facilitation (Brooker et al. 2015; Brooker et al. 2016), the topic of intraspecific plant - soil feedbacks have received very little attention.

Arbuscular mycorrhizal fungi (AMF) can enhance plant growth by increasing access to limiting soil resources, specifically relatively immobile nutrients like phosphorus $(\mathrm{P})$, thereby influencing plant development, productivity and fitness (Smith and Read 2008). Plant species respond in a species-specific way to different AMF (Callaway 1998; Klironomos 2003; Van der Heijden et al. 1998). Moreover, AMF leave legacies (in terms of inoculum potential and the species composition of the AMF community) for subsequent plants (including those of their own species) in a specific way. Plants with their associated AMF can therefore generate both positive and negative feedbacks (Umbanhowar and McCann 2005). AMF create positive feedback if they associate with (or are selected by) plants that derive most benefit from that association; however, plants 


\section{Chapter 5}

can also be preferentially associated with those AMF from which they do not receive the largest benefit, while a competing species derives more benefit from those AMF. Bever (2002a, b) described how AMF generated negative feedback dynamics, because the plants did not associate with the AMF from which they derived the largest benefit. While many studies have implicated arbuscular mycorrhiza in generating positive feedback dynamics, little is known about the generality of feedback effects due to different AMF species and communities. The extent to which different ecotypes or varieties of the same (agriculturally important) plant species differ in or benefit from the AMF communities that they harbour is poorly known. There is therefore a need for more studies to test how plant - soil feedback varies in soils with different AMF species in the presence of different varieties of the same species. The main goal of our study was therefore to explore the effect of previous plant growth and the significance of AMF species on plant productivity of two different maize varieties in a second growth cycle. By calculating the interaction coefficient in the non-mycorrhizal and mycorrhizal condition we want to address the question to which extent plants can select among or within species of AMF.

We executed a greenhouse experiment with two phases that consisted of: (i) a soil conditioning phase, where sterilized soil was inoculated with different species of AMF (including a mixed community) or not. The soil was separately conditioned by two maize varieties, viz. an old variety (bred in the 1950s) and a new variety (bred in 2000); and (ii) a subsequent feedback phase, where the same two varieties were grown in soil conditioned by the variety itself (home soil) and by the other variety (away soil) to determine relative effects of these different AMF species on shoot biomass and P uptake.

\section{Methods and materials}

\section{Plants and Soil}

\section{Conditioning phase}

A calcareous loamy soil was collected from field plots at the Changping LongTerm Fertilizer Station of China Agricultural University in Beijing, China. The soil contained $17.8 \mathrm{~g} \mathrm{~kg}^{-1}$ organic C, $2.9 \mathrm{mg} \mathrm{kg}^{-1}$ Olsen-P, $87.2 \mathrm{mg} \mathrm{kg}^{-1} \mathrm{~N}, 155.7 \mathrm{mg} \mathrm{kg}$ ${ }^{1}$ exchangeable $\mathrm{K}$, and had a $\mathrm{pH}$ value (in $\mathrm{CaCl}_{2}$ ) of 7.8. The soil was passed through a 2 -mm sieve and sterilized by $\gamma$-radiation with ${ }^{60} \mathrm{Co}$ at $10 \mathrm{kGy}$. It was 
then used to fill plastic pots of $18 \mathrm{~cm}$ height and $16 \mathrm{~cm}$ in diameter $(2 \mathrm{~kg}$ dw soil per pot).

Inoculum of three AMF species: Funneliformis mosseae (formerly Glomus mosseae), Claroideoglomus etunicatum (formerly Glomus etunicatum) and Gigaspora margarita was obtained from the Bank of Glomeromycota of China, Institute of Plant Nutrition and Resources, Beijing Academy of Agriculture and Forestry Research. Every species was propagated in a 5:1 mixture (w/w) of zeolite and river sand with maize for 4 months in a greenhouse, and the inoculum consisted of substrate containing spores, mycelium, and fine root fragments. Forty $\mathrm{g}$ inoculum per pot was used for inoculation; in the mixed treatment, where the three AMF species were combined, $13.3 \mathrm{~g}$ of each AMF was used. To the nonmycorrhizal pots, $40 \mathrm{~g}$ of sterilized mixed inoculum was added. To minimize differences in microbial communities of mycorrhizal and non-mycorrhizal treatments, $10 \mathrm{ml}$ of AMF-free filtrate from the inoculum was added to each nonmycorrhizal compartment, and $10 \mathrm{ml}$ of deionized water was added to each mycorrhizal pot.

Two maize varieties were used: Huangmaya (HMY), an open-pollinated, early senescing variety, which was bred in the 1950s; and Xianyu335 (XY335), a modern hybrid. Under P-poor conditions HMY had a higher mycorrhizal responsiveness than XY335 both in the greenhouse (Chu 2013) and in the field (Chapter 2). HMY also acquired more P from phytate than XY335 in the mycorrhizal condition (Chapter 3). When growing together the mixture resulted in overyielding in the mycorrhizal condition but not in the non-mycorrhizal condition (Chapter 4; Fig. 4S2).

Two maize seeds (surface-sterilized for $10 \mathrm{~min}$ in $10 \% \mathrm{H}_{2} \mathrm{O}_{2}$ followed by $3 \mathrm{~min}$ in $70 \%$ ethanol) were sown in every pot; they were thinned to one plant after germination. Soil moisture was kept at $18-20 \%$ (w/w, i.e. $70 \%$ of water holding capacity) as determined gravimetrically by weighing the pots every 2 days during the experiment and adding tap water when necessary. The glasshouse temperature range was $23-31^{\circ} \mathrm{C}$.

Nutrients ( $\mathrm{kg}^{-1}$ soil) were added in the following amounts: $20 \mathrm{mg} \mathrm{P}$ (as $\mathrm{KH}_{2} \mathrm{PO}_{4}$ ); $200 \mathrm{mg} \mathrm{N}$ (as $\mathrm{KNO}_{3}$ ), $50 \mathrm{mg} \mathrm{Mg}$ (as $\mathrm{MgSO}_{4}$ ), $5 \mathrm{mg} \mathrm{Zn}$ (as $\mathrm{ZnSO}_{4}$ ), and $2 \mathrm{mg} \mathrm{Cu}\left(\mathrm{as} \mathrm{CuSO}_{4}\right)$. Earlier investigations showed extremely poor maize growth in the absence of $\mathrm{P}$ fertilization. It has been shown that plants in all treatments at this level of P-addition remain P-limited (Chu et al. 2013). The nutrients were 


\section{Chapter 5}

mixed with the soil before pot filling. Three weeks after sowing, another $100 \mathrm{mg}$ $\mathrm{N}$ (as $\left.\mathrm{KNO}_{3}\right) \mathrm{kg}^{-1}$ soil was added to every pot.

\section{Feedback phase}

After harvesting shoots and roots of the first generation maize, the soil of each treatment was separately collected, homogenized and then dried. To test for plant - soil feedback, we grew both maize varieties in home (conditioned by the same variety), and in away (conditioned by the other variety) soil.

Nutrients $\left(\mathrm{kg}^{-1}\right.$ soil) in the second phase were added in the following amounts: $200 \mathrm{mg} \mathrm{N}$ (as $\mathrm{KNO}_{3}$ ), $50 \mathrm{mg} \mathrm{Mg}$ (as $\mathrm{MgSO}_{4}$ ), $5 \mathrm{mg} \mathrm{Zn} \mathrm{(as} \mathrm{ZnSO}_{4}$ ), and $2 \mathrm{mg} \mathrm{Cu}\left(\right.$ as $\left.\mathrm{CuSO}_{4}\right)$. No P was added in the second phase. The nutrients were mixed with the soil before filling of the pots. Three weeks after sowing, another $100 \mathrm{mg} \mathrm{N}$ (as $\mathrm{KNO}_{3}$ ) $\mathrm{kg}^{-1}$ soil was added to every pot (of $12 \mathrm{~cm}$ height and $10 \mathrm{~cm}$ in diameter). Every pot contained $0.75 \mathrm{~kg}$ soil.

The same two maize varieties were used in the second phase. The plants were not re-inoculated and relied on the build-up of mycorrhizal inoculum during the conditioning phase. Two maize seeds (surface-sterilized for $10 \mathrm{~min}$ in 10\% $\mathrm{H}_{2} \mathrm{O}_{2}$ followed by 3 min in $70 \%$ ethanol) were sown; they were thinned to one plant after germination. Soil moisture was kept at $18-20 \%$ (w/w, i.e. $70 \%$ of water holding capacity) as determined gravimetrically by weighing the pots every 2 days during the experiment and adding tap water when necessary. The glasshouse temperature range was $23-31{ }^{\circ} \mathrm{C}$.

\section{Harvest and sample analysis}

Plants were harvested 45 days after sowing in both phases. At harvest, soil samples of each pot were mixed to obtain a uniform matrix for subsequent analysis of hyphal length density. Plants were separated into shoots and roots. The shoots were oven-dried at $105{ }^{\circ} \mathrm{C}$ for $30 \mathrm{~min}$ to cease metabolic activity and then at $72{ }^{\circ} \mathrm{C}$ for $48 \mathrm{~h}$ and finally ground to fine powder. Roots were washed with deionized water and then preserved at $-20^{\circ} \mathrm{C}$. Roots were cut into $1-\mathrm{cm}$ segments for the measurement of mycorrhizal root colonization. Mycorrhizal colonization of roots was measured using the method of Trouvelot et al. (1986). Root segments were cleared with $10 \%(\mathrm{w} / \mathrm{v}) \mathrm{KOH}$ at $90{ }^{\circ} \mathrm{C}$ for $2 \mathrm{~h}$ and stained with Trypan blue for subsequent quantification of mycorrhizal colonization. Extraradical hyphae were extracted from two 5-g soil sub-samples from mycorrhizal pots using the 
membrane filter technique (Jakobsen et al. 1992b). Hyphal length was assessed using the gridline intercept method at $200 \times$ magnification and then converted to hyphal length density ( $\mathrm{m} \mathrm{g}^{-1} \mathrm{dw}$ soil). Shoot $\mathrm{P}$ concentration was determined by the standard vanado-molybdate method (Murphy and Riley 1962), after the pulverized shoots were digested in $\mathrm{H}_{2} \mathrm{SO}_{4}-\mathrm{H}_{2} \mathrm{O}_{2}$ mixture at $360{ }^{\circ} \mathrm{C}$ for $2 \mathrm{~h}$.

\section{Experimental design and statistical analysis}

\section{Conditioning phase}

The experiment was set up in a randomized complete full factorial block design with two factors: (1) Varieties - two maize varieties, HMY and XY335; (2) AMF five treatments, without AMF, and inoculated with F. mosseae or C. etunicatum or Gi. margarita or their mixture. The experiment was carried out with four replicates, giving 40 pots in total. The 10 pots within a block were arranged randomly in the glasshouse, with the positions re-randomized weekly.

\section{Feedback phase}

The experiment was set up in a randomized complete full factorial block design with three factors: (1) Soil origin - two levels, home soil and away soil; (2) Varieties - HMY and XY335 (3) AMF - five treatments, as in the first phase. The experiment was carried out with four replicates, giving 80 pots in total. The 20 pots within a block were arranged randomly in the glasshouse, with the positions re-randomized weekly.

\section{Calculations and Statistical analysis}

Calculation of feedback dynamics was inspired by the method described by Bever (2003). However, the magnitude of the interaction coefficient for pairwise feedback dynamics is also dependent on plant biomass or P uptake. Consequently, interaction coefficients could be smaller in case of non-mycorrhizal plants than for mycorrhizal plants. In order to overcome that problem we used the formula proposed by Kuyper and De Goede (2013) for a scaled interaction coefficient:

Feedback coefficient $=\ln (($ variety $\mathrm{A}$ in its own soil $[\mathrm{a}]+$ variety $\mathrm{B}$ in its own soil [b] / (variety A in away soil [b] + variety B in away soil [a]))

This coefficient is symmetrical around zero. The formula can be applied for biomass, P uptake, fractional mycorrhizal root colonization and hyphal length density. 


\section{Chapter 5}

We did not calculate feedback values for individual varieties.

The relative mycorrhizal responsiveness $\left(\mathrm{MR}_{\text {biom; }} \mathrm{MR}_{\mathrm{P}}\right)$ in this paper includes mycorrhiza-induced increases in shoot biomass and shoot P content. MR was calculated according to:

$$
\mathrm{MR}=(\mathrm{M}-\mathrm{NM}) / \mathrm{M} \times 100
$$

where $\mathrm{M}$ and $\mathrm{NM}$ refer to the shoot biomass or shoot $\mathrm{P}$ content of mycorrhizal and non-mycorrhizal plants, respectively. As MR was always positive (for both $\mathrm{MR}_{\text {biom }}$ and $\mathrm{MR}_{\mathrm{P}}$ ), we chose the commonly used metric (Plenchette et al. 1983) over a metric that is symmetrical around zero.

Statistical analyses were performed with SPSS software, version 22.0 (SPSS Inc., Chicago, IL, USA). The experiment was set up in a randomized complete full factorial block design. There was no block effect. All data met the requirements for normality (Kolmogorov-Smirnov) and homogeneity of variance (Levene's test). We report results of ANOVA for colonization and hyphal length density excluding the non-mycorrhizal treatment. Two-way analysis of variance (with maize variety and mycorrhizal treatment) was done on data of the conditioning phase for shoot biomass, shoot P content, mycorrhizal colonization, and hyphal length density. Three-way analysis of variance (with home versus away soil, maize variety and mycorrhizal treatment) was done on data of the feedback phase for shoot biomass, shoot P content, mycorrhizal colonization and hyphal length density. We calculated the scaled interaction coefficient for each block. Means were compared with Tukey's Honestly Significant Differences test at the $5 \%$ level of probability. A feedback coefficient $>0$ indicates positive feedback dynamics, and $<0$ indicates negative feedback dynamics.

\section{Results}

\section{Conditioning phase}

\section{Shoot biomass and $P$ content}

Shoot biomass and $\mathrm{P}$ content were significantly affected by variety and mycorrhiza, and the interaction (Table 5.1). Shoot biomass was on average higher for HMY than for XY335 in the mycorrhizal condition, but was similar in the nonmycorrhizal treatment. Mycorrhizal responsiveness was positive and ranged from $20 \%$ to $60 \%$. With HMY, mycorrhizal responsiveness was highest when inoculated with C. etunicatum, followed by the mixed inoculum, whereas 
mycorrhizal responsiveness of XY335 was highest when inoculated with the mixed inoculum, followed by C. etunicatum (Fig. 5.1a). Shoot P content showed a similar pattern (Fig 5.1b). Mycorrhizal responsiveness and mycorrhizal P responsiveness were significantly correlated for both varieties. In most cases $\mathrm{MR}_{\mathrm{P}}$ was higher than $\mathrm{MR}_{\text {biom, }}$, suggesting some luxury $\mathrm{P}$ uptake (data not shown). In the non-mycorrhizal control, shoot P content of HMY was significantly higher than of XY335, but in the treatment with the mixed inoculum it was higher in XY335 than in HMY.

\section{Mycorrhizal colonization and hyphal length density}

The control plants remained free of mycorrhizal colonization. Mycorrhizal colonization of inoculated plants was significantly affected by AMF species and its interaction with variety (Fig. 5.2a). For HMY, the mixed inoculum resulted in the highest root colonization (about 63\%); variation among AMF species was smaller for XY335 than for HMY.

Table 5.1. ANOVA results for the conditioning phase with shoot biomass, $\mathrm{P}$ content, colonization and hyphal length density (HLD) as dependent variable, and varieties and mycorrhizas as independent variables. The non-mycorrhizal control has been excluded in the ANOVA for colonization and hyphal length density.

\begin{tabular}{lccccccccccc}
\hline Independent & \multicolumn{4}{c}{$\begin{array}{c}\text { Shoot } \\
\text { biomass }\end{array}$} & \multicolumn{2}{c}{$\begin{array}{c}\text { Shoot P } \\
\text { content }\end{array}$} & \multicolumn{3}{c}{ Colonization } & \multicolumn{2}{c}{ HLD } \\
\hline variable & df & F & $\begin{array}{c}P \\
\text { value }\end{array}$ & F & $P$ value & df & F & $P$ value & F & $P$ value \\
Varieties $(C V)$ & 1 & 52.6 & $<0.001$ & 13.8 & 0.001 & 1 & 3.0 & 0.097 & 26.0 & $<0.001$ \\
$\begin{array}{l}\text { Mycorrhizas } \\
(\mathrm{M})\end{array}$ & 4 & 29.0 & $<0.001$ & 25.4 & $<0.001$ & 3 & 8.8 & $<0.001$ & 22.5 & $<0.001$ \\
$\mathrm{CV} \times \mathrm{M}$ & 4 & 8.3 & $<0.001$ & 18.6 & $<0.001$ & 3 & 11.2 & $<0.001$ & 24.4 & $<0.001$ \\
\hline
\end{tabular}

The effect of inoculation on hyphal length density (HLD) in the soils was variety-dependent (Table 5.1; Fig. 5.2b). In all treatments HLD was $>2 \mathrm{~m} \mathrm{~g}^{-1}$ soil. The effect of AM species on HLD hardly varied for variety XY335 (around $2.5 \mathrm{~m}$ $\mathrm{g}^{-1}$ ), but for HMY HLD varied two fold (from 2 to $4 \mathrm{~m} \mathrm{~g}^{-1}$ ) among AMF. Fractional root colonization and hyphal length density were not significantly correlated; neither were both parameters correlated with mycorrhizal (P) responsiveness (data not shown). 

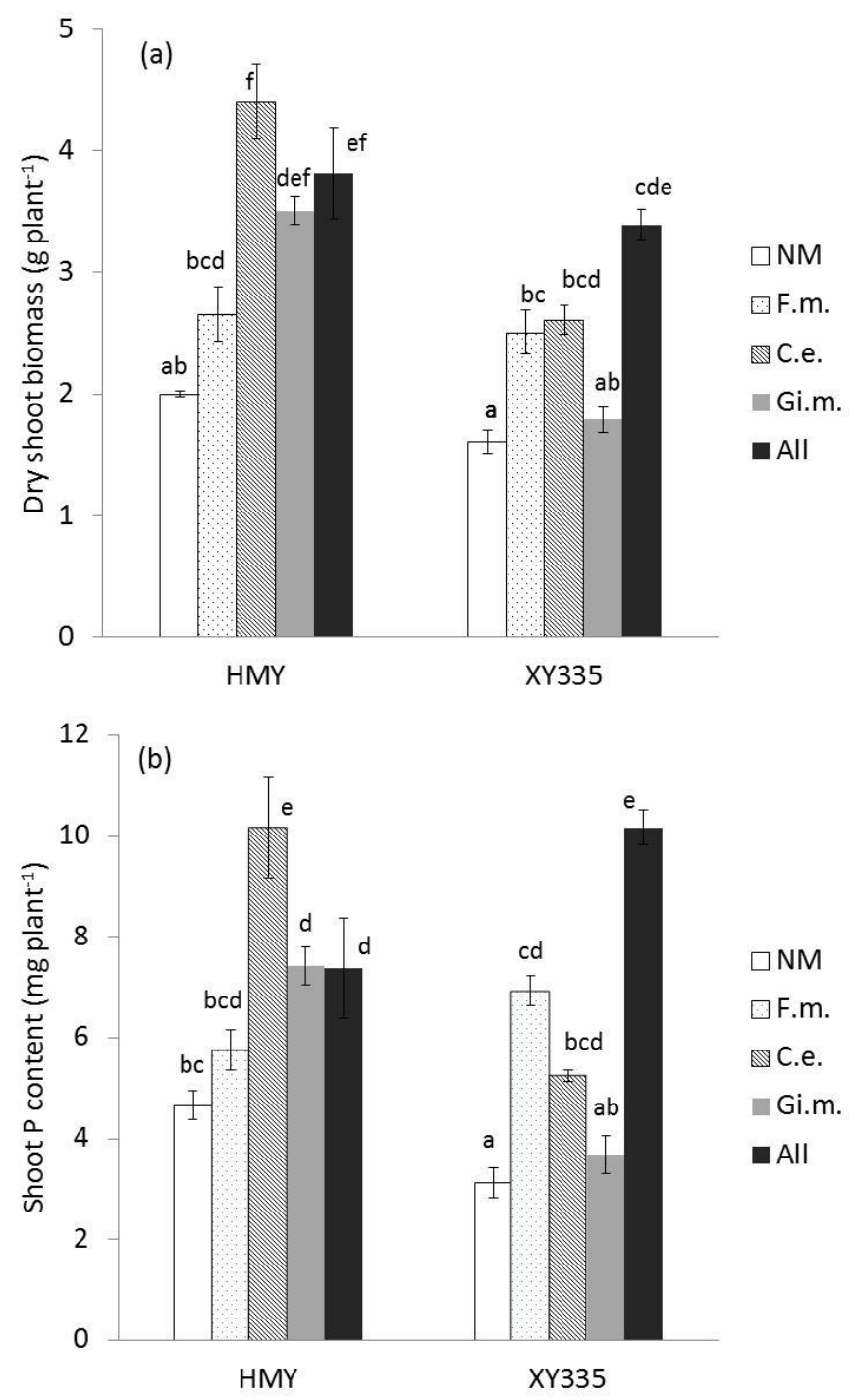

Fig. 5.1. Shoot biomass of (A) and shoot $\mathrm{P}$ content (B) of two maize varieties (HMY and XY335) grown in the conditioning phase. Plants were non-mycorrhizal (NM) or inoculated with F. mosseae (F.m.), C. etunicatum (C.e.)) Gi. margarita (Gi.m.), or mixed inoculum (All). Bars represent means \pm SE $(n=4)$. Bars with the same letter are not significantly different (Tukey: $P<0.05$ ). 

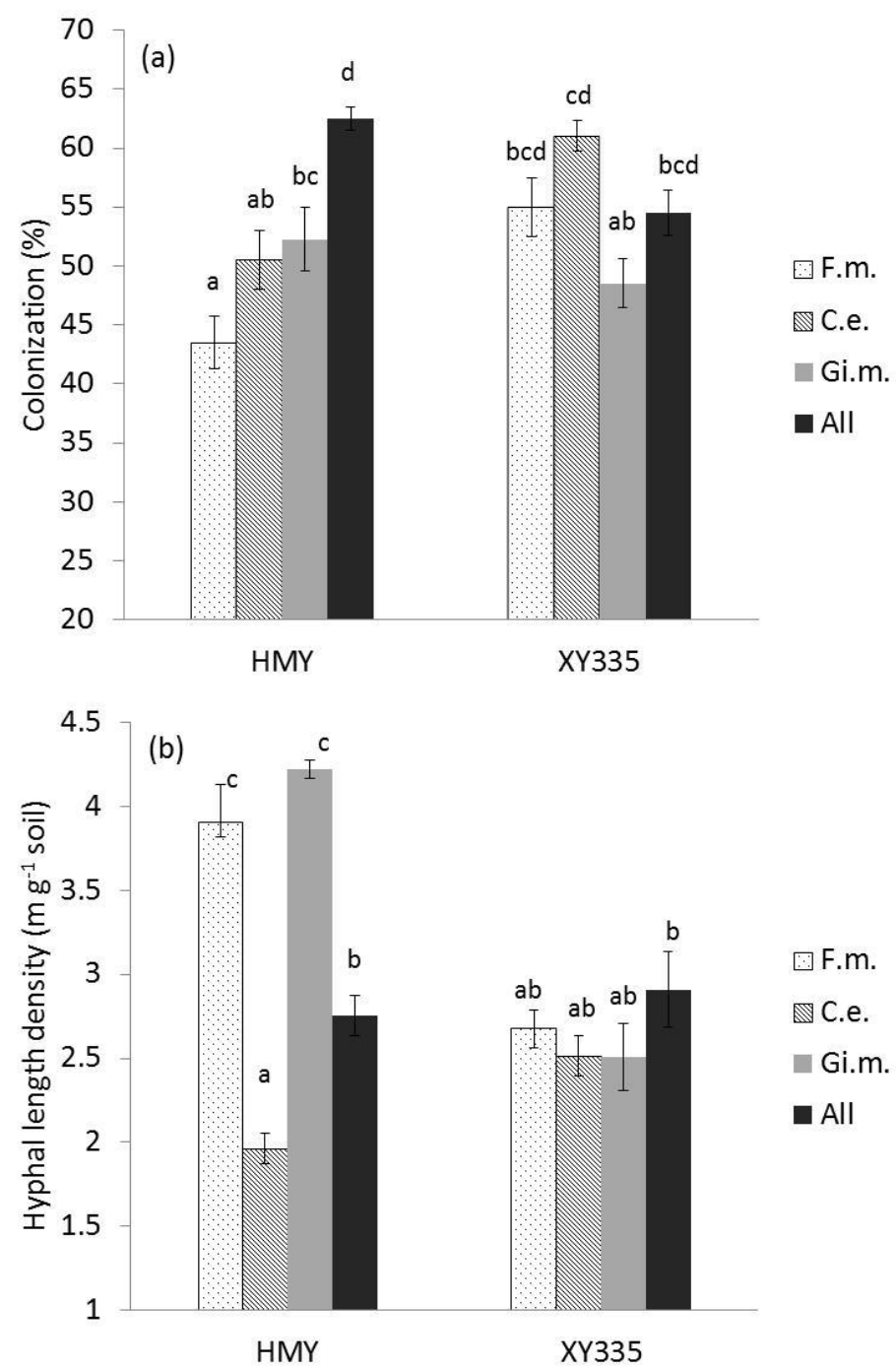

Fig. 5.2. Fractional mycorrhizal colonization (a) and hyphal length density (b) of two maize varieties (HMY and XY335) in the conditioning phase. Plants were inoculated with F. mosseae (F.m.), C. etunicatum (C.e.), Gi. margarita (Gi.m.), or mixed inoculum (All). Bars represent means $\pm \mathrm{SE}(\mathrm{n}=4)$. Treatments with the same letter are not significantly different (Tukey: $P<0.05$ ). 


\section{Chapter 5}
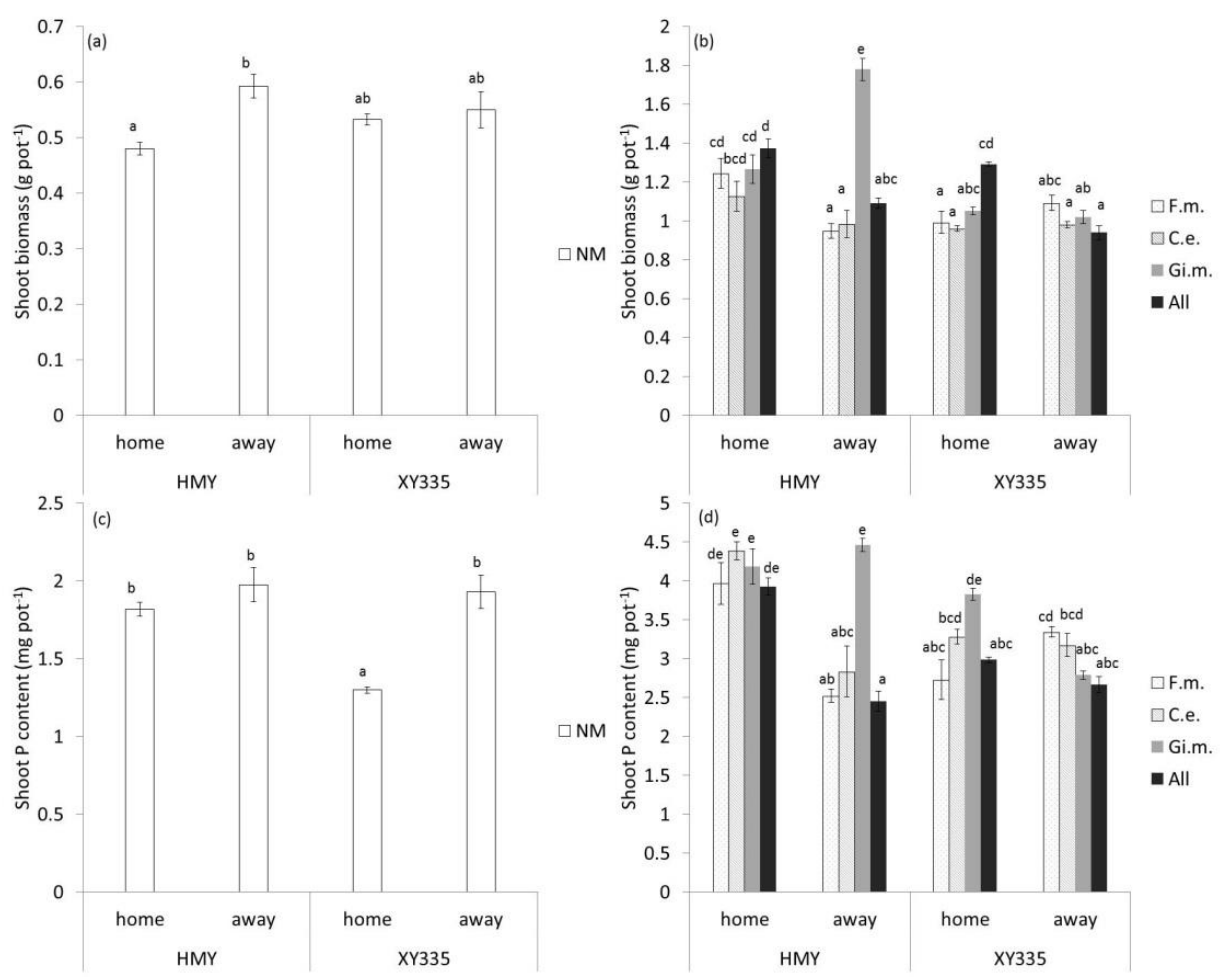

Fig. 5.3. Shoot biomass of $(a, b)$ and shoot $P$ content $(b, d)$ of two maize varieties (HMY and XY335) grown in home and away soil in the feedback phase. The plants were non-mycorrhizal (NM) (a, c), or inoculated with F. mosseae (F.m.), C. etunicatum (C.e.), Gi. margarita (Gi.m.), or mixed inoculum (All) (b, d). Note the different scales for the two columns. Bars represent means \pm SE $(n=4)$. Bars with the same letter are not significantly different (Tukey: $P<0.05$ ).

\section{The feedback phase}

\section{Shoot biomass and $P$ content}

Shoot biomass and shoot $\mathrm{P}$ content in the feedback phase were much lower than in the conditioning phase (Fig. 5.3). In the non-mycorrhizal control shoot biomass was only $30 \%$ of biomass in the conditioning phase on average; in the mycorrhizal treatment shoot biomass was on average around $40 \%$ of the biomass in the conditioning phase. Reduction in biomass was more severe when plants were 
inoculated with C. etunicatum. Shoot P content followed the similar pattern, although the degree of reduction was somewhat smaller.
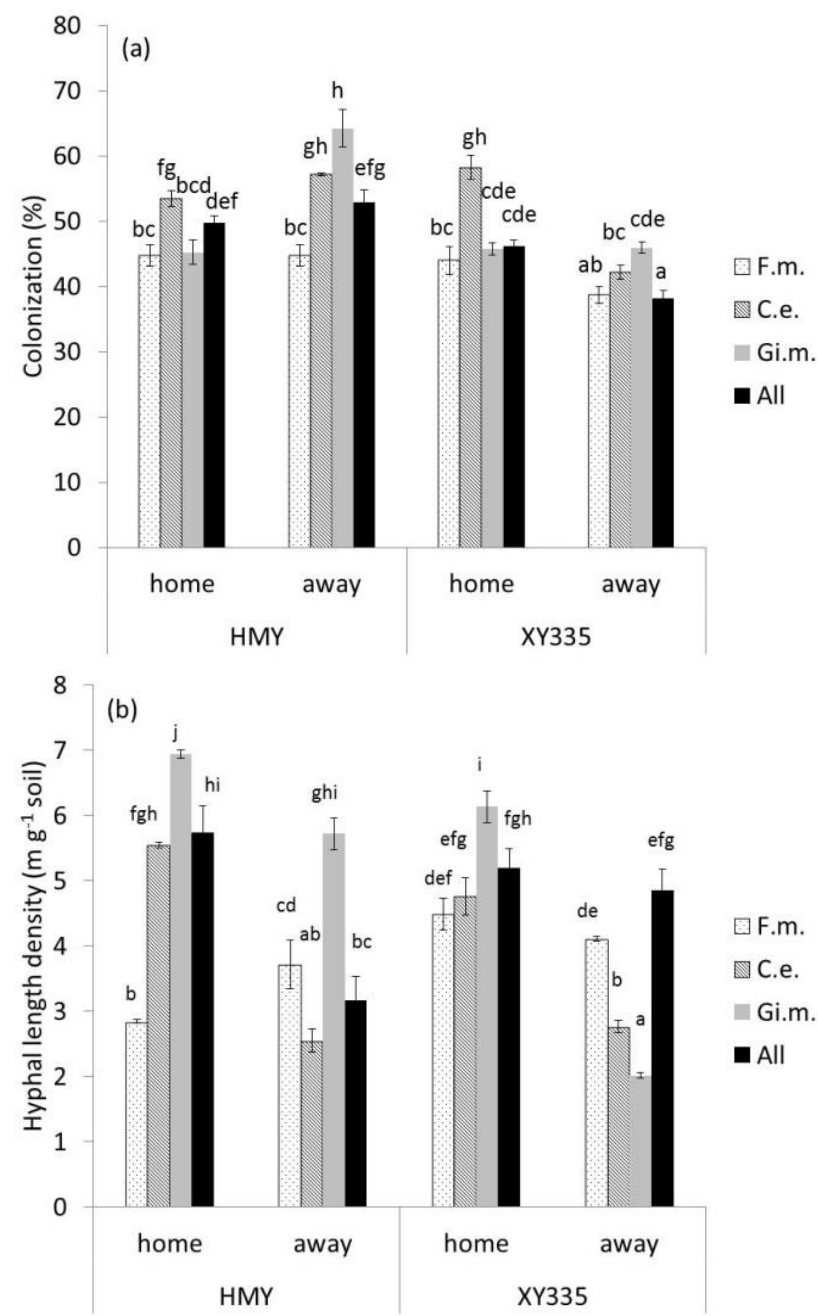

Fig. 5.4. Fractional mycorrhizal root colonization (a) and hyphal length density (b) for two maize varieties (HMY and XY335) grown in home and away soil in the feedback phase. The AMF were F. mosseae (F.m.), or C. etunicatum (C.e.), or Gi. margarita (Gi.m.), or mixed inoculum (All). Bars represent means $\pm \mathrm{SE}(\mathrm{n}=4)$. Treatments with the same letter are not significantly different (Tukey: $P<0.05)$. 


\section{Chapter 5}

In the non-mycorrhizal treatment, soil origin significantly affected shoot biomass (Fig. 5.3a) and shoot P content (Fig. 5.3c); there was also a significant interaction between soil origin and variety. Home soil reduced shoot biomass of non-mycorrhizal HMY (Fig. 5.3a) and shoot P content of non-mycorrhizal XY335 (Fig. 5.3c) compared to the away soil by $23 \%$ and $49 \%$, respectively.

For mycorrhizal plants, shoot biomass was significantly affected by soil origin, variety and mycorrhiza, and most two-way interactions (except for the interaction between soil origin and variety) and the three-way interaction (Table 5.2). $\mathrm{MR}_{\text {biom }}\left(34 \%\right.$, on average) and $\mathrm{MR}_{\mathrm{P}}(38 \%$, on average) in the conditioning phase were usually lower than $\mathrm{MR}_{\text {biom }}$ and $\mathrm{MR}_{\mathrm{P}}$ in the feedback phase, both in home $\left(\mathrm{MR}_{\text {biom, }} 55 \%\right.$ on average; $\mathrm{MR}_{\mathrm{P}}, 57 \%$ on average) and away soil $\left(\mathrm{MR}_{\text {biom, }}\right.$ $46 \%$; $\left.M R_{P}, 33 \%\right)$. There was a conspicuous difference between $M_{\mathrm{P}}$ for the mixed inoculum on the home soil (53-56\%) and the away soil (19-27\%), suggesting that varieties did select the fungi from the mixture that provided them the larger benefit in P-uptake. In the mycorrhizal condition, HMY produced more biomass in the home soil in three out of four cases; when inoculated with $G i$. margarita, the plants growing in away soil produced significantly more biomass than plants growing in home soil. For XY335, there was no significant difference between home soil and away soil in three cases; when inoculated with the mixed inoculum the home soil resulted in higher biomass than the away soil (Fig. 5.3b).

For mycorrhizal plants, shoot $\mathrm{P}$ content followed the similar pattern as shoot biomass: in three out of four cases the mycorrhizal plants growing in home soil had higher shoot $\mathrm{P}$ content than the plants growing in away soil (except for the treatment with Gi. margarita where no significant difference between both soils was noted). For HMY only the treatment with Gi. margarita resulted in higher shoot $\mathrm{P}$ content in the home soil than in the away soil; for the three other mycorrhizal treatments, there was no difference between soil origins (Fig. 5.3d).

\section{Mycorrhizal colonization and hyphal length density}

In the feedback phase the non-mycorrhizal controls remained free of mycorrhizal colonization. Therefore, hyphal length density was not assessed in these treatments. Variation in root colonization was found $(P<0.001)$ in the home and in the away soil and among the four mycorrhizal inocula $(P<0.001)$, but not between both maize varieties ( $P=0.63$, Table 5.2). Root colonization of AMFinoculated plants ranged from $38 \%$ to $65 \%$ (Fig. 5.3). For HMY, colonization did 
not show any difference between the home and away soil ( $P=0.82$; Fig. 5.4a); however, for XY335, it was significantly higher in the home soil in the treatments with C. etunicatum, Gi. margarita and the mixed inoculum (Fig. 5.4b).

Variation in hyphal length density was found $(P<0.001)$ between the home and the away soil and among the four mycorrhizal inocula $(P<0.001)$, whereas the effect of variety was marginally significant $(P=0.06$, Table 5.2). Hyphal length density ranged between 2.5 and $7 \mathrm{~m} \mathrm{~g}^{-1}$ soil. For HMY hyphal length density was significantly higher in home soil than in away soil in three out of four cases, but significantly lower in the home soil when inoculated with $F$. mosseae. For XY335 hyphal length density was significantly higher in the home soil in two cases (C. etunicatum and Gi. margarita), whereas no significant difference was noted with the two other inocula.

\section{Feedback}

The results of the calculation of interaction coefficients are given in Fig. 5.5 and 5.6. In the non-mycorrhizal condition feedbacks dynamics were negative, both for biomass (Fig. 5.5a) and P content (Fig. 5.5b). In the mycorrhizal condition, feedbacks were always positive for $\mathrm{P}$ uptake. For biomass, feedback was negative only for the Gi. margarita treatment, and positive for the treatments of F. mosseae, or C. etunicatum and AMF mixtures in the feedback phase. The highest value for the interaction coefficient was always obtained in the case of the mixed inoculum.

Interaction coefficients for mycorrhizal colonization and hyphal length density are provided in Fig. 5.6. The interaction coefficient in the case of colonization was positive, except in the case of Gi. margarita, while the interaction coefficient, in the case of hyphal length density, was significantly lower in the case of F. mosseae than for the other mycorrhizal treatments.

Combined with the data of $\mathrm{P}$ uptake (and to a smaller extent the data on biomass), the interaction coefficient show positive feedback dynamics, implying that plants select and reward the fungi they derive more benefit from. This is shown in Fig. 5.7 as a significantly positive correlation between the feedback coefficient for root colonization and both shoot biomass and $\mathrm{P}$ content. The feedback coefficient for hyphal length density was not significantly correlated with the feedback coefficients for both plant parameters. 

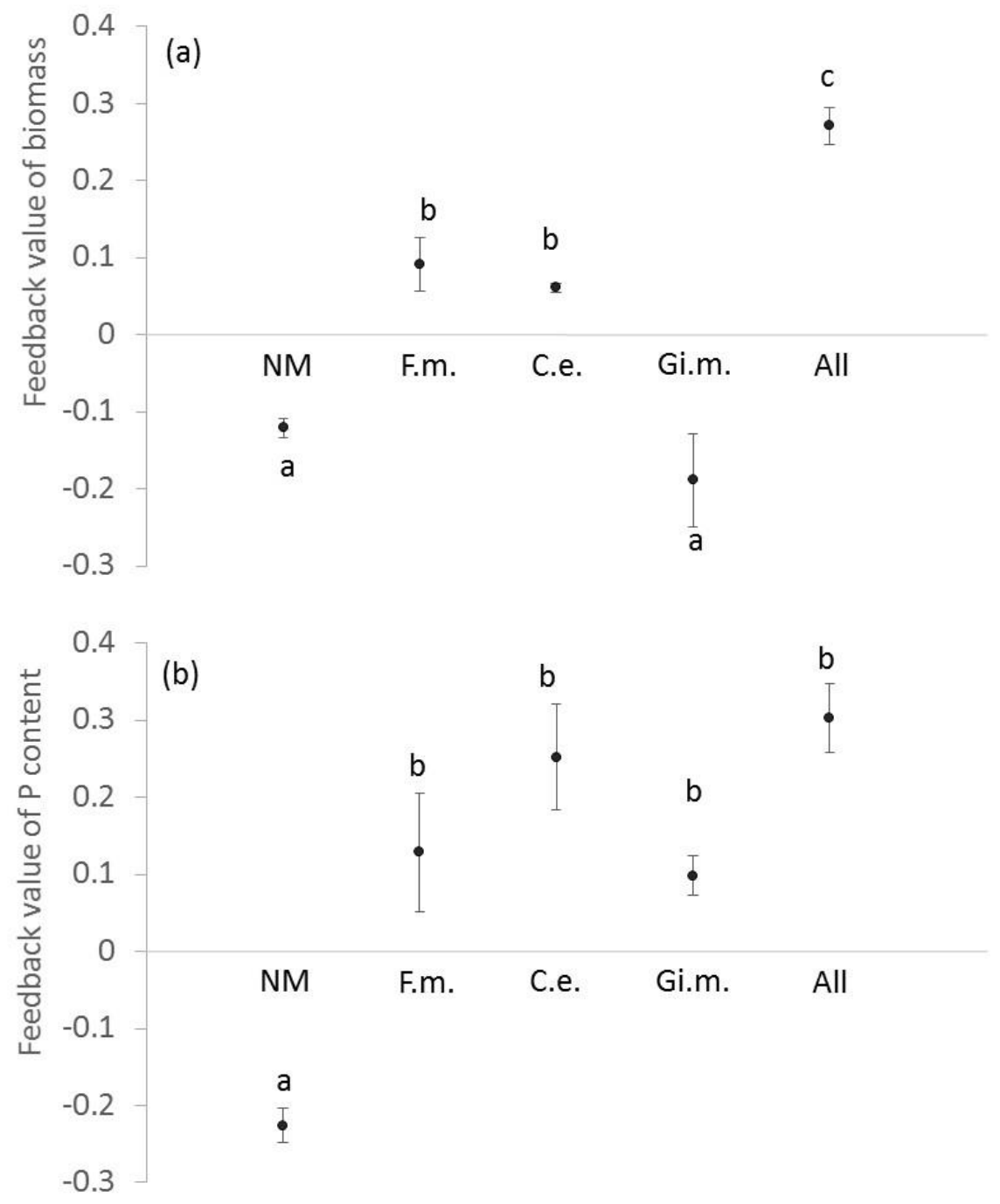

Fig. 5.5 Interaction coefficients (see formula 1) for feedback for plant biomass (a) and plant P content (b). The AMF were NM (non-mycorrhizal), F. mosseae (F.m.), or C. etunicatum (C.e.), or Gi. margarita (Gi.m.), or mixed inoculum (All). Bars represent means $\pm \mathrm{SE}(\mathrm{n}=4)$. Treatments with the same letter are not significantly different (Tukey: $P$ $<0.05)$. 


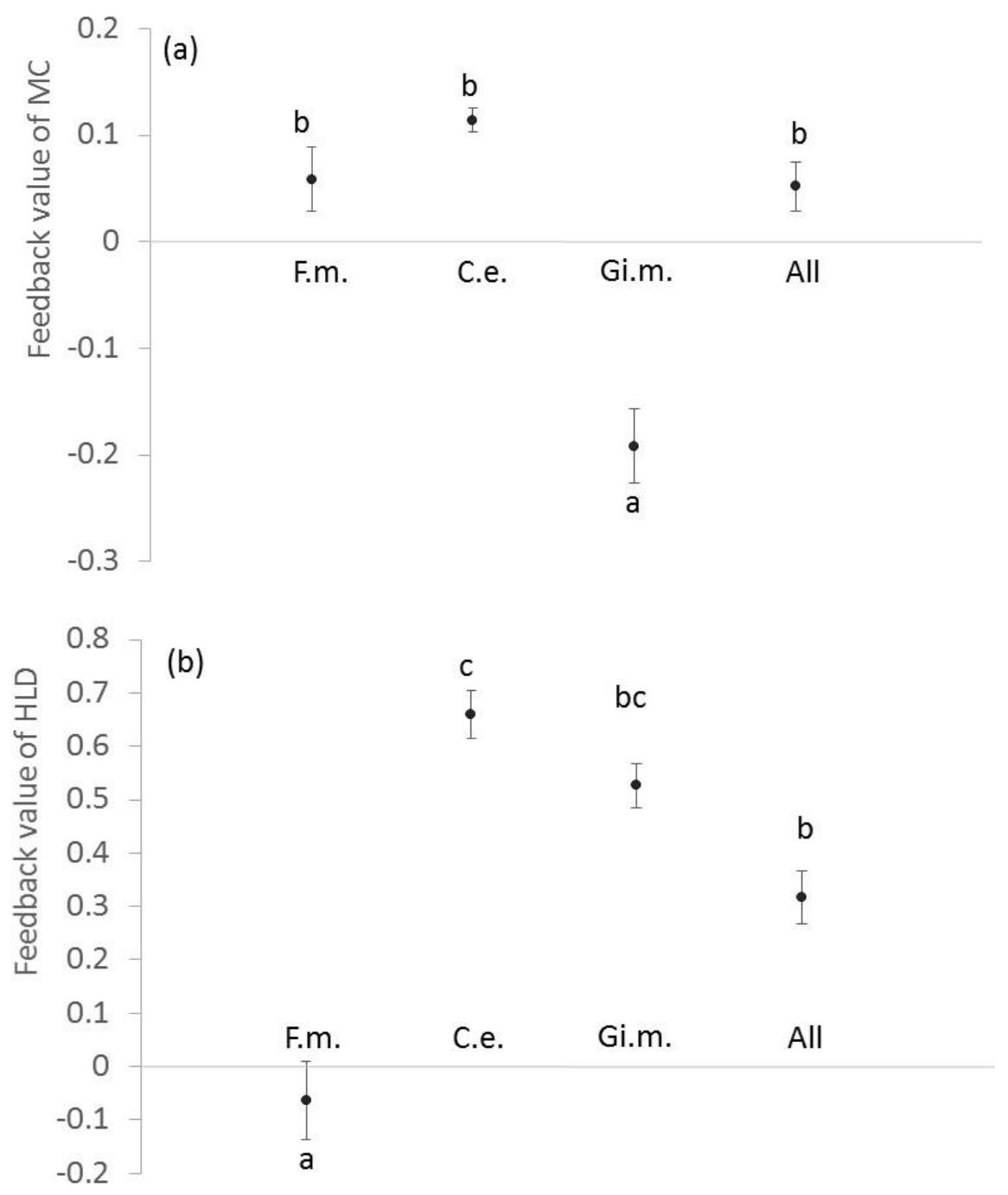

Fig. 5.6 Interaction coefficients (see formula 1) for feedback for mycorrhizal colonization (a) and hyphal length density (b). The AMF were, F. mosseae (F.m.), or C. etunicatum (C.e.), or Gi. margarita (Gi.m.), or mixed inoculum (All). Bars represent means \pm SE $(\mathrm{n}=4)$. Treatments with the same letter are not significantly different (Tukey: $P$ $<0.05)$. 


\section{Chapter 5}

\section{Discussion}

\section{Significance of results}

In our pair-wise feedback calculations, we noted negative feedback in the absence of mycorrhiza (Fig. 5.5). At the same time we noted consistent positive feedback in the presence of mycorrhiza for P uptake. Biomass in the mycorrhizal treatments showed the same pattern of positive feedback dynamics, except in the case of $G i$. margarita, where negative feedback was demonstrated (Fig. 5.5). This relatively straightforward picture of a mycorrhizal role in determining the direction of feedback is easier to interpret than the results of the ANOVAs (Table 5.2). In these analyses not only the main factors but also the two-way and three-way interactions were almost always significant sources of variation, making interpretation of these data very challenging (Table 5.2). Despite differences between both varieties, which we discuss below, general patterns emerged that apparently indicate a role of plant selectivity for mycorrhizal fungi (individuals; or species in the case of the three-species mixture) that resulted in associations from which the variety benefitted more than the other variety. To the best of our knowledge this is the first time that a mycorrhizal role in intraspecific plant - soil feedback for a major crop has been reported.

\section{Non-mycorrhizal maize and negative plant - soil feedback}

Shoot biomass and shoot $\mathrm{P}$ content of non-mycorrhizal plants showed negative feedback (Fig. 5.5a, b). We identify two potential causes, but admit that our experiment was not designed to test these mechanisms. The presence of hostspecific or selective pathogens has been invoked to explain the occurrence of negative plant - soil feedback (Bever et al. 2012; Klironomos 2002; Mills and Bever 1998; Van der Putten et al. 1993). Although the soil before the conditioning phase had been sterilized by $\gamma$-radiation and the seeds surface-sterilized, endophytic microbiota or organisms subsequently colonizing the pots from outside may have accumulated; if these organisms differentially impact on different maize varieties, they may cause negative plant - soil feedback dynamics. Moreover, the microbial wash that was applied to the non-mycorrhizal pots may have contained pathogens that could have caused the negative feedback in the absence of pathogen suppression activity by AMF. It is therefore important to 
identify in future experiments the microbiota in the rhizosphere of both maize varieties when grown in their home and away soil.

Table 5.2. ANOVA results for the feedback phase with biomass $\mathrm{P}$ content, colonization and hyphal length density (HLD) as dependent variable, and soil origin, varieties and mycorrhiza as independent variables. The non-mycorrhizal control was not included in the analysis.

\begin{tabular}{lcccccccccc}
\hline Independent & \multicolumn{4}{c}{$\begin{array}{c}\text { Shoot } \\
\text { Biomass }\end{array}$} & \multicolumn{2}{c}{$\begin{array}{c}\text { Shoot P } \\
\text { content }\end{array}$} & \multicolumn{2}{c}{ Colonization } & \multicolumn{2}{c}{ HLD } \\
Variable & df & F & $P$ value & F & $P$ value & F & $P$ value & F & $P$ value \\
\hline $\begin{array}{l}\text { Soil origin } \\
\text { (SO) }\end{array}$ & 1 & 5.9 & 0.02 & 63.1 & $<0.001$ & 0.2 & 0.631 & 173.8 & $<0.001$ \\
Varieties (CV) & 1 & 58.5 & $<0.001$ & 38.5 & $<0.001$ & 72.9 & $<0.001$ & 3.8 & 0.06 \\
Mycorrhizas & 3 & 23.5 & $<0.001$ & 20.3 & $<0.001$ & 29.9 & $<0.001$ & 31.4 & $<0.001$ \\
$(\mathrm{M})$ & 1 & 0.09 & 0.8 & 27.7 & $<0.001$ & 78.5 & $<0.001$ & 0.9 & 0.3 \\
$\mathrm{SO} \times \mathrm{CV}$ & 3 & 22.1 & $<0.001$ & 2.9 & 0.04 & 19.7 & $<0.001$ & 30.6 & $<0.001$ \\
$\mathrm{SO} \times \mathrm{M}$ & 3 & 17.3 & $<0.001$ & 5.1 & 0.004 & 3.3 & 0.03 & 36 & $<0.001$ \\
$\mathrm{CV} \times \mathrm{M}$ & 3 & 17.1 & $<0.001$ & 21.8 & $<0.001$ & 4.8 & 0.005 & 22.6 & $<0.001$ \\
$\mathrm{SO} \times \mathrm{CV} \times \mathrm{M}$ & & & & & & & & &
\end{tabular}

A second potential explanation for the negative feedback is nutrient depletion. In the feedback phase we fertilized the plants with $\mathrm{N}$ and $\mathrm{K}$, but did not add P. So the P pools were depleted in the feedback phase, compared to the conditioning phase. In the conditioning phase, HMY showed higher shoot $\mathrm{P}$ content, implying larger soil $\mathrm{P}$ depletion. This $\mathrm{P}$ depletion may then cause a yield reduction in the second phase, compared to pots where less $\mathrm{P}$ had been taken up and where the soil was therefore less depleted. We consider this explanation unlikely for two reasons. First, while that mechanism would explain why HMY performed less on the soil that it conditioned than on the soil that was conditioned by XY335, it would also imply that XY335 would suffer more when grown on its away soil (conditioned by HMY) than on the soil that it conditioned. However, XY335 also grew more poorly on its own-conditioned soil. Second, and more importantly, nutrient depletion was much higher in the various mycorrhizal treatments. The fact that the mycorrhizal treatments, especially with regard to $\mathrm{P}$ uptake, generated positive feedback dynamics is inconsistent with nutrient depletion as an explanation for negative feedback dynamics. Thus, for the time being we attribute negative feedback dynamics, when non-mycorrhizal, to pathogens. 


\section{Chapter 5}

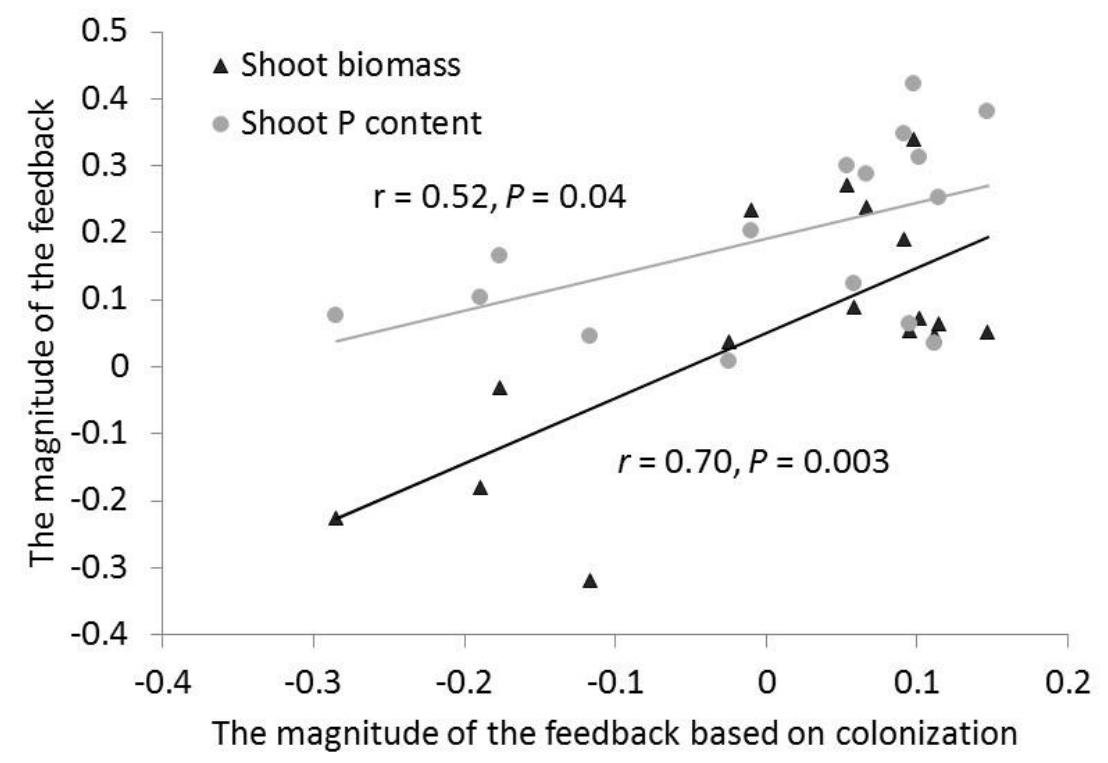

Fig. 5.7. The relationship between the feedback coefficient for colonization (X-axis) and the feedback coefficients for biomass and shoot $\mathrm{P}$ content (Y-axis). Both correlations are statistically significant.

\section{Mycorrhizal maize and positive plant - soil feedback}

Our results (Fig. 5.5a, b) show positive feedback in the presence of mycorrhiza, except that soil with Gi. margarita showed negative feedback for biomass (but not for $\mathrm{P}$ uptake). The difference between both parameters is due to a strong difference in $\mathrm{P}$ concentration of both maize varieties when grown in their home soil (3.5 $\left.\mathrm{mg} \mathrm{P} \mathrm{g}^{-1}\right)$ compared to when both varieties grew in away soil $(2.6 \mathrm{mg} \mathrm{P} \mathrm{g}$ $\left.{ }^{1}\right)$, a difference that was highly significant $(P<0.001)$. We cannot explain the causes for this difference in shoot $\mathrm{P}$ concentration.

Field studies have shown that agricultural plants usually perform better in the away soil relative to their home soils and thereby generate negative feedback dynamics, due to the fact that the negative effect of pathogens overrides the beneficial effect of mutualist rhizosphere organisms (Bakker and Schippers 1987; Olsson and Gerhardson 1992). However, in our experiment, mycorrhizal maize generally exhibited positive plant - soil feedback dynamics. This differential 
outcome may have been caused by soil sterilization at the start of the experiment, and subsequent addition of mycorrhizal inoculum (in the mycorrhizal treatment) or a filtrate of the mycorrhizal inoculum (in the non-mycorrhizal treatment). Pathogen densities may have been much lower than under field conditions.

A plausible mechanism for positive plant - soil feedback in this study is that every maize variety to some extent selects from the original mycorrhizal inoculum in a way that increases its fitness or biomass. Plant selection of AMF for more beneficial symbionts has been proposed by several authors (Bever et al. 2009; Kiers et al. 2011). If plants do select (even when inoculum consists of one species) for more beneficial fungi, we might predict that maize plants, growing in their own soils, cause a larger hyphal length density, resulting in larger $\mathrm{P}$ uptake. This pattern was only partly observed (positive feedback in the case of $C$. etunicatum, $G i$. margarita and the mixed inoculum). We also noted co-occurrence of positive feedback for hyphal length density in these three treatments and positive feedback for shoot P uptake (Fig. 5.5 and 5.6). While we cannot exclude that the causal chain runs in the opposite direction (maize plants that took up more $\mathrm{P}$ are generally larger (but not in the case of Gi. margarita) and allocated more $\mathrm{C}$ belowground, resulting in increased hyphal length density; see also Chapter 4 for a similar argument), we consider that explanation unlikely, as evidence for plant selection of mycorrhizal symbionts is consistent with the observation that the mixed inoculum (where opportunities for plants to select are largest) had the largest positive feedback (for biomass and $\mathrm{P}$ content). Molecular studies demonstrating divergent selection for different fungi in the mixed inoculum are needed to further test this hypothesis.

It would need a more systematic comparison among maize varieties to test whether mycorrhizal responsiveness (see Chapter 2) links to the nature of the feedback dynamics. Equally, the differential behaviour of Gi. margarita is currently unexplained. While it is known that the structure of AMF communities (Mangan et al. 2004) impacts on the plant - soil feedback, we cannot yet link traits of individual AMF species to the direction and magnitude of the feedback. Considering that the positive feedback may be due to overriding the negative feedback caused by pathogens, it may be noteworthy that members of the Gigasporaceae have been claimed to be better soil colonizers, and members of the Glomeraceae to be better root colonizers (Hart and Reader 2002). Better soil 


\section{Chapter 5}

colonizers would translate into higher hyphal length density and this has indeed been observed for Gi. margarita in most cases.

Several studies have suggested that there is a positive correlation between the magnitude of the feedback value by plants and the feedback value of the mutualists (Gubry-Rangin et al. 2010; Heath and Tiffin 2009). Our results support this suggestion, as the feedback coefficient based on root colonization was positively correlated with the feedback coefficients for biomass and shoot $\mathrm{P}$ content (Fig. 5.7). It should be noted, however, that other studies failed to find such correlated behaviour. Bever et al. (2009) noted that in some cases fungal fitness was highest when associated with a plant who did not derive the higher benefit from it.

\section{Methodological considerations}

When designing the experiment, we were unsure how large the magnitude of the feedback would be, and therefore we decided to use all soil of the conditioning phase for the subsequent feedback phase, rather than to dilute that original soil with sterile soil. Because the feedback phase needed twice as many pots (as we included an additional factor, viz. home and away soil; assuming the same number of replicates), we opted for smaller pot sizes and volumes (2 $\mathrm{kg}$ soil in the conditioning phase, $0.75 \mathrm{~kg}$ soil in the feedback phase). Smaller pot size likely explains smaller shoot biomass and shoot $\mathrm{P}$ content in the feedback phase. Smaller pots likely also explain higher hyphal length density. However, besides these consequences of using smaller pots, we think that the design did not generate problems for the interpretation of the results: mycorrhizal responsiveness was comparable (only slightly higher) between the conditioning and feedback phase of the experiment. For that reason we argue that the difference between both varieties when grown in home and away soils, and the difference between non-mycorrhizal and mycorrhizal plants, can indeed be attributed to plant - soil feedback.

\section{Conclusion}

The main finding of this study is that AMF tended to revert negative plant - soil feedback into positive feedback in a system where two different maize varieties where grown on home and away soil. As there are no earlier studies on intraspecific plant - soil feedback in the absence and presence of arbuscular 
mycorrhiza, we cannot interpret our results in a more general framework. Our results suggest that plants can select for more beneficial mutualists (both among species, the mixed inoculum treatment, and within fungal species) and that this selectivity is a driving force for these potential positive feedback dynamics. 



\section{CHAPTER 6}

General discussion 


\section{Chapter 6}

\section{Introduction and main findings in this thesis}

In this thesis I investigated several aspects of the interaction between arbuscular mycorrhizal fungi (AMF) and maize varieties in order to explore options to enhance $\mathrm{P}$ acquisition efficiency. To the best of my knowledge, my thesis is the first study that has documented that combining maize varieties can improve $\mathrm{P}$ efficiency and productivity. Also positive plant - soil feedbacks between different mycorrhizal maize varieties have not been described before. Both results were only obtained in the mycorrhizal condition; non-mycorrhizal mixtures of maize did not enhance productivity and did not show positive plant - soil feedback in a pot experiment. In this final chapter, I will first summarize my main findings as described in the separate chapters. In the following sections, I will try to link these results through (1) comparing organic and inorganic $\mathrm{P}$ uptake by different varieties under the mycorrhizal condition; (2) comparing the performance of varietal combinations in space and time; and (3) comparing the impact of individual AMF species versus communities of AMF. I will finally reflect on the roles of AMF in agricultural systems using approaches that are partly derived from ecological research. I try to integrate my results in a new conceptual model based on AMF functioning (Fig. 6.1).

The main findings of my research were:

1. Mycorrhizal responsiveness and fractional root colonization of old varieties (landraces) did not differ significantly from that of modern varieties (inbred lines, hybrids) (Chapter 2);

2. Mycorrhizal responsiveness was negatively correlated with the ability to grow at low $\mathrm{P}$ under non-mycorrhizal conditions and with $\mathrm{P}$ acquisition efficiency (Chapter 2);

3. Different maize varieties harboured somewhat different AMF assemblages in the field (Chapter 2);

4. Mycorrhizal responsiveness in the field was not correlated with mycorrhizal responsiveness under controlled conditions (where mycorrhizal plants are compared with non-mycorrhizal controls) (Chapter 2);

5. Measuring phytase activity was necessary when studying phytate utilization; assessing only acid phosphatase was insufficient (Chapter 3);

6. Acquisition of $\mathrm{P}$ through mineralization of phytate by mycorrhizal hyphae made only a limited contribution to plant $\mathrm{P}$ acquisition (Chapter 3); 
7. When studying $\mathrm{P}$ acquisition from phytate, competitive sorption of orthophosphate and phytate to mineral surfaces should be considered (Chapter 3); 8. Combining maize varieties in the presence of AMF resulted in overyielding (due to increased $\mathrm{P}$ uptake as a consequence of increased hyphal density) compared to monocultures (Chapter 4);

9. Combining maize varieties in the absence of the mycorrhizal symbiosis did not result in overyielding (Chapter 4);

10. In the non-mycorrhizal condition, combination of two maize varieties showed negative plant - soil feedback (Chapter 5);

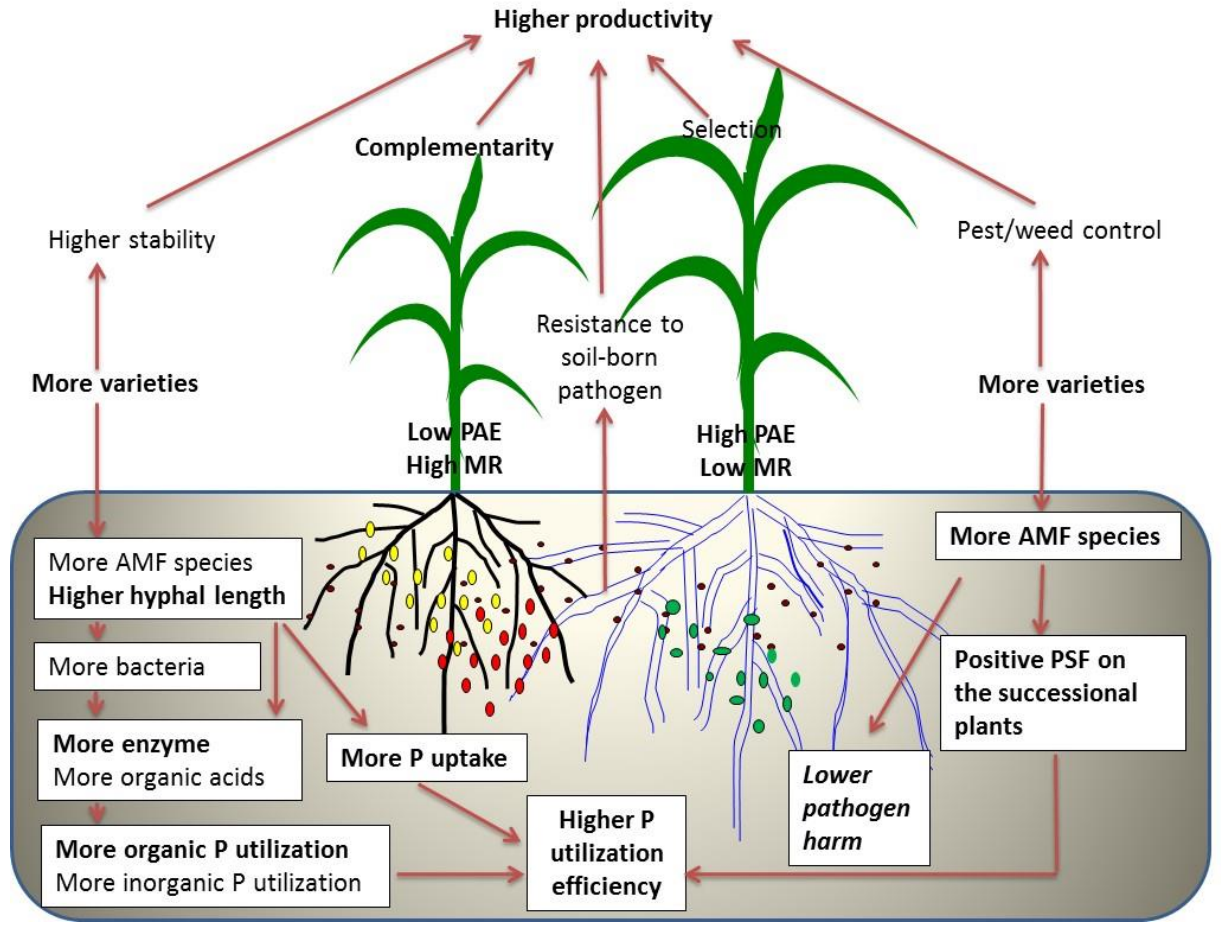

Fig. 6.1 A conceptual model of mycorrhiza-related benefits of mixing different varieties of one cereal species. Words in bold refer to mechanisms demonstrated in my thesis; words in italics to hypothesized mechanisms. Abbreviations: PAE = phosphorus acquisition efficiency; MR = mycorrhizal responsiveness; PSF = Plant Soil Feedback. 


\section{Chapter 6}

11. AMF reverted these negative feedbacks into positive plant - soil feedback dynamics, as maize varieties grown in home soil outperformed the same variety when grown in away soil (Chapter 5).

The main message of my thesis is that combining maize varieties in space (through intercropping) can be a more successful route towards more efficient $\mathrm{P}$ use. Intraspecific intercropping of maize, depending on varietal choice, can result in overyielding. The ability to overyield is connected to (and likely caused by) the arbuscular mycorrhizal symbiosis, through enhanced uptake of $\mathrm{P}$ through complementarity. However, the specific P acquisition traits of different cultivars (including traits related to mycorrhizal functioning) and the competitive ability of these cultivars likely determines which combinations can be used to increase $\mathrm{P}$ acquisition efficiency. Future research should therefore be directed at these traits and trait combinations.

\section{The linkage between phosphorus efficiency and mycorrhizal responsiveness within one crop species}

It has been repeatedly demonstrated that maize varieties with different root morphological or physiological characteristics can react differently to AMF in pot experiments (Chu et al. 2013; Wright et al. 2005). However, experiments to assess mycorrhizal responsiveness under controlled greenhouse conditions suffer from a number of potential drawbacks, of which the two major ones are: (1) relative responsiveness is determined through a comparison of mycorrhizal and nonmycorrhizal plants; however, we know that in the field non-mycorrhizal plants would hardly, if ever, be found; (2) responsiveness is often determined in the presence of one specific AMF fungus, thereby neglecting the possibility that plant species or varietal selectivity (see also Chapter 5) will produce different results depending on species choice, as under field conditions plants are normally confronted with an assemblage of different species. For maize, several studies have been executed that compared mycorrhizal responsiveness of different varieties (Chu et al. 2013; Hao et al. 2008; Kaeppler et al. 2000). Therefore I assessed how different maize varieties respond to native AMF assemblages using in-growth cores that could be rotated to create plants with (very) low levels of mycorrhizal colonization. Such plants were significantly smaller and the method is therefore suitable to assess field responsiveness among maize varieties. I executed the experiment in three different soils with three different P-levels (while all other 
soil properties were likely not different among these fields). I observed, in agreement with previous studies, that high $\mathrm{P}$ availability reduced mycorrhizal responsiveness.

Mycorrhizal responsiveness had for some time been considered as a potential target for natural selection, based on the observation that older wheat varieties showed higher responsiveness (at that time still called dependency) than modern varieties (Hetrick et al. 1992; Zhu et al. 2001). It was then suggested that the selective environment of modern varieties (in soils with high doses of mineral fertilizer) had resulted in selection against the ability to benefit from mycorrhiza; and for that reason modern breeding programs for sustainable agriculture should select varieties with higher responsiveness (Galván et al. 2011; Sawers et al. 2010; Sawers et al. 2008). However, studies by Kaeppler et al. (2000) and Galván et al. (2011) suggested an alternative explanation for changes in responsiveness due to modern plant breeding. If modern varieties can grow more efficiently at low $\mathrm{P}$ in the absence of mycorrhiza, they will be inherently less responsive to mycorrhiza. In fact, later data by Hetrick et al. (1996) provide support for this hypothesis. They noted a positive correlation between mycorrhizal responsiveness and $\mathrm{P}$ responsiveness (defined as the relative yield increment at high $\mathrm{P}$ compared to low $\mathrm{P}$; in fact the inverse of $\mathrm{P}$ acquisition efficiency as defined in Chapter 2). $\mathrm{P}$ responsiveness is high if the variety grows poorly under P-poor conditions. Selection for yield stability (the ability to produce well under a variety of conditions, including conditions of low and high mycorrhizal inoculum density) would then translate in high $\mathrm{P}$ efficiency (or low $\mathrm{P}$ responsiveness) and low mycorrhizal responsiveness. In such cases modern varieties would indeed show lower responsiveness. In maize the situation appeared different. Breeding seems to have reduced $\mathrm{P}$ efficiency (as it was significantly higher in landraces than in inbred lines and modern hybrids), which should translate rather into a higher mycorrhizal responsiveness. Due to the large variation within the categories the differences were not significant, however. The study by Wright et al. (2005) also demonstrated a higher mycorrhizal responsiveness for the modern European variety than for the African landrace. My data confirm that high responsiveness is not a desirable trait per se, as responsiveness, especially under P-poor conditions, correlated negatively with growth in the non-mycorrhizal condition and with $\mathrm{P}$ acquisition efficiency (Fig. 2.5), implying that selection for high responsiveness may inadvertently select for varieties with poor growth when non-mycorrhizal. 


\section{Chapter 6}

There were also no significant differences in levels of root colonization among these three groups, consistent with a study by An et al. (2010), who showed no differences in mycorrhizal colonization in a comparison of old varieties, inbred lines and modern hybrids. They claimed that modern maize breeding programs do not necessarily lead to the suppression of colonization. To this observation I add that modern breeding programs do not necessarily select against responsiveness.

Initial molecular analysis of AMF communities of four varieties grown at two P-levels suggested minor divergence in species composition in different fields and with different varieties. Similar data had been reported by (Oliveira et al. 2009), but in that study the variety effect seemed more important that the fertilizer effect. AMF selectivity may be important for overyielding in the field (Chapter 4) and for the mycorrhizal role in generating positive feedback (Chapter 5).

In the pot experiment by Yang (2009), old landraces had a larger biomass than modern hybrids under low inoculum $(P=0.072)$. Better performance of landraces was also found in the field experiment in the rotated cores at P0 (average biomass of landraces, $0.67 \mathrm{~g}$; average biomass of hybrids, $0.47 \mathrm{~g} ; P=$ 0.054). These consistent results imply that old landraces were selected to perform reasonably in the non-mycorrhizal conditions when soil available $\mathrm{P}$ was low, while modern hybrids to some extent lost the ability to grow efficiently at low-P in the non-mycorrhizal condition. High P efficiency was essential before the 1950s in China, as mineral $\mathrm{P}$ use was very low, with only minor $\mathrm{P}$ application through animal manure. Currently the high use of mineral $\mathrm{P}$ fertilizer may have resulted in reduced $\mathrm{P}$ acquisition efficiency. The low soil $\mathrm{P}$ availability resulted in landraces having a higher $\mathrm{P}$ efficiency than hybrids (Fig. 6.2).

To avoid problems with rotation (non-mycorrhiza) and non-rotation (mycorrhiza) in our field and pot experiment, an index was employed for plant breeders and growers: average performance (when mycorrhizal and nonmycorrhizal) (Galván et al. 2011). We found that old landraces had a higher average performance than modern hybrids at low $\mathrm{P}$ both in the pot and field experiment, while at high $\mathrm{P}$ in the field experiment hybrids had a higher average performance. These results may explain the difference of phosphorus efficiency of maize groups where landraces had a relatively higher stability under low P conditions while hybrids had a relatively higher stability under high $\mathrm{P}$ conditions 
(Fig. 6.3). Thus, considering the stability problem, selecting for high average performance may a good choice.

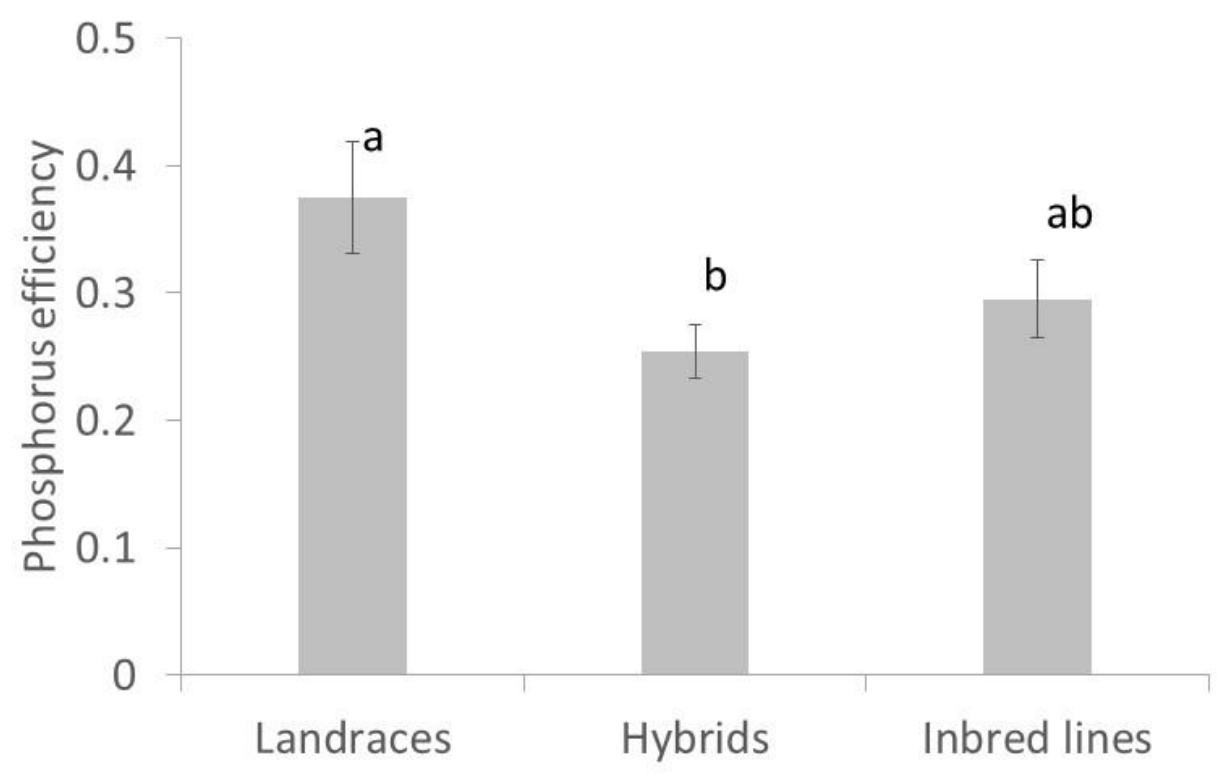

Fig. 6.2. Phosphorus efficiency (shoot biomass in rotated cores at $\mathrm{P}_{0} /$ shoot biomass in rotated cores at $\mathrm{P}_{2}$ ) among three categories of maize. Data from Chapter 2. Means with the same letter are not significantly different $(P<0.05)$. 


\section{Chapter 6}
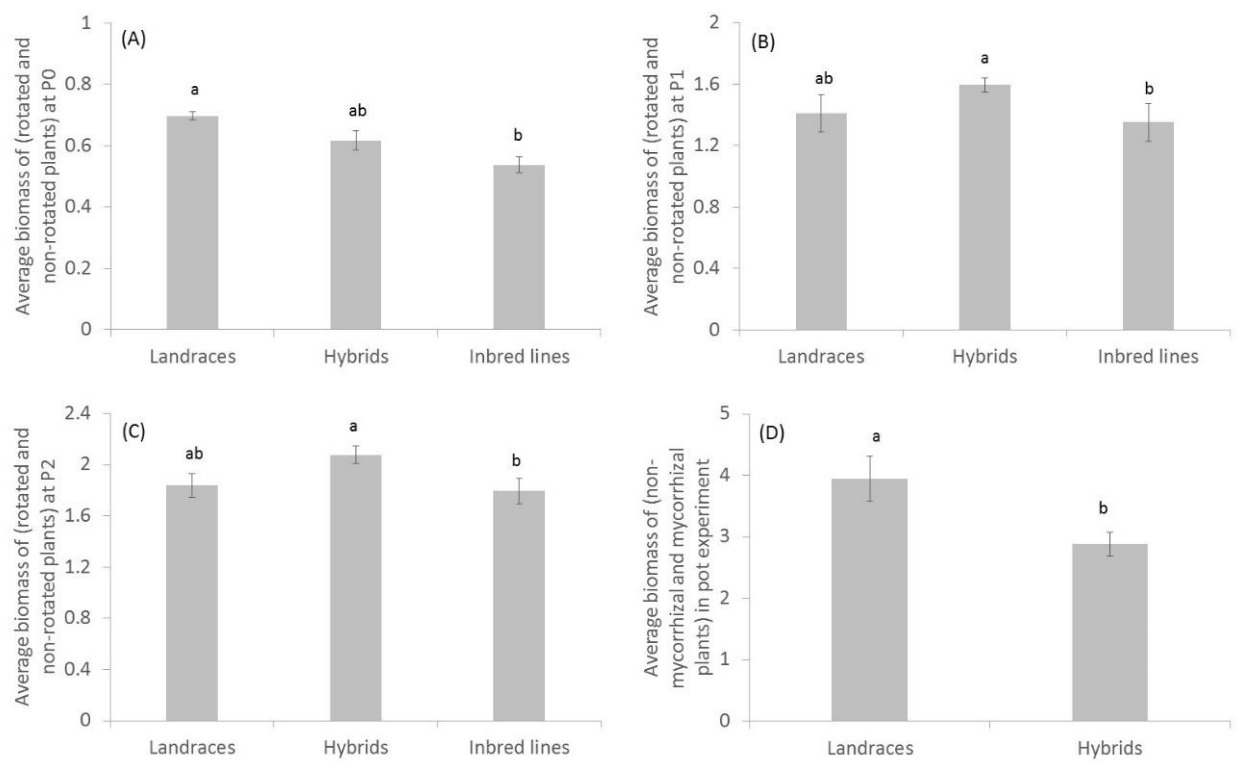

Fig. 6.3 Average performance in the field experiment at P0 (2.9 mg Olsen-P kg-1 soil, A), P1 (6.4 mg Olsen-P kg-1 soil, B), P2 (15.0 mg Olsen-P kg-1 soil, C) and in the pot experiment (5.3 mg Olsen-P kg-1 soil, D). Means with the same letter are not significantly different $(P<0.05)$.

\section{Phytate utilization by mycorrhizal maize}

Phytate is the most abundant organic P form in soil. It has been reported that mycorrhizal plants can use phytate as a P source (Feng et al. 2003; Wang et al. 2013). However, as noted in Chapter 3, earlier studies disregarded two important problems in the study of phytate utilization, viz., phosphate desorption from the mineral matrix after adding phytate and the differential effects of phytase and phosphatase on phytate mineralization. I showed that phytate adsorption (and concomitant phosphate desorption) and phytase activity cannot be ignored in studying phytate use by plants. I found a (small) increase of P uptake after phytate addition in the hyphal compartment by mycorrhizal maize. My study confirmed that AMF with associated hyphosphere organisms can acquire P from phytate; however, I cannot address the question whether the ability to produce phytase is a property of the fungus or of bacteria that are closely associated with hyphal walls. The small uptake also suggests that the mycorrhizal contribution to phytate use is unlikely to result in significant rates of phytate mineralization, which fits with the 


\section{General discussion}

result (Fig. 3.3) that the large phytate pool reflects its low potential for use by plants because of the strong sorption of phytate to metal (hydr)oxides and precipitation under high-pH conditions. So it is phytate availability, rather than enzyme activity, that determines its potential usefulness as $\mathrm{P}$ source in soil.

The second issue pertains to the nature of the enzymes that are involved in phytate degradation. Numerous studies have demonstrated that extraradical hyphae can increase acid or alkaline phosphatase activity in soil (Dodd et al. 1987; Tarafdar and Marschner 1994). In Chapter 3 I report increases in phytase and acid phosphatase activity after phytate addition to the hyphal compartment. The role of phytase released by plant roots in decomposition of phytate in soil has been shown (Hayes et al. 2000; Hayes et al. 1999; Richardson et al. 2000). Phytase is considered crucial for removing the first phosphate groups of the phytate molecule that contains six phosphate groups (Turner et al. 2002). Thus, phytase cannot be ignored in studies of phytate utilization. In Chapter 3 we found a positive correlation between acid phosphatase activity and phytase activity; also in Chapter 4 (the pot experiment in 2013) we also found a significantly positive correlation between enzymes $(r=0.48, P<0.001)$. Phosphatase enzymes hydrolyse the molecule with a lower number of phosphate groups. Their activities in concert may explain why phosphatase and phytase were correlated, and why in many studies (though not in mine) acid phosphatase activity correlated significantly positively with $\mathrm{P}$ acquisition from phytate. It has been found that in the rhizosphere phytase activity is positively correlated with acid phosphatase activity ( $\mathrm{Li}$ et al. 1997). Considering the soil $\mathrm{pH}(>7)$, the question may be raised whether it would have been better to measure alkaline phosphatase rather than acid phosphatase. However, according to Aono et al. (2004) alkaline phosphatase is primarily produced intracellularly and may be important in nutrient exchange at the symbiotic interface rather than in phosphate acquisition from the soil.

Although phytate was utilized by mycorrhizal plants, the maximum $\mathrm{P}$ recover rate was only $2 \%$, meaning that phytate is still a hard-used $\mathrm{P}$ resource by AMF. On the other hand, the $\mathrm{P}$ recovery rate of $\mathrm{KH}_{2} \mathrm{PO}_{4}$ was around $7 \%$ in an earlier study that used the same soil with the same maize varieties (Chu et al. 2013). From this perspective (in comparison with $\mathrm{KH}_{2} \mathrm{PO}_{4}$ ), phytate utilization by mycorrhizal plants cannot be ignored. Data from the experiment described in Chapter 4 (the pot experiment in 2012) confirm that phytate-P use may not be much lower than use of $\mathrm{KH}_{2} \mathrm{PO}_{4}$. When three cultivars were grown singly in pots 


\section{Chapter 6}

where phytate was added, biomass was $70 \%$ and $\mathrm{P}$ content $86 \%$ of that of pots where mineral $\mathrm{P}$ was added in the same amounts. In combination (where complementarity effects were noted), biomass in pots where phytate was added was $93 \%$ of that of pots with mineral P, and P content even $110 \%$. In Chapter 3 we found a significant interaction between maize varieties and AMF species for $\mathrm{P}$ uptake from phytate (Fig. 3.3; Table 3.4). To be more specific, HMY benefited more from F. mosseae than C. etunicatum, while XY335 benefited more from $C$. etunicatum than F. mosseae. This result suggests that mixing maize varieties in the presence of a multispecies mycorrhizal fungal inoculum will result in a better application of organic $P$.

\section{AMF functioning in plant-plant interactions}

Plant roots of different individuals of the same species or of different species can be linked by common mycorrhizal networks (CMNs) that constitute pathways for the transfer of resources. CMNs can regulate plant-plant interactions and plant community composition. Plant-plant interaction experiments showed that CMNs can reduce or amplify competitive inequalities among plants (Merrild et al. 2013). For example, Festuca ovina responded to AMF positively in monoculture, but negatively when mixed with other plant species (Scheublin et al. 2007). This result indicates that the cost-benefit ratio of plants connected to a mycorrhizal network is not the same for each plant species. This conclusion was supported by (Walder et al. 2012), who used the isotopes ${ }^{13} \mathrm{C},{ }^{15} \mathrm{~N}$ and ${ }^{33} \mathrm{P}$ to demonstrate that the carbon invested by different plant species in the CMNs was not proportional to the nutrients gained from that CMNs; in fact sorghum largely paid for the $\mathrm{C}$ that went to the mycorrhizal fungus, whereas flax obtained the larger nutritional benefits $(\mathrm{N}$ and P). Studies with agriculturally important crops show cases of complementarity. In a pot experiment with rice and mung bean grown singly and in mixtures, inoculation with AMF resulted in increases in fractional mycorrhizal colonization of both plants in the mixtures. Also above-ground biomass of both rice $(+57 \%)$ and mung bean $(+48 \%)$ increased in the mycorrhizal mixtures compared to the crops when grown singly. Total above-ground $\mathrm{N}$ and $\mathrm{P}$ content of rice in the mixture increased with $86 \%$ and $113 \%$ respectively, whereas that of mung bean increased with $149 \%$ and $319 \%$ respectively, compared to their monocultures (Xiao et al. 2010). Another experiment with rice and mung bean yielded comparable results (Li et al. 2009). By using various barriers they separated the 
root systems of both plants either completely, or allowed access between both plants by the mycorrhizal fungal network only or by the complete (mycorrhizal) root system. They also noted increased colonization of both plants in the presence of a mycorrhizal network (compared to the complete barrier), increased biomass of mung bean (but not of rice), and increased P contents of both plants. However, the magnitude of the effects reported as much smaller than in the study by Xiao et al. (2010). Such studies indicate the potential of mycorrhizal networks to contribute to overyielding, however, it should also be noted that in such experiments under controlled conditions one species of AMF was inoculated. In the field, where a mixed inoculum of different AMF species occurs, plant species or varietal selectivity may result in a lower importance of such mycorrhizal networks. In fact, the study by Montesinos-Navarro et al. (2012) suggests plant selectivity to be a major cause for overyielding because of complementarity in AMF species composition. Preliminary results of the AMF species composition of the field experiment in Chapter 4 also indicate fungal species diversity effects through intercropping, which likely reduced the importance of fungal networks.

A meta-analysis, using twenty-six published studies and examining a total of 246 instances of variety mixtures of wheat (Triticum aestivum L.) and barley (Hordeum vulgare L.), confirmed the potential of overall grain yield increase when growing varieties in mixtures (Kiær et al. 2009). The best known benefit resulting from mixing varieties is enhanced disease-resistance and pest-control resulting in overyielding and higher economic gains from such intercropped fields (Gunton 2011; Zhu et al. 2000). The causes could be: 1) dilution of susceptible individuals or preferred hosts; 2) the barrier effect of resistant individuals; 3) induction of resistance in individuals neighbouring infected plants; 4) changes in microclimate affecting the infection processes; and 5) providing a more heterogeneous resource supply that supports a higher abundance and diversity of natural enemies of crop pests (Brooker et al. 2016; Gunton 2011; Letourneau et al. 2011). Zhu et al. (2000) showed that enhanced rice crop genetic diversity lead to a reduction in rice blast infestation, and proposed that dilution effects and associated reductions in pathogen populations specific to a particular rice variety played a role. A second mechanism to explain overyielding when mixing crop varieties is complementarity effects. Schöb et al. (2015) found that barley genetic diversity had positive effects on aboveground biomass and attributed the overyielding due to weak complementarity effects, without specifying the niche dimensions of the varieties 


\section{Chapter 6}

that enabled this complementarity. They proposed that limited trait variation associated within barley varieties is responsible for the complementarity effects in diversity-productivity studies. Mixing wheat varieties or barley varieties has been shown to be an effective planting pattern to gain more yield, but, as stated above, AMF can be critical in varieties mixing systems.

Increasing $\mathrm{P}$ acquisition efficiency demands understanding the traits that contribute to that effect; and understanding potential trade-offs among different traits. In rice it was shown that the ability of varieties to acquire $\mathrm{Zn}$ through the mycorrhizal pathway was negatively correlated with (and hence traded off against) the ability to acquire $\mathrm{Zn}$ in the non-mycorrhizal condition (Gao et al. 2007). The same negative correlation and trade-off was found for members of the genus Kennedia (Ryan et al. 2012). It has been demonstrated that there are architectural tradeoffs between adventitious and basal roots (Walk et al. 2006; Zhu and Lynch 2004). In Chapter 2, we demonstrated, through the negative correlation between mycorrhizal responsiveness and $\mathrm{P}$ acquisition efficiency, that there is a trade-off between the mycorrhizal and root pathway of taking up $\mathrm{P}$ in the field. Such tradeoffs make it unlikely that we can stack all beneficial traits related to efficient $\mathrm{P}$ acquisition into one variety (Lynch 2007). We therefore designed experiments with mixing maize varieties in a pot experiments with and without AMF, and in a field experiment with natural AMF communities (Chapter 4). The results showed that mixing varieties with different strategies to acquire $\mathrm{P}$ may be an alternative approach to enhance productivity and to increase $\mathrm{P}$ uptake when plants are mycorrhizal (Fig. 6.1).

Various mechanisms for overyielding can be forwarded. First, I repeatedly observed increased mycorrhizal fungal hyphal length density, mycorrhizal root colonization, acid phosphate activity, P uptake and plant biomass when combining varieties both in pots and in the field. Both in the pot and field experiments, the soil $\mathrm{P}$ availability was low. Thus, $\mathrm{I}$ attribute more biomass in mixtures to more $\mathrm{P}$ uptake, and the latter to enhanced mycorrhizal fungal activity particularly the increase of hyphal length density in mixtures compared to that in monocultures (Fig. 4.2). The lack of overyielding in non-mycorrhizal pots strongly suggests that AMF were causally involved in overyielding. These results were due to complementarity effects (when calculated using the formula of Hector and Loreau (2001)). My studies are consistent with (but I did not provide an explicit test for) a role of reducing pathogen pressure as a consequence of mixing varieties, in space 
(Chapter 4) or time (Chapter 5). In natural systems, higher plant species diversity leads to higher productivity.

My observations seem to raise an interesting paradox, as overyielding was found in pots (when plants were inoculated with one mycorrhizal fungal species) and in the field (where the maize plants interacted with multiple fungal species and where preliminary analyses indicated a beneficial effect of variety mixing on AMF species richness). Reinhart and Anacker (2014) found that related plant species tended to have more divergent AMF communities than distantly related plant species, suggesting that functional complementarity may be increased by association with distinct AMF taxa. Such AMF species divergence may counteract niche conservatism, as related plants often possess similar traits and are therefore more likely to have similar niches and cause intense resource competition (Bennett et al. 2013). Very little is known, currently, to what extent different varieties of the same (crop) species also have divergent AMF communities. A lower limit to that divergence was noted by File et al. (2012), who showed that mycorrhizal network size and root colonization were greater when Ambrosia artemisiifolia was grown with siblings compared to conspecific but unrelated individuals (strangers). They claimed that plants benefit more from AMF growing with siblings compared to growing with strangers (File et al. 2012). They also found a decrease of hyphal length density when plants were grown with strangers compared to grown with siblings. This result was opposite to our result (Fig. 4.4.). I cannot explain the contradictory results so far.

In order to translate my results to field conditions (and especially to optimize the benefits from variety maxing), several issues need to be addressed, which were not considered when I did my experiments described in Chapter 4. First, different varieties have different growth rates. Species with higher growth rates in intercropping systems may pre-empt resources, amplifying competitive inequalities. I think that we need to mix varieties with comparable growth rates in order to increase chances for higher P uptake efficiency. Second, competition for light between maize varieties is also a relevant factor (Zhang et al. 2008). However, I did not consider the light factor. To optimize variety mixtures, we may need to use varieties with similar plant height. Third, both in the field and pot experiments, we only sampled once. To understand the balance between resource competition and complementarity between maize varieties, more above- and below-ground 


\section{Chapter 6}

sampling may be needed. The method described by Trinder et al. (2012) and Qiao et al. (2015) may constitute a useful approach.

\section{Intraspecific plant - soil feedbacks and the role of arbuscular mycorrhiza}

In Chapter 5, the presence and the identity of AMF influenced the growth of subsequent maize varieties, which was either the same variety (grown in "home" soil) or another variety (grown in "away" soil). I showed negative plant - soil feedback when two maize varieties were grown in the non-mycorrhizal condition. AMF generally reverted this negative plant - soil feedback into a positive feedback.

It has been shown that the legacy of AMF that the previous crop leaves behind can impact subsequent plant growth (Elbon and Whalen 2015). Moreover, AMF species or AMF species composition has an impact on feedback effects (Bever 2002a; b). For example, the presence of Panicum sphaerocarpon increased the relative abundance of Acaulospora morrowiae and Archaeospora trappei, thereby increasing the relative performance of Plantago lanceolata (Bever 2002b). This study provides a case of negative feedback generated by AMF. My results, which suggest positive feedback by AMF as well, do not allow a firm conclusion in this respect, as we measured hyphal length density and colonization, both of which are likely poor proxies for fungal fitness. Interestingly, the results of Chapter 5 showed that when the soil was inoculated with a mixture of three AMF species, the feedback coefficient for biomass and P uptake was largest (Fig. 5.4). It seems to mean that a more diverse AMF may generate more positive feedback dynamics. A more diverse plant community would also be expected to maintain a greater AMF community. In Chapter 4, initial analyses indicated a higher AMF richness in mixtures than in monocultures (data not shown). It is hard to predict the relationship between AMF diversity and hyphal length density (Chapter 4) or mycorrhizal responsiveness (Chapter 4); however, from Chapter 5, the positive effect of AMF diversity on feedback is evident. But I have to admit that in the second phase of the feedback experiment, we did not determine the AMF composition of plants in soils with the AMF mixture. We are not sure whether the three AMF species at the start of the experiment were still present and colonized plants in the second phase (Wagg et al. 2011), or whether the roots were colonized by only one AMF species (Jansa et al. 2007). These studies, together with Chapter 
4 and 5, call for heightened attention to the potential importance of AMF function and feedbacks due to AMF in mixing maize varieties.

\section{The relationship between plant - soil feedback and overyielding (complementarity)}

The negative plant - soil feedback for non-mycorrhizal plants, as described in Chapter 5, is interpreted by me as having been likely caused by pathogens. Pathogen inoculum tends to be higher in plants grown in conspecific-trained soils than heterospecific-trained soils (Zhu et al. 2000), and productivity increased and host-specific disease decreased with increasing community diversity (Schnitzer et al. 2011). Observations suggest that pathogen pressure could be a main reason for the reduced productivity in monoculture (Zhu et al. 2000). Schnitzer et al. (2011) and Maron et al. (2011) demonstrated that niche complementarity was a weaker determinant of the diversity-productivity relationship than pathogens. Under field condition, there is a yield suppression from pathogens, while with higher diversity, the pathogen-induced negative feedback was weaker. These data are part of increasing attention to the role of pathogens in causing the diversity-productivity relationship, but whereby focus shifts from explaining overyielding in mixtures towards underyielding in monocultures. In Chapter 4, I noted overyielding in mixtures compared to monoculture but only when plants are mycorrhizal, suggesting a mycorrhizal role in pathogen suppression as described by Newsham et al. (1994) and Newsham et al. (1995).

There is a trade-off between pathogen colonization and mycorrhizal colonization (Cordier et al. 1996). If there is only one crop variety, its host-specific pathogens could increase and lead to reduced productivity compared to a mixture of varieties (Zhu et al. 2000). Increased pathogen density could increase competition for root colonization with AMF. As pathogens are often faster colonizers than AMF, intercropping systems, which cause pathogen dilution, could result in higher mycorrhizal colonization. In Chapter 4, we also found a higher root colonization by AMF in mixtures than in monocultures (Fig. 4.S7). Similar results that intercropping leads to a higher colonization have previously been reported as well (Dawo et al. 2009; Li et al. 2009). Our data suggest that the negative plant - soil feedback due to pathogens and the suppression of that negative feedback by AMF (even resulting in positive feedback dynamics) are interrelated processes that should be examined together. 


\section{Chapter 6}

\section{Suggestions for further research}

Although I found overyielding in terms of P uptake and shoot biomass by mixing maize varieties, I did not find any significant overyielding in terms of grain production in the field. The reason could be that Olsen-P was high in our field (8.9 and $14.6 \mathrm{mg} \mathrm{kg}^{-1}$ in 2012 and 2013, respectively). In China and developed countries, it is hard to find farmland with very low available P. So, mixing maize varieties could be suitable for African agricultural farmland where soil available $\mathrm{P}$ is relatively low.

We may also need to pay attention to soil changes induced by mixing varieties besides AMF colonization and community (data not shown in Chapter 4, but we found increased AMF diversity in mixtures compared with monocultures), e.g. organic carbon and nitrogen (Cong et al. 2015) or microbial carbon and phosphorus (Tang et al. 2014). Maybe, on the short term, these do not change to such an extent that we can measure it, but on the long run, these soil traits may be affected by increased maize genetic diversity as well. Yields could benefit from such changes. At the same time, the aboveground competition for light and leaf space among maize varieties needs future research, because Zhu et al. (2015) found that the increased yield in maize-wheat intercropping system was mainly associated with shoot architectural plasticity.

I only combined two maize varieties. The question needs to be answered whether mixing more than two maize varieties will lead to higher P uptake, and/or higher yield and a further increase in AMF diversity, because Kiær et al. (2009) found that the relative mixing effect significantly increased with the effective number of component varieties by mixing wheat varieties or barley varieties.

There is increasing evidence that negative plant - soil feedback in monocropping is the main reason for overyielding through intercropping in agriculture, or random plant mixtures in natural ecosystems (Kulmatiski et al. 2012). We also found the importance of plant - soil feedback on maize growth in Chapter 5 and discussed the relationship between plant - soil feedback (pathogen dilution through mixing maize varieties) and an increased positive mycorrhizal role in increased P uptake by mixing maize varieties. However, how to mechanistically understand this relationship still needs further research. 


\section{Conclusion}

I undertook four empirical studies, which showed variation in mycorrhizal field responsiveness of maize varieties, the ability of mycorrhizal maize varieties to take up P from phytate, the role of AMF (species and community) in overyielding and in generating positive plant - soil feedbacks, and the possibility of overyielding by mixing maize varieties. Through these four chapters, I gave some new insights in the relationships among native AMF community, organic $\mathrm{P}$ and maize genetic diversity. Such new insights might support management of intraspecific crop diversity, AMF diversity, improving $\mathrm{P}$ acquisition efficiency and using organic $\mathrm{P}$, which should be seen as crucial for sustainable agriculture. 



\section{References}

Altschul SF, Madden TL, Schaffer AA, Zhang JH, Zhang Z, Miller W, Lipman DJ (1997) Gapped BLAST and PSI-BLAST: a new generation of protein database search programs. Nucleic Acids Research 25: 3389-3402.

An GH, Kobayashi S, Enoki H, Sonobe K, Muraki M, Karasawa T, Ezawa T (2010) How does arbuscular mycorrhizal colonization vary with host plant genotype? An example based on maize (Zea mays) germplasms. Plant and Soil 327: 441-453.

Aono T, Maldonado-Mendoza IE, Dewbre GR, Harrison MJ, Saito M (2004) Expression of alkaline phosphatase genes in arbuscular mycorrhizas. New Phytologist 162: 525-534.

Aulakh MS, Garg AK, Kabba BS (2007) Phosphorus accumulation, leaching and residual effects on crop yields from long-term applications in the subtropics. Soil Use and Management 23: 417-427.

Bais HP, Weir TL, Perry LG, Gilroy S, Vivanco JM (2006) The role of root exudates in rhizosphere interactions with plants and other organisms. Annual Review of Plant Biology 57: 233-266.

Bakker AW, Schippers B (1987) Microbial cyanide production in the rhizosphere in relation to potato yield reduction and Pseudomonas spp-mediated plant growth-stimulation. Soil Biology and Biochemistry 19: 451-457.

Baon JB, Smith SE, Alston AM (1993) Mycorrhizal responses of barley cultivars differing in P-efficiency. Plant and Soil 157: 97-105.

Barrett-Lennard EG, Dracup M, Greenway H (1993) Role of extracellular phosphatases in the phosphorus-nutrition of clover. Journal of Experimental Botany 44: 1595-1600.

Baylis G (1975) Magnolioid mycorrhiza and mycotrophy in root systems derived from it. Endomycorrhizas; Proceedings of a Symposium.

Bennett JA, Lamb EG, Hall JC, Cardinal-McTeague WM, Cahill JF (2013) Increased competition does not lead to increased phylogenetic overdispersion in a native grassland. Ecology Letters 16: 1168-1176.

Bever JD (2002a) Host-specificity of AM fungal population growth rates can generate feedback on plant growth. Plant and Soil 244: 281-290. 


\section{References}

Bever JD (2002b) Negative feedback within a mutualism: host-specific growth of mycorrhizal fungi reduces plant benefit. Proceedings of the Royal Society B-Biological Sciences 269: 2595-2601.

Bever JD (2003) Soil community feedback and the coexistence of competitors: conceptual frameworks and empirical tests. New Phytologist 157: 465-473.

Bever JD, Platt TG, Morton ER (2012) Microbial population and community dynamics on plant roots and their feedbacks on plant communities. Annual Review of Microbiology 66: 265-283.

Bever JD, Richardson SC, Lawrence BM, Holmes J, Watson M (2009) Preferential allocation to beneficial symbiont with spatial structure maintains mycorrhizal mutualism. Ecology Letters 12: 13-21.

Bever JD, Westover KM, Antonovics J (1997) Incorporating the soil community into plant population dynamics: the utility of the feedback approach. Journal of Ecology 85: 561-573.

Bezemer T, Lawson CS, Hedlund K, Edwards AR, Brook AJ, Igual JM, Mortimer SR, Van Der Putten WH (2006) Plant species and functional group effects on abiotic and microbial soil properties and plant-soil feedback responses in two grasslands. Journal of Ecology 94: 893-904.

Brooker RW, Bennett AE, Cong WF, Daniell TJ, George TS, Hallett PD, Hawes C, Iannetta PPM, Jones HG, Karley AJ, Li L, McKenzie BM, Pakeman RJ, Paterson E, Schob C, Shen JB, Squire G, Watson CA, Zhang CC, Zhang FS, Zhang JL, White PJ (2015) Improving intercropping: a synthesis of research in agronomy, plant physiology and ecology. New Phytologist 206: 107-117.

Brooker RW, Karley AJ, Newton AC, Pakeman RJ, Schöb C (2016) Facilitation and sustainable agriculture: a mechanistic approach to reconciling crop production and conservation. Functional Ecology: 98-107.

Brundrett MC, Abbott LK (1994) Mycorrhizal fungus propagules in the jarrah forest .1. Seasonal study of inoculum levels. New Phytologist 127: 539546.

Callaway RM (1998) Are positive interactions species-specific? Oikos: 202-207.

Cardoso IM, Kuyper TW (2006) Mycorrhizas and tropical soil fertility. Agriculture, Ecosystems and Environment 116: 72-84. 


\section{References}

Chen XP, Cui ZL, Fan MS, Vitousek P, Zhao M, Ma WQ, Wang ZL, Zhang WJ, Yan XY, Yang JC, Deng XP, Gao Q, Zhang Q, Guo SW, Ren J, Li SQ, Ye YL, Wang ZH, Huang JL, Tang QY, Sun YX, Peng XL, Zhang JW, He MR, Zhu YJ, Xue JQ, Wang GL, Wu L, An N, Wu LQ, Ma L, Zhang WF, Zhang FS (2014) Producing more grain with lower environmental costs. Nature 514: 486-489.

Chu Q (2013) The contribution of mycorrhizal pathway to P uptake efficeincy of maize (Zea mays L.). Dissertation for Doctor Degree, China Agricultural University.

Chu Q, Wang XX, Yang Y, Chen FJ, Zhang FS, Feng G (2013) Mycorrhizal responsiveness of maize (Zea mays L.) genotypes as related to releasing date and available P content in soil. Mycorrhiza 23: 497-505.

Cong WF, Hoffland E, Li L, Six J, Sun JH, Bao XG, Zhang FS, van der Werf W (2015) Intercropping enhances soil carbon and nitrogen. Global Change Biology 21: 1715-1726.

Cordell D, Drangert JO, White S (2009) The story of phosphorus: Global food security and food for thought. Global Environmental Change 19: 292-305.

Cordier C, Gianinazzi S, Gianinazzi-Pearson V (1996) Colonisation patterns of root tissues by Phytophthora nicotianae var parasitica related to reduced disease in mycorrhizal tomato. Plant and Soil 185: 223-232.

Da Silva ÁE, Gabelman WH, Coors JG (1992) Inheritance studies of lowphosphorus tolerance in maize (Zea mays L.), grown in a sand-alumina culture medium. Plant and Soil 146: 189-197.

Dalal R (1977) Soil organic phosphorus. Advances in Agronomy 29: 83-117.

Dalal RC, Quilt P (1977) Effects of N, P, liming, and Mo on nutrition and grainyield of pigeon pea. Agronomy Journal 69: 854-857.

Dawo MI, Wilkinson JM, Pilbeam DJ (2009) Interactions between plants in intercropped maize and common bean. Journal of the Science of Food and Agriculture 89: 41-48.

de Kroon H, Hendriks M, van Ruijven J, Ravenek J, Padilla FM, Jongejans E, Visser EJW, Mommer L (2012) Root responses to nutrients and soil biota: drivers of species coexistence and ecosystem productivity. Journal of Ecology 100: 6-15. 


\section{References}

Denison RF (2012) Darwinian agriculture: How understanding evolution can improve agriculture. Princeton University Press.

Dodd J, Burton C, Burns R, Jeffries P (1987) Phosphatase activity associated with the roots and the rhizosphere of plants infected with vesicular-arbuscular mycorrhizal fungi. New Phytologist 107: 163-172.

Ehrenfeld JG, Ravit B, Elgersma K (2005) Feedback in the plant-soil system. Annual Review of Environment and Resources 30: 75-115.

Elbon A, Whalen JK (2015) Phosphorus supply to vegetable crops from arbuscular mycorrhizal fungi: a review. Biological Agriculture and Horticulture 31: 73-90.

Fellbaum CR, Mensah JA, Cloos AJ, Strahan GE, Pfeffer PE, Kiers ET, Bucking $\mathrm{H}$ (2014) Fungal nutrient allocation in common mycorrhizal networks is regulated by the carbon source strength of individual host plants. New Phytologist 203: 646-656.

Feng G, Song Y, Li X, Christie P (2003) Contribution of arbuscular mycorrhizal fungi to utilization of organic sources of phosphorus by red clover in a calcareous soil. Applied Soil Ecology 22: 139-148.

File AL, Klironomos J, Maherali H, Dudley SA (2012) Plant kin recognition enhances abundance of symbiotic microbial partner. PLoS ONE 7.

Finckh M, Gacek E, Goyeau H, Lannou C, Merz U, Mundt C, Munk L, Nadziak J, Newton A, de Vallavieille-Pope C (2000) Cereal variety and species mixtures in practice, with emphasis on disease resistance. Agronomie 20: 813-837.

Fixen P, Grove J, Westerman R (1990) Testing soils for phosphorus. Soil Testing and Plant Analysis: 141-180.

Fox JW (2005) Interpreting the 'selection effect' of biodiversity on ecosystem function. Ecology Letters 8: 846-856.

Gai JP, Gao WJ, Liu L, Chen Q, Feng G, Zhang JL, Christie P, Li XL (2015) Infectivity and community composition of arbuscular mycorrhizal fungi from different soil depths in intensively managed agricultural ecosystems. Journal of Soils and Sediments 15: 1200-1211.

Galván GA, Kuyper TW, Burger K, Keizer LCP, Hoekstra RF, Kik C, Scholten OE (2011) Genetic analysis of the interaction between Allium species and 
arbuscular mycorrhizal fungi. Theoretical and Applied Genetics 122: 947960.

Galván GA, Parádi I, Burger K, Baar J, Kuyper TW, Scholten OE, Kik C (2009) Molecular diversity of arbuscular mycorrhizal fungi in onion roots from organic and conventional farming systems in the Netherlands. Mycorrhiza 19: 317-328.

Gao XP, Hoffland E, Stomph T, Grant CA, Zou CQ, Zhang FS (2012) Improving zinc bioavailability in transition from flooded to aerobic rice. A review. Agronomy for Sustainable Development 32: 465-478.

Gao XP, Kuyper TW, Zou CQ, Zhang FS, Hoffland E (2007) Mycorrhizal responsiveness of aerobic rice genotypes is negatively correlated with their zinc uptake when nonmycorrhizal. Plant and Soil 290: 283-291.

Garrett KA, Mundt CC (1999) Epidemiology in mixed host populations. Phytopathology 89: 984-990.

Gliessman SR (1985) Multiple cropping systems: A basis for developing an alternative agriculture. Office of Technology Assessment (ed) Innovative Technologies for Lesser Developed Countries Government Printing Office, Washington: 69-86.

Gollotte A, Van Tuinen D, Atkinson D (2004) Diversity of arbuscular mycorrhizal fungi colonising roots of the grass species Agrostis capillaris and Lolium perenne in a field experiment. Mycorrhiza 14: 111-117.

Gosling P, Mead A, Proctor M, Hammond JP, Bending GD (2013) Contrasting arbuscular mycorrhizal communities colonizing different host plants show a similar response to a soil phosphorus concentration gradient. New Phytologist 198: 546-556.

Gubry-Rangin C, Garcia M, Bena G (2010) Partner choice in Medicago Truncatula-Sinorhizobium symbiosis. Proceedings of the Royal Society BBiological Sciences 277: 1947-1951.

Gunton RM (2011) Integrating associational resistance into arable weed management. Agriculture, Ecosystems and Environment 142: 129-136.

Hajiboland R, Aliasgharzadeh N, Laiegh SF, Poschenrieder C (2010) Colonization with arbuscular mycorrhizal fungi improves salinity tolerance of tomato (Solanum lycopersicum L.) plants. Plant and Soil 331: 313-327. 


\section{References}

Hao L, Zhang J, Christie P, Li X (2008) Response of two maize inbred lines with contrasting phosphorus efficiency and root morphology to mycorrhizal colonization at different soil phosphorus supply levels. Journal of Plant Nutrition 31: 1059-1073.

Harrison KA, Bardgett RD (2010) Influence of plant species and soil conditions on plant-soil feedback in mixed grassland communities. Journal of Ecology 98: 384-395.

Hart MM, Reader RJ (2002) Does percent root length colonization and soil hyphal length reflect the extent of colonization for all AMF? Mycorrhiza 12: 297301.

Hayes J, Richardson A, Simpson R (2000) Components of organic phosphorus in soil extracts that are hydrolysed by phytase and acid phosphatase. Biology and Fertility of Soils 32: 279-286.

Hayes JE, Richardson AE, Simpson RJ (1999) Phytase and acid phosphatase activities in extracts from roots of temperate pasture grass and legume seedlings. Australian Journal of Plant Physiology 26: 801-809.

Heath KD, Tiffin P (2009) Stabilizing mechanisms in a legume-rhizobium mutualism. Evolution 63: 652-662.

Helgason T, Daniell TJ, Husband R, Fitter AH, Young JPW (1998) Ploughing up the wood-wide web? Nature 394: 431-431.

Helgason T, Merryweather JW, Denison J, Wilson P, Young JPW, Fitter AH (2002) Selectivity and functional diversity in arbuscular mycorrhizas of cooccurring fungi and plants from a temperate deciduous woodland. Journal of Ecology 90: 371-384.

Hetrick BAD, Wilson GWT, Cox TS (1992) Mycorrhizal dependence of modern wheat-varieties, landraces, and ancestors. Canadian Journal of Botany 70: 2032-2040.

Hetrick BAD, Wilson GWT, Todd TC (1996) Mycorrhizal response in wheat cultivars: relationship to phosphorus. Canadian Journal of Botany 74: 1925.

HilleRisLambers J, Harpole WS, Tilman D, Knops J, Reich PB (2004) Mechanisms responsible for the positive diversity-productivity relationship in Minnesota grasslands. Ecology Letters 7: 661-668. 


\section{References}

Hinsinger P (2001) Bioavailability of soil inorganic P in the rhizosphere as affected by root-induced chemical changes: a review. Plant and Soil 237: 173-195.

Hinsinger P, Betencourt E, Bernard L, Brauman A, Plassard C, Shen J, Tang X, Zhang F (2011) P for two, sharing a scarce resource: soil phosphorus acquisition in the rhizosphere of intercropped species. Plant Physiology 156: 1078-1086.

Hooper D, Chapin Iii F, Ewel J, Hector A, Inchausti P, Lavorel S, Lawton J, Lodge D, Loreau M, Naeem S (2005) Effects of biodiversity on ecosystem functioning: a consensus of current knowledge. Ecological Monographs 75: 3-35.

Hooper DU, Vitousek PM (1997) The effects of plant composition and diversity on ecosystem processes. Science 277: 1302-1305.

Jakobsen I (1983) Vesicular-arbuscular mycorrhiza in field-grown Crops. 2. Effect of inoculation on growth and nutrient-uptake in barley at 2 phosphorus levels in fumigated Soil. New Phytologist 94: 595-604.

Jakobsen I, Abbott LK, Robson AD (1992a) External hyphae of vesiculararbuscular mycorrhizal fungi associated with Trifolium Subterraneum L. 1. Spread of hyphae and phosphorus inflow into roots. New Phytologist 120: 371-380.

Jakobsen I, Abbott LK, Robson AD (1992b) External hyphae of vesicular arbuscular mycorrhizal fungi associated with Trifolium Subterraneum L. 2. Hyphal transport of P32 over defined distances. New Phytologist 120: 509-516.

Janos DP (2007) Plant responsiveness to mycorrhizas differs from dependence upon mycorrhizas. Mycorrhiza 17: 75-91.

Jansa J, Smith FA, Smith SE (2007) Are there benefits of simultaneous root colonization by different arbuscular mycorrhizal fungi? New Phytologist 177: 779-789.

Johnson D, Leake J, Ostle N, Ineson P, Read D (2002) In situ ${ }^{13} \mathrm{CO}_{2}$ pulse labelling of upland grassland demonstrates a rapid pathway of carbon flux from arbuscular mycorrhizal mycelia to the soil. New Phytologist 153: 327-334. 


\section{References}

Johnson D, Leake JR, Read DJ (2001) Novel in-growth core system enables functional studies of grassland mycorrhizal mycelial networks. New Phytologist 152: 555-562.

Joner EJ, Johansen A (2000) Phosphatase activity of external hyphae of two arbuscular mycorrhizal fungi. Mycological Research 104: 81-86.

Kaeppler SM, Parke JL, Mueller SM, Senior L, Stuber C, Tracy WF (2000) Variation among maize inbred lines and detection of quantitative trait loci for growth at low phosphorus and responsiveness to arbuscular mycorrhizal fungi. Crop Science 40: 358-364.

Khalil S, Loynachan TE, Tabatabai MA (1994) Mycorrhizal dependency and nutrient-uptake by improved and unimproved corn and soybean cultivars. Agronomy Journal 86: 949-958.

Kiær LP, Skovgaard IM, Østergård H (2009) Grain yield increase in cereal variety mixtures: a meta-analysis of field trials. Field Crops Research 114: 361373.

Kiers ET, Duhamel M, Beesetty Y, Mensah JA, Franken O, Verbruggen E, Fellbaum CR, Kowalchuk GA, Hart MM, Bago A, Palmer TM, West SA, Vandenkoornhuyse P, Jansa J, Bucking H (2011) Reciprocal rewards stabilize cooperation in the mycorrhizal symbiosis. Science 333: 880-882.

Klironomos JN (2002) Feedback with soil biota contributes to plant rarity and invasiveness in communities. Nature 417: 67-70.

Klironomos JN (2003) Variation in plant response to native and exotic arbuscular mycorrhizal fungi. Ecology 84: 2292-2301.

Klironomos JN, McCune J, Hart M, Neville J (2000) The influence of arbuscular mycorrhizae on the relationship between plant diversity and productivity. Ecology Letters 3: 137-141.

Koide RT (1991) Nutrient supply, nutrient demand and plant-response to mycorrhizal infection. New Phytologist 117: 365-386.

Koide RT (2000) Functional complementarity in the arbuscular mycorrhizal symbiosis. New Phytologist 147: 233-235.

Koide RT, Kabir Z (2000) Extraradical hyphae of the mycorrhizal fungus Glomus intraradices can hydrolyse organic phosphate. New Phytologist 148: $511-$ 517. 


\section{References}

Koopmans GF, Chardon WJ, McDowell RW (2007) Phosphorus movement and speciation in a sandy soil profile after long-term animal manure applications. Journal of Environmental Quality 36: 305-315.

Krüger M, Krüger C, Walker C, Stockinger H, Schüßler A (2012) Phylogenetic reference data for systematics and phylotaxonomy of arbuscular mycorrhizal fungi from phylum to species level. New Phytologist 193: 970-984.

Kulmatiski A, Beard KH, Heavilin J (2012) Plant-soil feedbacks provide an additional explanation for diversity-productivity relationships. Proceedings of the Royal Society B-Biological Sciences 279: 3020-3026.

Kuyper TW, De Goede RGM (2013) Interactions between higher plants and soil - dwelling organisms. Vegetation Ecology, Second Edition: 260-284.

Lehmann A, Barto EK, Powell JR, Rillig MC (2012) Mycorrhizal responsiveness trends in annual crop plants and their wild relatives-a meta-analysis on studies from 1981 to 2010. Plant and Soil 355: 231-250.

Leifheit EF, Verbruggen E, Rillig MC (2014) Rotation of hyphal in-growth cores has no confounding effects on soil abiotic properties. Soil Biology and Biochemistry 79: 78-80.

Lekberg Y, Koide RT (2005) Is plant performance limited by abundance of arbuscular mycorrhizal fungi? A meta-analysis of studies published between 1988 and 2003. New Phytologist 168: 189-204.

Letourneau DK, Armbrecht I, Rivera BS, Lerma JM, Carmona EJ, Daza MC, Escobar S, Galindo V, Gutierrez C, Lopez SD, Mejia JL, Rangel AMA, Rangel JH, Rivera L, Saavedra CA, Torres AM, Trujillo AR (2011) Does plant diversity benefit agroecosystems? A synthetic review. Ecological Applications 21: 9-21.

Li H, Huang G, Meng Q, Ma L, Yuan L, Wang F, Zhang W, Cui Z, Shen J, Chen X, Jiang R, Zhang F (2011) Integrated soil and plant phosphorus management for crop and environment in China. A review. Plant and Soil 349: 157-167.

Li H, Liu J, Li G, Shen J, Bergstrom L, Zhang F (2015) Past, present, and future use of phosphorus in Chinese agriculture and its influence on phosphorus losses. Ambio 44: S274-S285. 


\section{References}

Li HY, Smith SE, Holloway RE, Zhu YG, Smith FA (2006) Arbuscular mycorrhizal fungi contribute to phosphorus uptake by wheat grown in a phosphorus-fixing soil even in the absence of positive growth responses. New Phytologist 172: 536-543.

Li L, Tang C, Rengel Z, Zhang FS (2004) Calcium, magnesium and microelement uptake as affected by phosphorus sources and interspecific root interactions between wheat and chickpea. Plant and Soil 261: 29-37.

Li L, Tilman D, Lambers H, Zhang FS (2014) Plant diversity and overyielding: insights from belowground facilitation of intercropping in agriculture. New Phytologist 203: 63-69.

Li M, Osaki M, Rao IM, Tadano T (1997) Secretion of phytase from the roots of several plant species under phosphorus-deficient conditions. Plant and Soil 195: 161-169.

Li SM, Li L, Zhang FS, Tang C (2004) Acid phosphatase role in chickpea/maize intercropping. Ann Bot-London 94: 297-303.

Li XL, George E, Marschner H (1991) Extension of the phosphorus depletion zone in VA-mycorrhizal white clover in a calcareous soil. Plant and Soil 136: 41-48.

Li YF, Ran W, Zhang RP, Sun SB, Xu GH (2009) Facilitated legume nodulation, phosphate uptake and nitrogen transfer by arbuscular inoculation in an upland rice and mung bean intercropping system. Plant and Soil 315: 285296.

Lin GG, McCormack ML, Guo DL (2015) Arbuscular mycorrhizal fungal effects on plant competition and community structure. Journal of Ecology 103: 1224-1232.

Liu Y, Mi GH, Chen FJ, Zhang JH, Zhang FS (2004) Rhizosphere effect and root growth of two maize (Zea mays L.) genotypes with contrasting P efficiency at low P availability. Plant Science 167: 217-223.

Loreau M, Hector A (2001) Partitioning selection and complementarity in biodiversity experiments. Nature 412: 72-76.

Lynch JP (2007) Roots of the second green revolution. Australian Journal of Botany 55: 493-512. 
Maherali H, Klironomos JN (2007) Influence of phylogeny on fungal community assembly and ecosystem functioning. Science 316: 1746-1748.

Mangan SA, Eom AH, Adler GH, Yavitt JB, Herre EA (2004) Diversity of arbuscular mycorrhizal fungi across a fragmented forest in Panama: insular spore communities differ from mainland communities. Oecologia 141: 687-700.

Mangan SA, Herre EA, Bever JD (2010) Specificity between neotropical tree seedlings and their fungal mutualists leads to plant-soil feedback. Ecology 91: 2594-2603.

Maron JL, Marler M, Klironomos JN, Cleveland CC (2011) Soil fungal pathogens and the relationship between plant diversity and productivity. Ecology Letters 14: 36-41.

McKane RB, Johnson LC, Shaver GR, Nadelhoffer KJ, Rastetter EB, Fry B, Giblin AE, Kielland K, Kwiatkowski BL, Laundre JA, Murray G (2002) Resource-based niches provide a basis for plant species diversity and dominance in arctic tundra. Nature 415: 68-71.

Merrild MP, Ambus P, Rosendahl S, Jakobsen I (2013) Common arbuscular mycorrhizal networks amplify competition for phosphorus between seedlings and established plants. New Phytologist 200: 229-240

Mills KE, Bever JD (1998) Maintenance of diversity within plant communities: Soil pathogens as agents of negative feedback. Ecology 79: 1595-1601.

Montesinos-Navarro A, Segarra-Moragues JG, Valiente-Banuet A, Verdu M (2012) The network structure of plant-arbuscular mycorrhizal fungi. New Phytologist 194: 536-547.

Moora M, Zobel M (1996) Effect of arbuscular mycorrhiza on inter- and intraspecific competition of two grassland species. Oecologia 108: 79-84.

Munkvold L, Kjoller R, Vestberg M, Rosendahl S, Jakobsen I (2004) High functional diversity within species of arbuscular mycorrhizal fungi. New Phytologist 164: 357-364.

Muriithi-Muchane MN (2013) Influences of agricultural management practices on arbuscular mycorrhizal fungal symbioses in Kenyan agro-ecosystems. Wageningen University. 


\section{References}

Murphy J, Riley JP (1962) A modified single solution method for the determination of phosphate in natural waters. Analytica Chimica Acta 27: 31-36.

Nannipieri P, Giagnoni L, Landi L, Renella G (2011) Role of phosphatase enzymes in soil. Phosphorus in Action. Springer.

Neumann G (2006) Quantitative determination of acid phosphatase activity in the rhizosphere and on the root surface. In: Jones, D.L. (Eds.), 4.2 Biochemistry. In: Luster, J., Finlay, R. (Eds.), Handbook of Methods used in Rhizosphere Research, Online Edition.

Newsham KK, Fitter AH, Watkinson AR (1994) Root pathogenic and arbuscular mycorrhizal fungi determine fecundity of asymptomatic Plants in the Field. Journal of Ecology 82: 805-814.

Newsham KK, Fitter AH, Watkinson AR (1995) Arbuscular mycorrhiza protect an annual grass from root pathogenic fungi in the field. Journal of Ecology 83: 991-1000.

Newton A, Guy D, Nadziak J, Gacek E (2002) The effect of inoculum pressure, germplasm selection and environment on spring barley cultivar mixtures efficacy. Euphytica 125: 325-335.

Oehl F, Sieverding E, Ineichen K, Mäder P, Boller T, Wiemken A (2003) Impact of land use intensity on the species diversity of arbuscular mycorrhizal fungi in agroecosystems of central Europe. Applied and Environmental Microbiology 69: 2816-2824.

Oehl F, Sieverding E, Mäder P, Dubois D, Ineichen K, Boller T, Wiemken A (2004) Impact of long-term conventional and organic farming on the diversity of arbuscular mycorrhizal fungi. Oecologia 138: 574-583.

Ognalaga M, Frossard E, Thomas F (1994) Glucose-1-phosphate and myoinositol hexaphosphate adsorption mechanisms on goethite. Soil Science Society of America Journal 58: 332-337.

Oliveira CA, Sá NM, Gomes EA, Marriel IE, Scotti MR, Guimarães CT, Schaffert RE, Alves V (2009) Assessment of the mycorrhizal community in the rhizosphere of maize (Zea mays L.) genotypes contrasting for phosphorus efficiency in the acid savannas of Brazil using denaturing gradient gel electrophoresis (DGGE). Applied Soil Ecology 41: 249-258. 


\section{References}

Olsson PA, Baath E, Jakobsen I (1997) Phosphorus effects on the mycelium and storage structures of an arbuscular mycorrhizal fungus as studied in the soil and roots by analysis of fatty acid signatures. Applied and Environmental Microbiology 63: 3531-3538.

Olsson S, Gerhardson B (1992) Effects of long-term barley monoculture on plantaffecting soil microbiota. Plant and Soil 143: 99-108.

Plenchette C, Fortin JA, Furlan V (1983) Growth-responses of several plantspecies to mycorrhizae in a soil of moderate P-fertility. 1. Mycorrhizal dependency under field conditions. Plant and Soil 70: 199-209.

Pugnaire FI, Haase P, Puigdefabregas J (1996) Facilitation between higher plant species in a semiarid environment. Ecology 77: 1420-1426.

Qiao X, Bei SK, Li CJ, Dong Y, Li HG, Christie P, Zhang FS, Zhang JL (2015) Enhancement of faba bean competitive ability by arbuscular mycorrhizal fungi is highly correlated with dynamic nutrient acquisition by competing wheat. Scientific Reports 5.

Ravenek JM, Bessler H, Engels C, Scherer-Lorenzen M, Gessler A, Gockele A, De Luca E, Temperton VM, Ebeling A, Roscher C, Schmid B, Weisser WW, Wirth C, de Kroon H, Weigelt A, Mommer L (2014) Long-term study of root biomass in a biodiversity experiment reveals shifts in diversity effects over time. Oikos 123: 1528-1536.

Reinhart KO, Anacker BL (2014) More closely related plants have more distinct mycorrhizal communities. Aob Plants 6.

Rengel Z, Marschner P (2005) Nutrient availability and management in the rhizosphere: exploiting genotypic differences. New Phytologist 168: 305312.

Richardson A, Hadobas P, Hayes J (2000) Acid phosphomonoesterase and phytase activities of wheat (Triticum aestivum L.) roots and utilization of organic phosphorus substrates by seedlings grown in sterile culture. Plant, Cell and Environment 23: 397-405.

Richardson AE, George TS, Hens M, Simpson RJ (2005) Utilization of soil organic phosphorus by higher plants. Organic Phosphorus in the Environment: 165-184. 


\section{References}

Ryan MH, Tibbett M, Edmonds-Tibbett T, Suriyagoda LDB, Lambers H, Cawthray GR, Pang J (2012) Carbon trading for phosphorus gain: the balance between rhizosphere carboxylates and arbuscular mycorrhizal symbiosis in plant phosphorus acquisition. Plant, Cell \& Environment 35: 2170-2180.

Sattari SZ, Bouwman AF, Giller KE, van Ittersum MK (2012) Residual soil phosphorus as the missing piece in the global phosphorus crisis puzzle. Proceedings of the National Academy of Sciences of the United States of America 109: 6348-6353.

Sawers RJH, Gebreselassie MN, Janos DP, Paszkowski U (2010) Characterizing variation in mycorrhiza effect among diverse plant varieties. Theoretical and Applied Genetics 120: 1029-1039.

Sawers RJH, Gutjahr C, Paszkowski U (2008) Cereal mycorrhiza: an ancient symbiosis in modern agriculture. Trends in Plant Science 13: 93-97.

Schöb C, Kerle S, Karley AJ, Morcillo L, Pakeman RJ, Newton AC, Brooker RW (2015) Intraspecific genetic diversity and composition modify specieslevel diversity-productivity relationships. New Phytologist 205: 720-730.

Scheublin TR, Van Logtestijn RSP, Van der Heijden MGA (2007) Presence and identity of arbuscular mycorrhizal fungi influence competitive interactions between plant species. Journal of Ecology 95: 631-638.

Schnitzer SA, Klironomos JN, HilleRisLambers J, Kinkel LL, Reich PB, Xiao K, Rillig MC, Sikes BA, Callaway RM, Mangan SA (2011) Soil microbes drive the classic plant diversity-productivity pattern. Ecology 92: 296-303.

Schoumans OF, Chardon WJ (2015) Phosphate saturation degree and accumulation of phosphate in various soil types in The Netherlands. Geoderma 237: 325-335.

Schwertmann U (1970) Der einfluss einfacher organischer anionen auf die bildung von goethit und hämatit aus amorphen Fe (III)-hydroxid. Geoderma 3: 207-214.

Sharpley A, Foy B, Withers P (2000) Practical and innovative measures for the control of agricultural phosphorus losses to water: An overview. Journal of Environmental Quality 29: 1-9. 


\section{References}

Shenoy VV, Kalagudi GM (2005) Enhancing plant phosphorus use efficiency for sustainable cropping. Biotechnology Advances 23: 501-513.

Sieverding E, Toro S (1988) Influence of soil-water regimes on va mycorrhiza .5. Performance of different vam fungal species with cassava. Journal of Agronomy and Crop Science 161: 322-332.

Smith SE, Read DJ (2008) Mycorrhizal symbiosis. Academic Press.

Smith SE, Smith FA, Jakobsen I (2003) Mycorrhizal fungi can dominate phosphate supply to plants irrespective of growth responses. Plant Physiology 133: 16-20.

Stewart J, Tiessen H (1987) Dynamics of soil organic phosphorus. Biogeochemistry 4: 41-60.

Tamura K, Stecher G, Peterson D, Filipski A, Kumar S (2013) MEGA6: Molecular Evolutionary Genetics Analysis Version 6.0. Molecular Biology and Evolution 30: 2725-2729.

Tang XY, Bernard L, Brauman A, Deleporte P, Desclaux D, Souche G, Placella S A, Hinsinger P (2014) Increase in microbial biomass and phosphorus availability in the rhizosphere of intercropped cereal and legumes under field conditions. Soil Biology and Biochemistry 75: 86-93.

Tarafdar J, Claassen N (1988) Organic phosphorus compounds as a phosphorus source for higher plants through the activity of phosphatases produced by plant roots and microorganisms. Biology and Fertility of Soils 5: 308-312.

Tarafdar J, Marschner H (1994) Phosphatase activity in the rhizosphere and hyphosphere of VA mycorrhizal wheat supplied with inorganic and organic phosphorus. Soil Biology and Biochemistry 26: 387-395.

Tian H, Drijber RA, Niu XS, Zhang JL, Li XL (2011) Spatio-temporal dynamics of an indigenous arbuscular mycorrhizal fungal community in an intensively managed maize agroecosystem in North China. Applied Soil Ecology 47: 141-152.

Tilman D, Reich PB, Knops JMH (2006) Biodiversity and ecosystem stability in a decade-long grassland experiment. Nature 441: 629-632.

Tinker P, Nye P (2000) Solute movement in the rhizosphere. Oxford University Press, Oxford. 


\section{References}

Trinder C, Brooker R, Davidson H, Robinson D (2012) Dynamic trajectories of growth and nitrogen capture by competing plants. New Phytologist 193: 948-958.

Trouvelot A, Kough, Gianiazzi-Pearson V (1986) Mesure du taux de mycorrhization VA d'un système radiculaire. Recherche de methodsd'estimation ayant une signification fonctionnelle. In: GianiazziPearson V, Gianiazzi S, (eds), Physiological Genetical Aspects of Mycorrhizae, Paris: INRA Press, 217-221.

Turner BL (2008) Resource partitioning for soil phosphorus: a hypothesis. Journal of Ecology 96: 698-702.

Turner BL, Cade-Menun BJ, Condron LM, Newman S (2005) Extraction of soil organic phosphorus. Talanta 66: 294-306.

Turner BL, McKelvie ID (2002) A novel technique for the pre-concentration and extraction of inositol hexakisphosphate from soil extracts with determination by phosphorus-31 nuclear magnetic resonance. Journal of Environmental Quality 31: 466-470.

Turner BL, Papházy MJ, Haygarth PM, McKelvie ID (2002) Inositol phosphates in the environment. Philosophical Transactions of the Royal Society of London Series B: Biological Sciences 357: 449-469.

Umbanhowar J, McCann K (2005) Simple rules for the coexistence and competitive dominance of plants mediated by mycorrhizal fungi. Ecology Letters 8: 247-252.

Van de Voorde TF, Van der Putten WH, Martijn Bezemer T (2011) Intra- and interspecific plant-soil interactions, soil legacies and priority effects during old - field succession. Journal of Ecology 99: 945-953.

Van der Heijden MG, Horton TR (2009) Socialism in soil? The importance of mycorrhizal fungal networks for facilitation in natural ecosystems. Journal of Ecology 97: 1139-1150.

Van der Heijden MG, Klironomos JN, Ursic M, Moutoglis P, Streitwolf-Engel R, Boller T, Wiemken A, Sanders IR (1998) Mycorrhizal fungal diversity determines plant biodiversity, ecosystem variability and productivity. Nature 396: 69-72. 


\section{References}

Van der Putten W, Van Dijk C, Peters B (1993) Plant-specific soil-borne diseases contribute to succession in foredune vegetation. Nature 362: 53 - 56.

Van der Zee SE, Van Riemsdijk WH (1988) Model for long-term phosphate reaction kinetics in soil. Journal of Environmental Quality 17: 35-41.

Van Tuinen D, Jacquot E, Zhao B, Gollotte A, Gianinazzi-Pearson V (1998) Characterization of root colonization profiles by a microcosm community of arbuscular mycorrhizal fungi using 25S rDNA-targeted nested PCR. Molecular Ecology 7: 879-887.

Vance CP (2001) Symbiotic nitrogen fixation and phosphorus acquisition. Plant nutrition in a world of declining renewable resources. Plant Physiology 127: 390-397.

Vance CP, Uhde-Stone C, Allan DL (2003) Phosphorus acquisition and use: critical adaptations by plants for securing a nonrenewable resource. New Phytologist 157: 423-447.

Vandenkoornhuyse P, Husband R, Daniell T, Watson I, Duck J, Fitter A, Young J (2002) Arbuscular mycorrhizal community composition associated with two plant species in a grassland ecosystem. Molecular Ecology 11: 15551564.

Verbruggen E, Kiers ET (2010) Evolutionary ecology of mycorrhizal functional diversity in agricultural systems. Evolutionary Applications 3: 547-560.

Vestberg M, Kahiluoto H, Wallius E (2011) Arbuscular mycorrhizal fungal diversity and species dominance in a temperate soil with long-term conventional and low-input cropping systems. Mycorrhiza 21: 351-361.

Vitousek PM, Naylor R, Crews T, David MB, Drinkwater LE, Holland E, Johnes PJ, Katzenberger J, Martinelli LA, Matson PA, Nziguheba G, Ojima D, Palm CA, Robertson GP, Sanchez PA, Townsend AR, Zhang FS (2009) Nutrient imbalances in agricultural development. Science 324: 1519-1520.

Wagg C, Jansa J, Stadler M, Schmid B, Van der Heijden MGA (2011) Mycorrhizal fungal identity and diversity relaxes plant-plant competition. Ecology 92: 1303-1313.

Walder F, Niemann H, Natarajan M, Lehmann MF, Boller T, Wiemken A (2012) Mycorrhizal networks: common goods of plants shared under unequal terms of trade. Plant Physiology 159: 789-797. 


\section{References}

Walk TC, Jaramillo R, Lynch JP (2006) Architectural tradeoffs between adventitious and basal roots for phosphorus acquisition. Plant and Soil 279: 347-366.

Wang DM, Marschner P, Solaiman Z, Rengel Z (2007) Belowground interactions between intercropped wheat and Brassicas in acidic and alkaline soils. Soil Biology and Biochemistry 39: 961-971.

Wang F, Jiang R, Kertesz MA, Zhang F, Feng G (2013) Arbuscular mycorrhizal fungal hyphae mediating acidification can promote phytate mineralization in the hyphosphere of maize (Zea mays L.). Soil Biology and Biochemistry 65: 69-74.

Wang X, Wang X, Feng G (2014) Optimized nitrogen fertilizer management achieved higher diversity of arbuscular mycorrhiza fungi and high-yielding maize (Zea mays L.). Crop and Pasture Science 66: 706-714

Weremijewicz J, Janos DP (2013) Common mycorrhizal networks amplify size inequality in Andropogon gerardii monocultures. New Phytologist 198: 203213.

Westerman RL (1990) Soil testing and plant analysis. Soil Science Society of America, Inc.

Wilson GWT, Hartnett DC (1998) Interspecific variation in plant responses to mycorrhizal colonization in tallgrass prairie. American Journal of Botany 85: 1732-1738.

Wolfe MS, Baresel JP, Desclaux D, Goldringer I, Hoad S, Kovacs G, Loschenberger F, Miedaner T, Ostergard H, van Bueren ETL (2008) Developments in breeding cereals for organic agriculture. Euphytica 163: 323-346.

Wright DP, Scholes JD, Read DJ, Rolfe SA (2005) European and African maize cultivars differ in their physiological and molecular responses to mycorrhizal infection. New Phytologist 167: 881-896.

Xiao TJ, Yang QS, Ran W, Xu GH, Shen QR (2010) Effect of inoculation with arbuscular mycorrhizal fungus on nitrogen and phosphorus utilization in upland rice-mungbean intercropping system. Agricultural Sciences in China 9: 528-535. 


\section{References}

Yang Y (2009) Variation of phosphorus (P) efficiencies and mycorrhizal dependence of maize cultivars breeded in different years. Dissertation for Master Degree, China Agricultural University.

Zhang L, Fan JQ, Ding XD, He XH, Zhang FS, Feng G (2014) Hyphosphere interactions between an arbuscular mycorrhizal fungus and a phosphate solubilizing bacterium promote phytate mineralization in soil. Soil Biology and Biochemistry 74: 177-183.

Zhang L, Van der Werf W, Bastiaans L, Zhang S, Li B, Spiertz JHJ (2008) Light interception and utilization in relay intercrops of wheat and cotton. Field Crops Research 107: 29-42.

Zhang T, Shi N, Bai DS, Chen YL, Feng G (2012) Arbuscular mycorrhizal fungi promote the growth of Ceratocarpus arenarius (Chenopodiaceae) with no enhancement of phosphorus nutrition. PLoS ONE 7.

Zhang WF, Ma WQ, Ji YX, Fan MS, Oenema O, Zhang FS (2008) Efficiency, economics, and environmental implications of phosphorus resource use and the fertilizer industry in China. Nutrient Cycling in Agroecosystems 80: 131-144.

Zhu JM, Lynch JP (2004) The contribution of lateral rooting to phosphorus acquisition efficiency in maize (Zea mays) seedlings. Functional Plant Biology 31: 949-958.

Zhu JQ (2015) Plant plasticity in intercropping: mechanisms and consequences. Wageningen University.

Zhu YG, Smith SE, Barritt AR, Smith FA (2001) Phosphorus (P) efficiencies and mycorrhizal responsiveness of old and modern wheat cultivars. Plant and Soil 237: 249-255.

Zhu YY, Chen HR, Fan JH, Wang YY, Li Y, Chen JB, Fan JX, Yang SS, Hu LP, Leung H, Mew TW, Teng PS, Wang ZH, Mundt CC (2000) Genetic diversity and disease control in rice. Nature 406: 718-722.

Zobel M, Moora M (1995) Interspecific competition and arbuscular mycorrhiza importance for the coexistence of 2 calcareous grassland species. Folia Geobotanica and Phytotaxonomica 30: 223-230. 


\section{References}

Zobel M, Öpik M (2014) Plant and arbuscular mycorrhizal fungal (AMF) communities-which drives which? Journal of Vegetation Science 25: $1133-1140$. 


\section{Summary}

Phosphorus $(\mathrm{P})$ is a main limiting factor for agricultural production, but overusing $\mathrm{P}$ fertilizer has brought serious environmental damages in China. Improving $\mathrm{P}$ acquisition efficiency of agricultural crops is an urgent topic. It has been proven repeatedly that arbuscular mycorrhizal fungi (AMF) and genetic diversity within one crop plant can play important roles in P uptake by crops. The main objective of this thesis was to understand the role of the arbuscular mycorrhizal symbiosis in $\mathrm{P}$ acquisition efficiency of different maize varieties. The specific objectives were to test: 1 ) how $\mathrm{P}$ uptake by maize varieties responds to colonization by the native AMF community in the field; and 2) whether AMF hyphae take up P for plants from phytate which is the most abundant organic $\mathrm{P}$ form in soil; 3) whether mixing maize cultivars can improve maize productivity and whether AMF can play a role in this system; and 4) how AMF species (or community) legacy affects successional maize growth. In this thesis, I combined field experiments and greenhouse experiments and made use of maize genetic diversity and (native) AMF to improve $\mathrm{P}$ (including inorganic and organic $\mathrm{P}$ ) acquisition.

The effects of one single AMF species on maize growth and nutrient uptake have been well studied, but how maize varieties respond to the native AMF community has been insufficiently studied. In Chapter 2, I focused on how maize varieties responded to the native AMF community by using rotated cores in the field, to compare mycorrhizal responsiveness among 20 maize varieties and the difference of the AMF native community of four maize varieties (two old landraces and two modern hybrids). The results indicated that, 1) increased $\mathrm{P}$ fertilizer significantly reduced mycorrhizal responsiveness in the field; 2) a complicated relationship exists between mycorrhizal responsiveness in the field and pot experiment; 3) there was no significant difference between old and modern maize varieties in terms of mycorrhizal responsiveness and colonization; 4) there were only small differences in AMF community composition among the four maize varieties. By comparing mycorrhizal responsiveness of maize varieties between in the pot experiment and in the field experiment (with in-growth cores), I found mycorrhizal responsiveness of maize varieties in the pot experiment was significantly larger than that in the field experiment. Thus, mycorrhizal responsiveness of varieties within one cereal plant species tested classically in pots may not present their realistically mycorrhizal responsiveness in field. 


\section{Summary}

Phytate is the most abundant form of organic $\mathrm{P}$ in soil. To explore the potential of phytate utilization by plants is agriculturally and environmentally essential. Increased P nutrition of mycorrhizal plants derived from phytate has been reported, indicating that phytate can be a potential P source. However, earlier studies assessed phytate use by using acid phosphatase rather than phytase, and did not consider that phytate adsorption could lead to phosphate release. Thus, I investigated the effect of mycorrhizal hyphae-mediated phytase activity on $\mathrm{P}$ uptake by maize in Chapter 3. I conducted a rhizobox experiment to explore phytate use by mycorrhizal hyphae for two maize varieties. The results showed that: 1) phytate addition increased phytase and acid phosphatase activity, and resulted in increased P uptake and plant biomass; 2) the increase in P uptake and biomass were correlated with the increase of phytase activity but not with the increase of acid phosphatase activity; 3) lower phytate addition rate increased, but higher addition rates decreased hyphal length density. I conclude that $\mathrm{P}$ from phytate can be used by mycorrhizal plants, but that the phytate contribution to plant nutrition is likely limited. Phytase activity is a more relevant indicator to assess phytate use. In addition, there was a significant interaction between maize varieties and AMF species in taking up $\mathrm{P}$ from phytate, which implies there is a possibility to combine different maize varieties to increase total yield using phytate. Besides, I used an empirical relationship to assess phosphate release due to phytate addition. My calculation implies that phosphate desorption cannot be ignored when assessing phytate use, particularly when a large amount of phytate is applied as a P source.

In multispecies natural ecosystems, AMF can play a key role in enhancing plant productivity. However, their role in enhancing crop productivity in mixed cropping systems is still poorly understood. In Chapter 4, I conducted both greenhouse and field experiments to investigate whether mixing maize varieties with different $\mathrm{P}$ acquisition strategies could lead to overyielding, and what roles AMF play in this system with two maize varieties. The results showed that mixing maize varieties resulted in overyielding, both in $\mathrm{P}$ uptake and shoot biomass, but only when plants were mycorrhizal. At the same time, I found higher hyphal length density and higher AMF diversity in mixtures compared to the monocultures in the field experiment, and higher colonization rate and higher hyphal length density in mixtures in the pot experiment. Thus, I propose that overyielding by mixing maize varieties might be due to increased mycorrhizal 
performance leading to more $\mathrm{P}$ uptake. I also used the partitioning formula to calculate the contribution through the selection effect and complementarity effect to overyielding. I found that the increase of the total yield and $\mathrm{P}$ uptake in mixtures was largely due to complementarity effect, implying that relative overyielding and enhanced $\mathrm{P}$ uptake were not due to enhanced competitive ability by the larger variety. The results of Chapter 4 suggest that mixing mycorrhizal maize varieties might be beneficial for enhancing productivity and $\mathrm{P}$ uptake efficiency.

Plant - soil feedback experiments have shown that AMF can play a crucial role in determining the direction and magnitude of that feedback. Most studies investigated plant - soil feedback dynamics between different plant species. However, it is unknown to what extent one variety of an agricultural crop can affect the performance of another variety of that same crop through plant - soil feedback. In Chapter 5, I carried out a two-phase experiment in a greenhouse, including conditioning phase and test phase to determine plant - soil feedbacks in the absence and presence of AMF species or community, to test the effects of AMF on feedback dynamics. The results in Chapter 5 showed that: 1) in the conditioning phase, both maize varieties were differentially influenced by different AMF species compared to non-mycorrhizal control; 2) in the feedback phase, non-mycorrhizal maize exhibited negative feedback dynamics for biomass and Puptake; 3) on the feedback phase, mycorrhizal maize generally exhibited positive feedback dynamics for biomass and P-uptake. The interaction coefficient was largest with the mixture of three different AMF species. The interaction coefficient for shoot and P uptake were significantly correlated with the coefficient for mycorrhizal colonization. These results imply that different maize varieties are affected differently by different AMF species, thereby influencing the productivity of the subsequent maize variety. The results also raise questions how AMF influence rhizosphere biota and how maize varieties may select more beneficial AMF.

In Chapter 6, I integrate the results from previous chapters. I discuss possible relationships between (negative) plant - soil feedback effect (due to pathogen) and the mycorrhizal effect on overyielding and improved P uptake due to mixing maize varieties (compared to the monoculture). I also discuss the linkage between phosphorus acquisition efficiency and mycorrhizal responsiveness within one crop species, and the relationship between plant genetic diversity and 


\section{Summary}

plant - soil feedback effects, and try to come up with a conceptual model how mixing maize varieties in the presence of AMF could be beneficial. 


\section{Acknowledgements}

I am so lucky that I had the opportunity of studying at Wageningen University. I have really learned a lot. Now, my life here almost ends. I want to express my gratitude to the people who have helped and accompanied me during the journey of my $\mathrm{PhD}$.

First and foremost, I owe a debt of gratitude to my promoter, Prof. Dr. Thom Kuyper, who gave me countless great suggestions from how to learn English to how to write a thesis. Thom always encouraged me to pursue basic scientific principles. Thom has played a huge role in my development during my time in the Netherlands. Thanks so much, Thom.

I am indebted to Prof. Dr. Ellis Hoffland, the other promoter, for stimulating my interest in science and statistics, elaborating scientific stories and encouraging me. I will never forget what she told me "In our life, we will face many difficulties. We should overcome our weakness and keep challenging ourselves to overcome the difficulties.". Moreover, I admire Ellis's professional spirit and high efficiency in working time. Thank you, my dear Ellis.

I thank my co-promoter in China Agricultural University (CAU), Prof. Dr. Gu Feng, who has supervised me since I was a master student. Teacher Feng always kept training me and tried his best to help me to become a qualified scientific researcher. Without his support, I could not have obtained the scholarship from CSC (China Scholarship Council); without his full help, I could not have finished my experiments. Thanks a lot, Teacher Feng.

I am also grateful of CSC funding to support me to complete the four years study. I also like to thank the group of Plant Nutrition in CAU. I got a lot of help from this group. I also would like to give my earnest thanks to Prof. Dr. Fusuo Zhang. I gained lots of inspirations and insights from him.

Life abroad was sometimes alone and helpless. If I would not have had the benefit of some Chines friends' caring, encouragement, delicious food, having fun together, and chatting, I would have spent more time finishing my $\mathrm{PhD}$ thesis. Wei Qin is always a big-brother-like friend, and Chunxu Song, Wei's wife, is always an old-sister-like friend. In the third day after I arrived at WUR, they invited me to have a dinner at their home. I always remember the time we shared with them. Mingtian Yao is another important friend to me in WUR. I really cherish the time we did fitness in the gym and chatted and cooked at your or my 


\section{Acknowledgements}

home. Chidu Huang and Wei He always gave me a welcome-back when I returned from China or a goodbye dinner when I left the Netherlands. I thank Chidu and Wei for their hospitality. Yang Yu gave me lots of fun when we played basketball together. Tingting Li cooked very delicious food so many times and made a cannot-be-better birthday cake for me. I really appreciate these.

I also want to express my thanks to my other Chinese friends in Wageningen, Dr. Liping Weng, Dr. Lin Ma, Dr. Xia Liu, Dr. Da Yan, Xiaosu Gao, Dr. Zhaohai Bai, Weijie Guo, Dr. Junqi Zhu, Fang Gou, Yong Hou, Dr. Guohua Li, Dr. Wenfeng Cong, Dr. Jingying Jing, Dr. Liansun Wu, Xuan Xu, Tian Zeng, Jingmeng Wang, Sha Wei, Li Meng, Dr. Hongming Zhang, Dr. Jianhong Xi, Dr. $\mathrm{Xu}$ Cheng, Dr. Feng Zhu. Without you guys, I really could not be that easy.

It was a pleasure to meet nice $\mathrm{PhD}$ fellows from other countries. Many thanks to Angela, Mart, Janna, Deivid, Tatiana, Paulo and many others. Thank you guys for talking with me and letting me know other cultures.

I appreciate the kind help from Marnella, our secretary, a nice lady.

The others I can always count on are my family members. They have been so encouraging and proud of me. It truly helps me appreciate myself better.

The last person whom I want to thank is my girlfriend, Chi Zhang. I thank her for her spiritual support and encouragement. She is like an anchor, and I am like a ship. She always gives me a sense of safety and home. However, I kept her waiting for me too long. I own her too much. 


\section{Publication list}

Chu Q, Wang XX, Yang Y, Chen FJ, Zhang FS, Feng G, 2013. Mycorrhizal responsiveness of maize (Zea mays L.) genotypes as related to releasing date and available P content in soil. Mycorrhiza 23, 497-505.

Wang XJ, Wang XX, Feng G, 2015. Optimised nitrogen fertiliser management achieved higher diversity of arbuscular mycorrhiza fungi and high-yielding maize (Zea mays L.). Crop and Pasture Science 66, 706-714.

Wang XX, Hoffland E, Wang F, Feng G, Kuyper TW, The arbuscular mycorrhizal symbiosis enhances $\mathrm{P}$ uptake and increases productivity by mixtures compared to monocultures (submitted).

Wang XX, Shi N, Wang F, Feng G, Mycorrhizal field responsiveness and phosphorus acquisition efficiency of maize (Zea mays L.) varieties (submitted).

Shi N, Wang F, Feng G, Intraradical mycelium of AM fungi cannot grow out from a donor plant to colonize a neighbouring plant (submitted). 



\section{PE\&RC Training and Education Statement}

With the training and education activities listed below the $\mathrm{PhD}$ candidate has complied with the requirements set by the C.T. de Wit Graduate School for Production Ecology and Resource Conservation (PE\&RC) which comprises of a minimum total of 32 ECTS (= 22 weeks of activities)

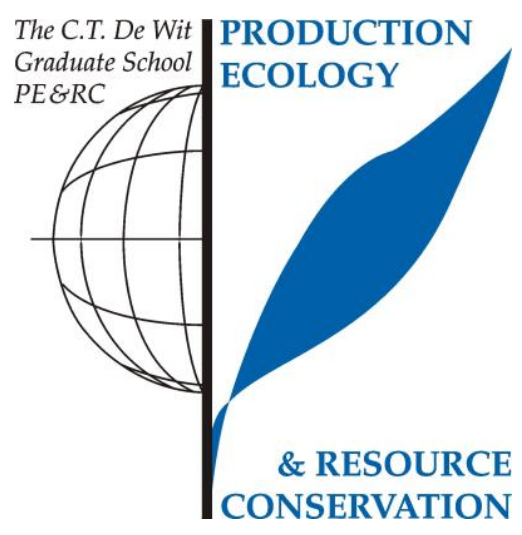

\section{Review of literature (6 ECTS)}

- Intercropping benefits of different genotypes-a search for belowground mechanisms for enhanced $\mathrm{P}$ acquisition

\section{Writing of project proposal (4.5 ECTS)}

- Genetic variation in phosphorus acquisition efficiency and mycorrhizal responsiveness of different maize genotypes and implications for genotype combination to increase maize yields (2011-2012)

\section{Post-graduate courses (4.5 ECTS)}

- Soil, Diversity and Life (2012)

- Introduction to R for statistical analysis (2014)

- Zero inflated models (2014)

Invited review of (unpublished) journal manuscript (2 ECTS)

- Annals of Botany: physiological adaptations of herbaceous perennial legumes allow differential access to sources of varyingly soluble phosphate (2013) 
- Functional Ecology: root phosphatase activity, root surface area, and their potent linkage with leaf phosphorus use efficiency in tropical montane forests Ushio (2014)

Deficiency, refresh, brush-up courses (6 ECTS)

- Biological interactions in soil (2011)

Competence strengthening / skills courses (2.1 ECTS)

- Competence assessment; WGS (2012)

- $\quad$ Scientific writing; WGS (2015)

PE\&RC Annual meetings, seminars and the PE\&RC weekend (1.5 ECTS)

- PE\&RC First year weekend (2011)

- PE\&RC Annual meetings (2013- 2014)

- PE\&RC Last year weekend (2014)

Discussion groups / local seminars / other scientific meetings (6 ECTS)

- PE\&RC Discussion group Soil-Plant Interactions (2012-2014)

- Wageningen Evolution and Ecology seminars (2012-2014)

International symposia, workshops and conferences (4.1 ECTS)

- Intercropping workshop; China (2013)

- Intercropping workshop; the Netherlands (2014)

- International Rhizosphere congress (2015) 


\section{Curriculum vitae}

Xinxin Wang was born on $9^{\text {th }}$ February, 1984 in Heilongiiang Province, China. In 2004, he graduated from Shuangyashan NO 1 Senior High School. In 2008, he finished his Bachelor of Sxcience degree in biological technology, at the College of Resources and Environmental Sciences, Northeast Agricultural University, Harbin, Heilongjiang, China. From 2008 to 2010, he studied Plant Nutrition at the College of Resources and Environmental Sciences, China Agricultural University, Beijing, China, for his Master of Science degree, with a master thesis titled "Mycorrhizal Dependency of Different Genotypes of Maize Under Field and Sterilized Pot Conditions". In 2010, he completed his Master degree and obtained a scholarship from China Scholarship Council. Then, he moved to the Netherlands and started his $\mathrm{PhD}$ program in Wageningen University. His $\mathrm{PhD}$ project specialized in interactions between maize varieties and the effect of arbuscular mycorrhizal fungi on phosphorus acquisition efficiency. 



\section{Affiliations of co-authors}

Ellis Hoffland, Thoms W. Kuyper

Department of Soil Quality, Wageningen University, P.O. Box 47, Wageningen 6700 AA, The Netherlands

Fanjun Chen, Fei Wang, Fusuo Zhang, Gu Feng, Ning Shi, Qun Chu, Xiaojing Wang, Yang Yang

College of Resources and Environmental Sciences, China Agricultural University, Beijing 100193, People's Republic of China 
Funding

\section{Funding}

The research described in this thesis was financially supported by China Scholarship Council (No. 2010635006). 